\title{
Atrial natriuretic peptides : their role in cardiovascular homeostasis
}

Citation for published version (APA):

de Vries, P. J. F. (1990). Atrial natriuretic peptides : their role in cardiovascular homeostasis. [Doctoral Thesis, Maastricht University]. Maastricht University. https://doi.org/10.26481/dis.19900921pv

Document status and date:

Published: 01/01/1990

DOI:

10.26481/dis.19900921pv

Document Version:

Publisher's PDF, also known as Version of record

\section{Please check the document version of this publication:}

- A submitted manuscript is the version of the article upon submission and before peer-review. There can be important differences between the submitted version and the official published version of record.

People interested in the research are advised to contact the author for the final version of the publication, or visit the DOI to the publisher's website.

- The final author version and the galley proof are versions of the publication after peer review.

- The final published version features the final layout of the paper including the volume, issue and page numbers.

Link to publication

\footnotetext{
General rights rights.

- You may freely distribute the URL identifying the publication in the public portal. please follow below link for the End User Agreement:

www.umlib.nl/taverne-license

Take down policy

If you believe that this document breaches copyright please contact us at:

repository@maastrichtuniversity.nl

providing details and we will investigate your claim.
}

Copyright and moral rights for the publications made accessible in the public portal are retained by the authors and/or other copyright owners and it is a condition of accessing publications that users recognise and abide by the legal requirements associated with these

- Users may download and print one copy of any publication from the public portal for the purpose of private study or research.

- You may not further distribute the material or use it for any profit-making activity or commercial gain

If the publication is distributed under the terms of Article $25 \mathrm{fa}$ of the Dutch Copyright Act, indicated by the "Taverne" license above, 
ATRIAL NATRIURETIC PEPTIDES 


\title{
ATRIAL NATRIURETIC PEPTIDES
}

\section{their role in cardiovascular homeostasis}

\author{
proefschrift \\ ter verkrijging van de graad van doctor \\ aan de Rijksuniversiteit Limburg te Maastricht, \\ op gezag van de Rector Magnificus, prof. dr. F.I.M. Bonke, \\ volgens het besluit van het College van Dekanen, \\ in het openbaar te verdedigen \\ op vrijdag, 21 september 1990 om 14.00 uur \\ door \\ Petrus Johannus Fransciscus de Vries \\ geboren te Nijmegen 1959
}


Promotor

Co-promotor

Beoordelingscommissie Prof. dr. A.C. Nieuwenhuijzen Kruseman

Prof. dr. P.J. Brombacher

Prof. dr. F. ten Hoor

Prof. dr. H. Koomans

Prof. dr. G.J. van der Vusse

\section{CIP-GEGEVENS KONINKLIJKE BIBLIOTHEEK, DEN HAAG}

de Vries, Petrus Johannus Fransciscus

Atrial natriuretic peptides: their role in cardiowascular homeostasis / Petrus Johannus Fransciscus de Vries ; [ill by the author]. - Maastricht: Datawyse. - Ill.

Proefschrift Maastricht. - With ref.

ISBN 90-5291-030-8

SISO 605.12 UDC [547.96:616.1](043.3) NUGI 743

Subject heading: renal function ; hemodynamics

Uitgave: Datawyse - Maastricht

Druk: Krips Repro Meppel

Omslag: Peter Soudant, Buro Vormaat

Financial support by the Netherland Heart Foundation for the study and for the publication of this thesis is gratefully acknowledged.

Met dank aan iedereen die heeft meegewerkt aan de totstandkoming van dit proefschrift 
Aan mijn ouders 


\section{Contents}

\section{Atrial Natriuretic Peptides 9}

1.1 Background 9

1.2 Structure and synthesis 9

1.3 Release, levels and clearance 11

1.4 Receptors and cellular actions 15

$1.5 \quad$ Nervous system 17

1.5.1 Central nervous system 17

1.5.2 Autonomic nervous system 19

1.6 Physiological effects 20

1.6.1 Effects on other hormones 22

1.6.2 Renal effects 22

1.6.3 Cardiovascular effects 24

$1.7 \quad$ ANP and cardiovascular pathophysiology 27

1.7.1 Hypertension 27

1.7.2 Congestive heart failure 29

1.8 Aim of this thesis 30

\section{Materials and methods 33}

$2.1 \quad$ Animals 33

$2.2 \quad$ Surgery 33

2.2.1 Arterial blood pressure measurement 33

2.2.2 Central venous pressure measurement 34

2.2.3 Intravenous administration of drugs or volume load 35

2.2.4 Bladder catheter for renal function measurements 35

2.2.5 Doppler flow probe implantation and regional flow measurement 36

2.2.6 Electromagnetic flow probe implantation and cardiac output measurement 38

2.2.7 Atrial appendectomy 39

2.2.8 Infarction 39

2.2.9 Dorsal microcirculatory chamber 40

2.4 Measurement of infarct size 42

2.5 Substances 43

2.5.1 Atrial natriuretic peptides 43

2.5.2 Antibodies 43

2.5.3 Radio active tracers for renal function and clearance studies 43

$2.6 \quad$ Statistics 44 


$\begin{array}{lll}3.1 & \text { Introduction } 47 \\ 3.2 & \text { Materials and methods } 48 \\ 3.3 & \text { Results } 49 \\ 3.4 & \text { Discussion } 52\end{array}$

4 Hemodynamic effects of ANP(1-28) and ANP(5-28) in conscious normotensive, spontaneously hypertensive rats and in experimental heart failure 55

4.1 Introduction 55

4.2 Materials and methods 56

4.3 Results 58

4.3.1 Regional hemodynamics 58

4.3.2 Central hemodynamcis 59

4.3.3 6 hour infusion 62

4.4 Discussion 62

5 Atrial natriuretic peptide (ANP) increases albumin extravasation in conscious rats 67

$5.1 \quad$ Introduction 67

5.2 Materials and methods 67

$5.3 \quad$ Results 69

5.4 Discussion 70

6 Effects of ANP on the microcirculation of the cutaneous skeletal muscle in conscious rats 73

6.1 Introduction 73

6.2 Materials and methods 73

6.3 Results 75

6.4 Discussion 77

7 Physiological role of ANP under resting and volume expanded conditions in normotensive rats 79

$7.1 \quad$ Introduction 79

7.2 Materials and methods 79

7.3 Results 81

7.4 Discussion 82 
8 Physiological role of atrial natriuretic peptide in normal and pathophystological rat models 85

8.1 Introduction 85

8.2 Materials and methods 86

8.3 Results 88

8.4 Discussion 91

9 ANP, its role in cardiovascular homeostasis 97

References 105

Summary 127

Samenvatting 131

Curriculum Vitae 


\section{Atrial Natriuretic Peptides}

\subsection{Background}

History Experiments by De Wardener and coworkers in 1961 [De Wardener et al 1961] were the basis of the idea that a natriuretic hormone affects sodium excretion. Before atrial specific granules had been identified [Kisch 1956, Jamieson et al 1964]. In the 1970s alterations in the morphology of the atrial specific granules were described in animals with changed salt and water balances [Marie et al 1976], thus raising the possibility that the granules were involved in the regulation of salt and water balance. In 1981 there was the remarkable report from the Bold and coworkers [De Bold et al 1981] illustrating that atrial extracts evoke strong natriuresis, associated directly with the atrial specific granules [De Bold 1982]. This work initiated intense research activities to elucidate the biochemical nature, function and physiopathological relevance of the substance involved. It was soon characterized as a peptide; its amino acid sequence was rapidly identified [Flynn et al 1983, Kangawa et al $1984 \mathrm{a}, \mathrm{b}$ ] and the peptide synthesized [Seidah et al 1984]. By 1984 it was clear that a group of related substances was involved, now referred to as atrial natriuretic factors (ANF), atrial natriuretic peptides (ANP) or atriopeptines. At the same time radio immunoassays (RIA) for ANP were developed [Gutkowska et al 1984a]. It was established by the use of specific RIA's that atrial peptides circulate in plasma [Tanaka et al 1984, Gutkowska et al 1984b]. Furthermore the gene, encoding for ANP was rapidly characterized [e.g. Maki et al 1984, Kangawa et al 1984b, Seidman et al 1984a] and specific receptors with affinity to ANP were localized [e.g. Bianchi et al 1985, Murphy et al 1985, Lynch et al 1986].

Aim of this

This introduction aims to give a brief overview of the main deveoverview lopments over the past few years in the field of atrial natriuretic peptides.

\subsection{Structure and synthesis}

Gene The elucidation of the amino acid sequence of rat ANP enabled several laboratories to isolate DNA and sequence cDNA clones containing sequences encoding for the ANP [Yamanaka et al 1984, Maki et al 1984, Seidman et al 1984, Nemer et al 1984]. The struc- 
tural organization of the ANP gene is similar in all species which have been studied so far [Matsuo 1987]. The coding sequences for ANP are divided between three exons. Two introns, a short first and a long second intron, separate the exons. The first exon contains sequences encoding the signal peptide and the first 16 amino acids of the ANP precursor. The second exon encodes up to the last but one ANP amino acid. The third exon contains the last codon for ANP. Overall the gene contains about 2000 base pairs, including the two introns (fig 1.1).

Synthiesis of atrial natriuretic peptides
Regulation of synthesis

Circulating bormone
The first synthesized form of ANP is a preprohormone. The number of amino acids of the signal peptide (the "pre" part) depends on the species: dogs have a 23 amino acid signal peptide whereas the rabbit and the mouse precursor contain 25 amino acid signal peptides [Seidman 1984]. Synthesized ANP is stored in the atrial granules as the mature 126-amino acid prohormone [Thibault et al 1987, Lang 1985, Morii 1986].

Several factors, related to sodium balance regulation, have been reported to influence the synthesis of ANP. Administration of glucocorticoids and vasopressin both stimulate the expression of the ANP-gene in the atria [Day et al 1986, Gardner et al 1986a, Rankin et al 1986, Nemer et al 1987]. Water deprivation causes a marked reduction of atrial prepro-ANP [Takayanagi et al 1985, Nakayama et al 1984]. The ventricles are also sites of ANP-gene expression [Day et al 1986, Lattion et al 1986] influenced by the same factors as atrial ANP mRNA. Expression of the gene for ANP has also been documented in the brain [Gardner et al 1987a], pituitary gland [Gardner et al 1986b], vascular tissue [Gardner et al $1987 \mathrm{~b}$, Springall et al 1988] and the lungs [Gardner et al 1986b].

The circulating form of ANP is a peptide consisting of 28 amino acids, containing a ring structure of 17 amino acids, an amino terminal chain of 6 amino acids and a carboxyl terminal chain containing 5 amino acids [De Bold et al 1983, Thibault et al 1983, Napier et al 1984, Forssmann et al 1984]. The ring structure is formed by a disulfide bridge between two cysteine-residues, in the 7 th and the 23 rd place respectively (fig 1.1 ). 


\section{1}

Structure of the gene (A), preprohormone

$(B)$, the peptide $(C)$ and several analogues. Arrows indicate sites of splicing in vivo.

* the 12 th aa in whANP is a methionine.
Species differences

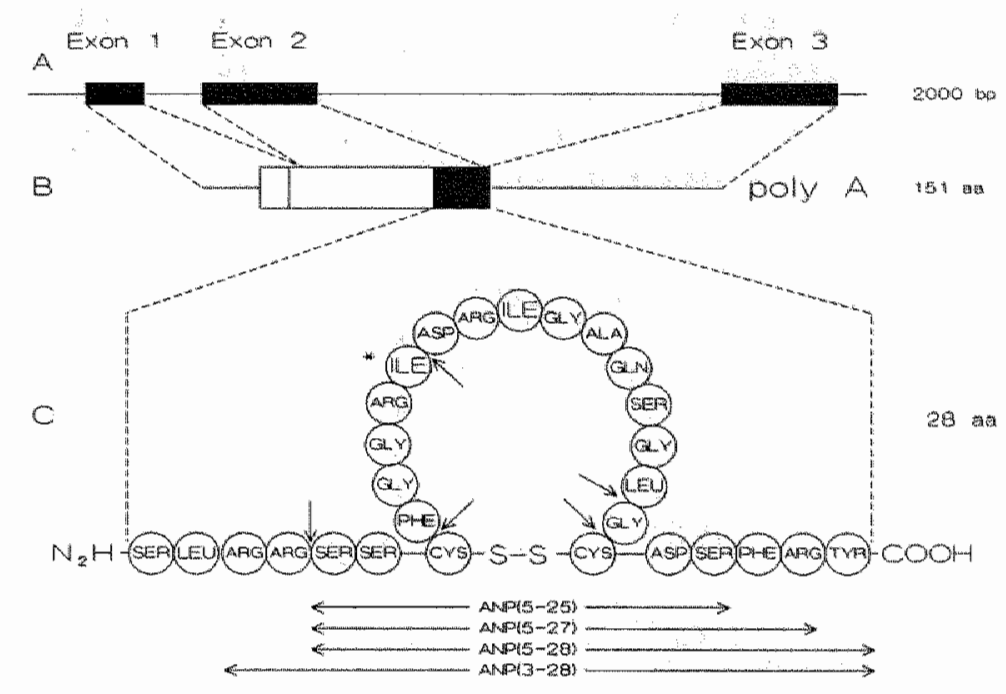

The circulating forms in rat and human differ at the 12th amino acid, a methionine in $\alpha$-hANP and an isoleucine in $\alpha$-rANP. Through chemical synthesis, several analogues, differing on both amino terminal and carboxy-terminal chains have been made. Some frequently used structures and names are given in fig 1.1.

\subsection{Release, blood levels and clearance}

Release Granules, specifically located in the atria, have already been described more than 30 years ago [Kisch 1955, Jamieson et al 1964]. Later, de Bold [1982] and Garcia and coworkers [1982] demonstrated ANP immunoreactivity in the secretory like granules. The first indirect evidence that ANP can be released by increased atrial pressure was illustrated in an isolated heart-lung preparation [Dietz 1984]. By means of a specific RIA, immuno reactive ANP was demonstrated in the perfusate fluid, in response to increased right atrial pressure. Pro-ANP undergoes proteolytic activation in the heart before it is secreted [Thibault et al 1986]. Although pro-ANP proteolytic activity is present in rat serum [Bloch et al 1985] this 
does not seem of physiological relevance [Thibault et al 1986 , Michener et al 1986]. The cardiac cellular or subcellular site of the myocardial proteolytic activity has yet to be determined. The carboxyl terminal 28 -amino acid fragment is secreted from the heart and is physiologically active [Thibault et al 1985, Schwartz et al 1985].

Triggers for The greater part of the evidence indicates that the main trigger to release release ANP is atrial stretch. The action of several agonists on ANP release in incubated atrial slices is contradictory [Lachance et al 1986, Arjamaa and Vuolteenaho 1985, Sonnenberg and Veress 1984]. In isolated atria biphasic release from the right atrium could also be induced by $\alpha$ - (the first peak) and $B$-adrenoceptor agonists (the late second peak) [Schiebinger et al 1987, Wong et al 1988]. Dietz [1984] demonstrated release of atrial natriuretic factor by atrial distension. In vivo it was demonstrated that ANP is released following saline volume expansion [Cantin et al 1984, Lang et al 1985]. This release was not modified by vagotomy, $B$-adrenoceptor blockade or direct sympathetic nerve stimulation [Ledsome et al 1985, 1986]. The effects of adrenergic agonists, arginine vasopressin and angiotensin, to ANP release in vivo have been controversial [Manning et al 1985, Katsube et al 1985a, Lachance and Garcia 1988]. In humans, experiments with saline volume load [Yandle et al 1986a] and redistribution of circulating blood to the thorax [Anderson et al 1986, Hollister et al 1986, Ogihara et al 1986a,b], increased circulating ANP, indicating that atrial stretch is an important factor in ANP release. Tachycardia and experimental pacing evoke increased plasma ANP [Schiffrin et a] 1985, Yamaji et al 1985, Tikkanen et al et al 1985]. However, at very high heart rates, atrial pressure increases also [Ledsome et al 1985]. Evidence for atrial stretch, and not atrial pressure, being the principal controlling determinant for acute ANP release, was demonstrated by Edwards et al [1988]. Cardiac tamponade, a method to increase intra-atrial pressure without increasing atrial stretch, did not increase ANP release, whereas aorta constriction, resulting in elevated atrial pressure and atrial stretch, enhanced ANP release. Chronic volume expansion through a high sodium diet has been reported to elevate plasma ANP concentrations [Tanaka et al 1984, Yandle et al 1986b, Hollister et al 1986, Takayanagi et al 1985, Sagnella et al 1985 , 1987] suggesting that ANP plays a role in the maintenance of sodium and volume balance. 
Intracellular pathways, involved in ANP

release

Determination of plasma levels

Table 1.1 Examples of representative plasma ANP levels in animals in physiolo-

gical and some experimental pathophysiological conditions

\begin{tabular}{|c|c|c|}
\hline Rats & plasma ANP (pg/ml) & \\
\hline Sprague Dawley rats & 30 & Horkey et al 1985 \\
\hline WKY & 100 & Gutkowska et al 1986a,c \\
\hline SHR & 200 & Gutkowsika et al $1986 a, \mathrm{c}$ \\
\hline SHRSP & 320 & Morii et al 1986 \\
\hline Dahl salt sensitive rats & 150 & Gutkowska et al 1986a \\
\hline Dahl salt resistant rats & 60 & Gutkowska al 1986a \\
\hline 2K-1C hypertension & 60 & Garcia et al $1987 b$ \\
\hline 1K-1C bypertension & 80 & Garcia of al $1987 \mathrm{a}, \mathrm{c}$ \\
\hline Uninephrectomized rats & 15 & Garcia et al $1987 \mathrm{~m}, \mathrm{c}$ \\
\hline DOCA hypertension & 150 & Tondo et al 1988 \\
\hline Experimental heart failure & 400 & Tikkamen et al 1987 \\
\hline Dogs & 8 & Riegger et al 1988 \\
\hline Experimental heart failure & 52 & Riegger et al 1988 \\
\hline Sheep & 15 & Parkes et al 1988 \\
\hline
\end{tabular}

Intracellular free calcium may play an important role in the mediation of ANP release [Ruskoaho et al 1985]. Infusions of calcium ionophore or calcium channel agonists, combined with certain phorbol esters, cause a rise in ANP release from the heart. This, and other studies, using phorbol esters [Ruskoaho 1986, 1988], indicate that the phosphoinositol system may be involved in the mediation of ANP release [Lang et al 1987]. Also, activation of the adenylate cyclase system promotes ANP secretion and potentiates the effects of phorbol esters [Ruskoaho 1986].

The concentration of circulating ANP is generally measured with immunological techniques, such as radio immuno assay [Gutkowska et al 1984a], and enzyme linked immuno sorbent assay [Greenwald et al 1988]. Radio receptor assays use the affinity of isolated receptors for ANP to determine plasma ANP levels [Bürgisser et al 1985]. Values found in normotensive rat plasma's vary widely from 90-6000 $\mathrm{pg} / \mathrm{ml}$. However, values above $300 \mathrm{pg} / \mathrm{mll}$ may not represent true ANP-levels [Lang et al 1987]. Some representative plasma ANP levels as reported in physiological and pathophysiological conditions in animals and humans are summarized in table 1.1. 
Half-life and ANP has a relatively short half-life in the circulation. Its disapclearance pearance from plasma is biphasic, with a first half-life ranging from 15-27 seconds for ANP in rats [Luft et al 1986, Murthy et al 1986] whereas the remaining ANP is cleared with a $t_{m}$ of 5 min [Condra et al 1988]. This biphasic character of clearance has also been demonstrated in dogs [Verburg et all 1986] and in man [Jüppner et al 1986, Yandle et al 1986], the first phase taking 1-5 minutes and the second phase being characterized by a half-life of approximately 15 min [Nakao et al 1986]. Breakdown in blood does contribute partly to the elimination of ANP [Koepke et al 1989] but the kidney plays the greatest role in the elimination of the peptide [Weselcouch et al 1985]. It is not yet clear how degradation takes place. It seems however, that the removal of ANP in vivo is principally mediated through binding to a clearance receptor, internalization and intracellular degradation. [Thibault 1988, Hirata et al 1985].

Table 1.2 Range of plasma ANP levels in humans in physiological conditions and consequences for experimental and pathophysiological situations ".?

\begin{tabular}{|c|c|c|}
\hline thealthy subjects & $8.2-180 \mathrm{pg} / \mathrm{ml}$ & Genest et al 1988 (review) \\
\hline low salt diet & 1.6 & Sagnella et al 1987 \\
\hline high salt diet & 2.1 & Sagnella et al 1987 \\
\hline Essential hypertension & $1-7$ & $\begin{array}{l}\text { Hedner et al } 1989 \text {, } \\
\text { Arendt et al } 1986\end{array}$ \\
\hline Cardiac failure & $2.4-5.0$ & $\begin{array}{l}\text { Cody et al } 1986, \\
\text { Lang et al } 1986\end{array}$ \\
\hline Chronic renal failure & 4.6 & Hasegawa et al 1986 \\
\hline Aldosteronism & $1.8-3.3$ & Yamaji et al 1988 \\
\hline Preeclampsia & $2.3-7.0$ & Thomsen et al 1987 \\
\hline Cushing's syndrone & 3.1 & Yamaji et al \\
\hline Liver cirrhosis & 1.6 & Arendt al 1986 \\
\hline
\end{tabular}

) Plasma ANP elevations given as factor of control situations in experimental and pathophysiological situations in the same studies. 


\subsection{Receptors and cellular actions}

Types of receptors ANP binding sites have been localized in the aorta [Vandlen et al 1985], the renal glomeruli [Murphy et al 1985, Bianchi et al 1985], renal medullary collecting ducts [Murphy et al 1985, Bianchi et al 1987], adrenal cortical zona glomerulosa cells [Meloche et al 1986, Hirose et al 1985, Bianchi et al 1985], smooth muscle cells [Scarborough et al 1986], endothelial cells [Leitman et al 1986] and several brain areas [Quirion et al 1984, 1986]. Analysis of ANP binding assays reveals two classes of binding sites, one with $\mathrm{Kd}=50$ $\mathrm{pM}$ and one with $\mathrm{Kd}=5 \mathrm{nM}$ for ANP [De Lean et al 1985]. Two major proteins of apparent molecular masses of approximately 70 $\mathrm{Kd}$ and $130 \mathrm{Kd}$ were demonstrated. The $70 \mathrm{Kd}$ site was found not to be linked to guanylate cyclase [Leitman et al 1986, Takayanagi et al 1987]. The $130 \mathrm{Kd}$ site is coupled to guanylate cyclase [Scarborough et al 1986]. The $130 \mathrm{Kd}$ ANP receptor has even been suggested to be the particulate guanylate cyclase itself [Chinkers et al 1989]. Very recently, a third receptor type, coupled to guanylate cyclase was defined. This receptor is almost identical to the $130 \mathrm{Kd}$ receptor, but is mainly activated by brain natriuretic peptide [Chang et al 1989], a peptide almost identical to ANP.

ANP increases cGMP

cGMP exokes a cascade of intracellular actions
Administration of atrial extracts and synthetic ANP analogues results in an increased plasma cGMP and urinary cGMP evoked by binding of ANP to $130 \mathrm{Kd}$ binding sites [Schenk et al 1985, Tremblay et al 1985, Hamet et al 1986]. Antibodies against ANP are able to inhibit increase in both plasma and urinary cGMP [Hirth et al 1986]. Administration of ANP increases intracellular cGMP levels [Hamet et al 1983, 1.984] as is illustrated in figure 1.2. The rise in extracellular cGMP results from the egresion of this nucleotide from the cell [Gerzer et al 1986]. The fact that particulate guanylate cyclase activation is long lasting might explain the elevations in plasma and urinary cGMP levels, persisting even after circulating ANP has returned to normal.

In cells from many tissues a correlation has been established between the increases in cGMP and vasodilation [Winquist et al 1984], steroidogenesis [Matsuoka et al 1985], glomerular filtration [Ballerman et al 1985] and renin secretion [Obana et al 1985]. The mechanism by which cGMP functions, remains unknown. In the retina cGMP can work directly, without any involvement of phosphorylation, via its physical interaction with sodium channels [Fesen- 
ko et al 1985]. Several other functions could be expressed via the phosphorylation of specific protein substrates which in turn could modify the activity of contractile proteins, leading to vasodilation (figure 12).

Role of ANP in cytosolic calcium regulatilon

The $70 \mathrm{Kd}$ receptor is involved in ANP clearance

Nomenclature of receptions

Receptor densifity regulation
ANP is a major intracellular mediator in excitation-response coupling in many tissues. The effectiveness of ANP in modifying free cytosolic calcium levels remains controversial. Increased as well as unchanged cytosolic calcium levels have been demonstrated after ANP administration [Knorr et al 1986, Yamamoto et al 1986]. Other results indicate that ANP is an antagonist of agonist inducedcalcium influx through "receptor operated" calcium channels [Taylor et al 1986]. Calcium dependent phosphorylation in rat adrenal zona glomerulosa and calcium influx and rellease from intracellular storage sites in aorta and renal arteries may be inhibited by ANP [Chartier and Schiffrin 1987, Taylor and Meisheri 1986, Fujii et al 1986]. The mechanism has not yet been elucidated.

The function of the $70 \mathrm{Kd}$ receptor was elucidated by the use of a ring deleted ANP analogue. In isolated perfused rat kidneys no hemodynamic or renal effects could be demonstrated [Pandey et al 1987]. In vivo, the ring deleted analogue did cause natriuresis and hypotension. It was paralleled by an increase of endogenous plasma ANP(1-28). These experiments suggest that the $70 \mathrm{Kd}$ receptor may represent storage or clearance binding sites. Saturation with the ring deleted analog results in accumulation of the endogenous ANP.

This resulted in the nomenclature of ANP receptors. The $70 \mathrm{Kd}$ guanylate cyclase uncoupled receptors was named C-receptor (clearance) whereas the $130 \mathrm{Kd}$ cyclase coupled receptor was named B-receptor (biologically active). The recently described $130 \mathrm{Kd}$ receptor, having high affinity to brain natriuretic peptide, has not yet been named.

The density of vascular receptors in mesenteric arteries is decreased during sodium loading [Schiffrin et al 1986b]. After mineralocorticoid treatment vascular ANP sites are also down regulated [Schiffrin and St-Louis 1985]. Down regulation has also been demonstrated in chronically ANP infused rats [Cachofeiro et al 1987]. In volume expanded hypertension, in which elevated plasma ANP was demonstrated, vascular ANP receptors in the mesenteric arteries and aorta are decreased suggesting that increased plasma ANP 
concentrations are responsible for the down regulation of ANP vascular sites [Schiffrin et al 1986b]. In the literature, it is not specified which types of receptors are involved in the down regulation. Down regulation is often parallelled by a decreased sensitivity to ANP although reduced sensitivity was also demonstrated without down regulation of ANP receptors [Schiffrin et al 1986a].

ANP and cAMP In several tissues, ANP is able to partly inhibit the adenylate cyclase activity, possibly through linkage of ANP receptors to the adenylate cyclase system by guanine nucleotides [Anand-Srivastava et al 1984, 1985, 1986, Gerzer et al 1986]. Possible mechanisms of action of ANP after binding to its receptor are presented in fig 1.2 .

fig 1.2

ANP receptors in vas: cular smooth muscle cells, their hypothetical cellular actions and the negative coupling to the adenylate cyclase.

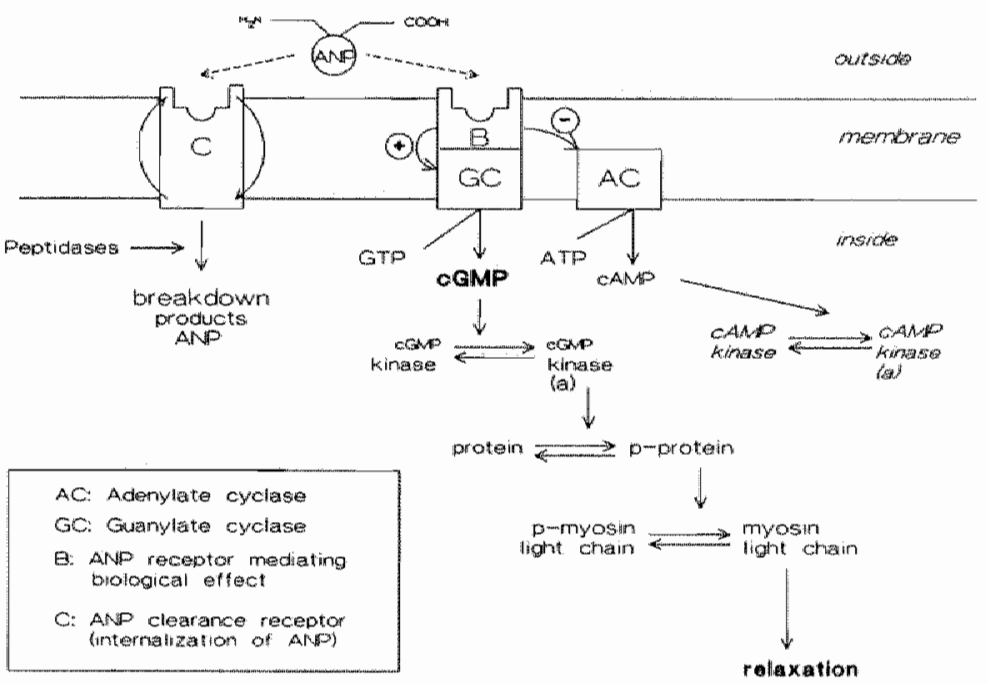

\subsection{Nervous system}

\subsubsection{Central nervous system}

Binding sites in Using autoradiography in the rat, high density of ANP binding sites central nervous was found in the olfactory bulb, subfornical organ, nucleus tractus system solitarius, area postrema, interpenduncular nucleus, amygdala and 
fig 1.3

Posivions of pesitiarya containing ANP (dots) and major area's of nervous tisstile with ANp containing fibers shown in crosssection (shaded area's in fig A) and dark area's in figg B).
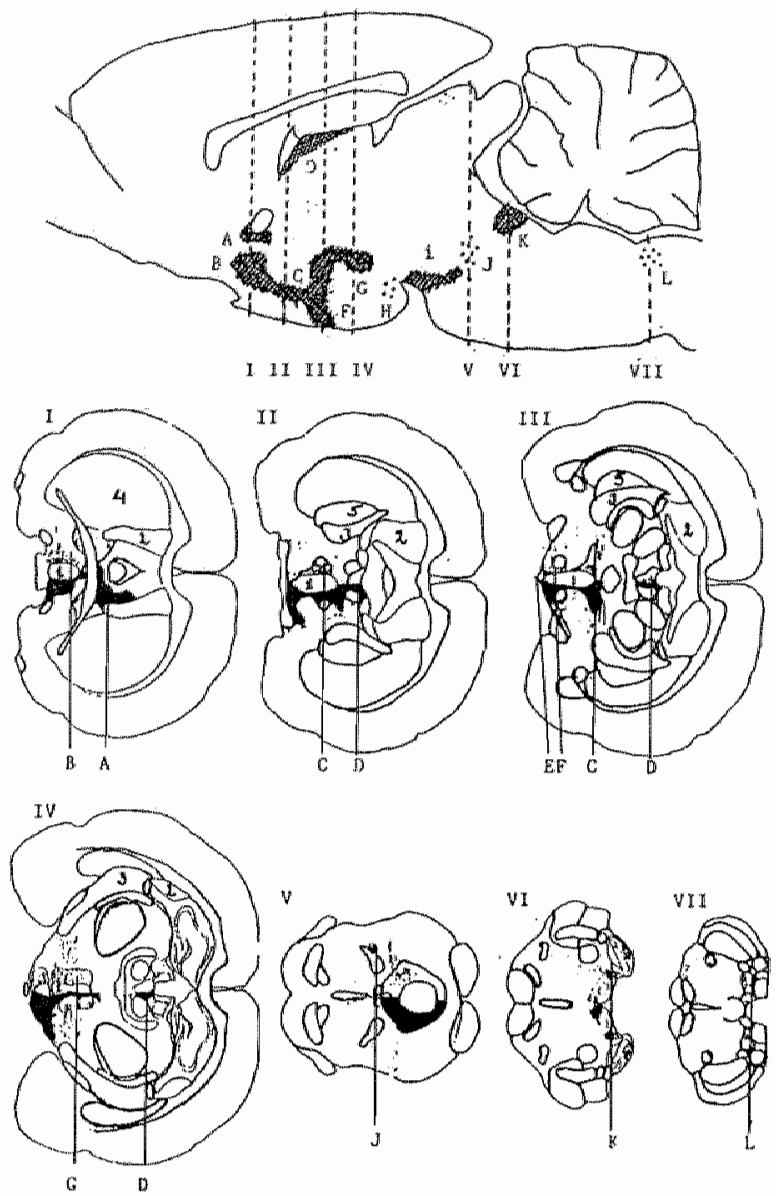

$A=$ Bed Nucleus of stria terminalis

$J=$ Pendunculopontin nucleus

$B=$ Anteroventral periventricualr nucleus

$\mathbf{K}=$ Parabrachial nucleus

$\mathrm{C}=$ Paraventricular nucleus of hypothalamus

$\mathrm{L}=$ Nucleus tractus solitarius

$\mathrm{D}=$ Periventricular nueleus of thallamus

$\mathbf{E}=$ Median aminence

$1=3$ rd ventricle

$F=$ Arcuate nucleus

$2=$ Lateral ventricle

$\mathrm{G}=\mathrm{L}$ sateral hypothalamic area

$3=$ Internal capsule

$4=$ Cerebral penduncle

$S=$ Globus pallidus 
hippocampus. Intermediate densities of binding sites were found in the median eminence, rostral hypothalamus and periventricular nucleus [Kawata et al 1985, Standaert et al 1986, Morii et al 1985]. The areas, where receptor binding sites were found [Quirion et al 1984,1986], show a major overlap deall with the areas containing cellular ANP as determined with immunohistochemistry and radio immuno assays and with areas related to cardiovascular and endocrine control. Cell bodies and neurons containing ANP, were found in several thalamic and hypothalamic nuclei along the 3rd ventricle, in the pons and the brain stem. No immunoreactivity was found in the cerebellum.

Projections Projections from hypothalamic to thalamic areas containing ANP positive cell bodies and neurons and vice versa were demonstrated as well as projections from hypothalamic areas to the spinal cord. Internal hypothalamic and thalamic projections and projections from hypothalamic and thalamic areas to various midbrain nuclei were also demonstrated [Standaert et al 1986]. An overview of the most important locations of ANP and its binding sites in the central nervous system and the projections are given in figure 1.3.

Possible function of ANP in the central nervous system

Interaction of ANP with the sympathetic aervous system
The ability of ANP to modulate hypothalamic neuronal excitability indicates that ANP may act as a neuromodulator or neurotransmitter in the central nervous system [Haskins et al 1986]. The major actions of ANP in the brain seem to be well coordinated with its actions in the periphery. The ANP central nervous system control is mainly projected on brain areas involved with the control of fluid volume and electrolyte balance [Kawata et al 1985, Standaert et al 1986].

\subsubsection{Autonomic nervous system}

ANP may act as an inhibitor of efferent sympathetic nervous system activity [Kuchel et al 1986]. Several sites of action have been described. Catecholamine synthesis has been demonstrated to be suppressed by ANP in vitro [Kuchel et al 1987]. In isolated inferior mesenteric ganglion of the guinea-pig ANP, decreases frequency of action potentials, prolonged afterpotential and increases threshold of action potentials [Cheung 1988]. Furthermore, an inhibition of norepinephrine release from vascular adrenergic nerve endings [Nakamura et al 1986, Tsuda et al 1987] decreases peripheral sympathetic nervous activity. In vivo Bergey et al [1989] demonstra- 
Interaction of ANP and the Baroreflex

ted that ANP directly depresses sympathetic nerve function in anesthetized "ganglion-blocked dogs. The inhibitory effect of ANP on norepinephrine stimulated vasoconstriction may be more pronounced in arteries with $\alpha_{1}$-receptor mediated functions than in veins, where norepinephrine mediates constriction via both $\alpha_{i}$ and $\alpha_{i}$ adrenoceptors [Kyncl et al 1987]. This suggestion is supported by the findings of Faber et al [1988] who found a inhibition of $\alpha_{5}$ mediated arteriolar constriction and no inhibition of $\alpha_{F_{2}}$ mediated venular constriction in the denervated cremaster muscle of anesthetized rats.

The fact that the ANP gene was found to be expressed in the aortic arch [Gardner et al 1987] points to a possible role for ANP in blood pressure regulation through the baroreceptor reflex. The tachycardic baroreceptor reflex activity during ANP administration was attenuated [Ferrarrio et al 1988, Ebert et al 1988, Holtz et al 1987]. Furthermore, ther is evidence that ANP interact with the efferent part of the baroreflex. Chemical and surgical renal sympathectomy reduce the baroreflex-mediated hemodynamic effects of ANP(5-27) on the kidneys [Lappe et al 1985a].

\subsection{Physiological effects}

\subsubsection{Efrects on other hormones}

Regulation of renin secrection in vitro
ANP affects several hormonal systems. The first is the reninangiotensin-aldosteron system. Results of experiments on the direct effects of ANP on the juxtaglomerular cells in vitro are conflicting [Obana et al 1985, Hiruma et al 1986, Kurtz et al 1986, Garcia et al $1987 \mathrm{~b}]$. ANP has been found to stimulate renin release in a dose dependent manner, in isolated perfused kidney preparations [Hackenthal et al 1985]. Studies in nonfiltering kidneys suggested no direct inhibitory action of ANP on juxtaglomerular cells [Opgenorth et al 1986, Deray et al 1987].

ANP and renin secretion in vivo
Renin secretion is suppressed by ANP in a single denervated nonfiltering kidney in anesthetized rats, through interaction with renal vascular receptors and the macula densa [Villarreal et al 1986]. In anesthetized dogs and dogs with inferior vena cava ligation, plasma renin activity is decreased by ANP [Freeman et al 1985, Maack et al 1984, Burnett et al 1984]. In other models, where 
basal renin secretion is high, such as two kidney-one clip hypertension and salt-depleted one-kidney, one clip hypertension, ANP seems to block renin secretion [Volpe et al 1985]. Similar effects of ANP on plasma renin activity have been demonstrated in humans [Cody et al 1986, Cuneo et al 1986, Atlas et al 1986b]. However, a lack of effect of ANP on plasma renin activity has also been reported in humans [Weidman et al 1986]. Thus, most of the results suggest a depressing activity of ANP on renin secretion. It is not clear from isolated kidney studies, if this is a direct or indirect effect of ANP.

Interaction with angiotensin II

Production and release of aldosterone is regulated by ANP

ANP in relation to vasopressin
In vitro studies clearly demonstrate that atrial natriuretic peptides are able to counteract the vasoconstrictive activity of angiotensin II in aorta, mesenteric and renal arteries [Winquist et al 1984a,b]. ANP also inhibits the contractile effects of angiotensin II on glomerular mesangial cells [Appel et al 1986]. The effects of ANP on angiotensin II induced proximal tubular sodium reabsorption, are contradictory [Harris et al 1987, Liu and Cogan 1988].

ANP affects aldosterone production in isolated adrenal cortical cells The aldosterone response to angiotensin II, ACTH, prostaglandin $\mathrm{E}_{\text {, }}$ and potassium was markedly inhibited by atrial extracts as well as by synthetic ANP [Atarashi et al 1984, De Lean et al 1985]. In vitro, effects of ANP administration on basal aldosterone levels are diverse. Some studies show an inhibition [De Léan et al 1984, Atarashi et al 1984, Goodfriend et al 1984] whereas others demonstrate little or no effect [Chartier et al 1984a]. In vivo, ANP does not decrease basal plasma levels of aldosterone [Atarashi et al 1985, Chartier et al 1984b]. However, in models with stimulated aldosterone secretion, such as sodium-depleted state and angiotensin II infused animals, physiological plasma ANP concentrations are able to block the hypersecretion of aldosterone [Chartier et all 1987]. This suggests that ANP inhibits angiotensin II stimulated aldosterone secretion [Maack et al 1984]. This inhibition was found to influence the early pathway of steroidogenesis [Goodfriend et al 1984], probably the conversion of cholesterol to pregnenolon. As a direct effect, ANP could block the absorption of sodium from the distal tubule by opposing the action of aldosterone, which promotes absorption at this site [Leckie 1987].

Several studies in vitro and in vivo suggest that ANP affects vasopressin (AVP) release. However, it appears that pharmacological 
circulating ANP levels are needed to exert effects on the hypothalamic-pituitary complex involved in the regulation of AVP release. Pharmacological doses of ANP by bolus, induced a significant decrease in resting AVP levels [Samson 1985, Januszewicz et al 1986], whereas intravenous infusion of $\alpha$ h-ANP did not change circulating AVP levels [Gnädinger et al 1986]. Intracerebroventricularly administered ANP can inhibit AVP release without changing arterial pressure, heart rate, plasma osmolality and sodium levels [Share et al 1986]. Other investigators have also demonstrated that central natriuretic peptide reduces vasopressin release in the rat [litake et al 1986, Casto et al 1987]. In the kidney ANP is able to oppose the action of AVP on the collecting duct thus leading to an increase in urine volume [Dillingham et al 1986].

\subsubsection{Renal effects}

Regulation of glomerular nitration rate

Regulation of tubular effects
The discovery of atrial natriuretic peptides was based on their natriuretic and diuretic action. Several years later, the precise natriuretic mechanism still remains unknown. The atrial peptides may influence renal function in several different ways. The glomerular filtration rate has been shown to increase [e.g. Maack et al 1984] but this is not strictly necessary for the natriuretic effect of ANP [Seymour et al 1985a, Pollock et al 1986, Salazar et al 1986]. An increase in GFR is possibly mediated by an afferent arteriolar vasodilation [Ohishi et al 1988] and a concomitant efferent arteriolar vasoconstriction [Marin-Grez et al 1986, Dunn et all 1986, Zeidel et al 1987b]. A second mechanism for the increased GFR could be antagonism of the angiotensin II mediated constriction of mesangial cells, thus changing the glomerular surface area [Appel et al 1986].

Micropuncture studies suggest that ANP does not affect sodium transport in the proximal tubule and the loop of Henle directly [Baum et al 1986]. Results concerning the interactions with angiotensin II on fluid reabsorption in the proximal tubules have been contradictory [Harris et al 1.987, Liu and Cogan 1988]. ANP does not exert a direct effect on the distal tubules, but could indirectly interfere with sodium reabsorption by blocking aldosterone synthesis or opposing aldosterone action [Leckie 1987]. Moreover ANP may affect renal water and sodium excretion by inhibiting vasopressin stimulated water absorption from the renal collecting 
ducts [Dillingham et al 1986] and inhibiting sodium transport in the medullary collecting duct [Sonnenberg et al 1986a]. Microdissected inner medullary collecting ducts exhibit increased cGMP levels when treated with ANP [Nonoguchi et al 1987], although the relevance of this phenomenon is not clear. The direct modulatory properties of ANP on renall excretory functions are summarized in fig 1.4.

fig 1.4

Sites of action of ANP in the kidney. Heavy arrows indicate possible interaction sites in the kidney.

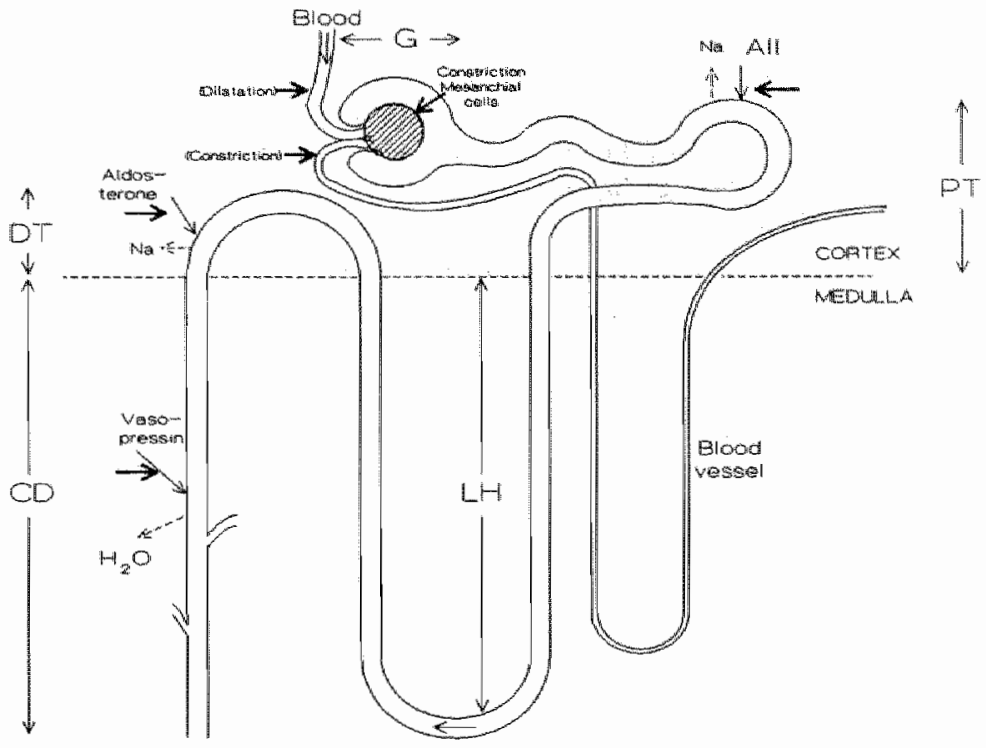

$\mathrm{G}=$ Glomerulus

PT $=$ Proximal tubule

AII = Angiotensin II

$\mathrm{LH}=$ Loop of Henle

DT $=$ Distal tubule

Intraremal ANP changes the distribution of blood flow towards the inner hemodymamic effect medulla [Fujioka et al 1985, Hansell and Uifendahl 1986] thus modulating renal function by reducing the inner medullary hypertonicity [Sosa et al 1986, Needleman et al 1985, Borenstein et al 1983]. This could reduce interstitial solute gradient. Such a medullary washout is thought to inhibit sodium reabsorption from the ascending limb [Sonnenberg et al 1986b]. 
Physiologicall A bolus of ANP results in an increased renal blood flow [Oshima et relevance of ANP

in the kidney

Atrial appendectomy as tooll to study remal effects of ANP

\subsubsection{Cardiovascular effects}

Vascular effects of ANP in vitro al 1984, Hintze et al 1985]. However, high and intermediate dose infusions of ANP cause renal wasoconstriction [Lappe et al 1985b], accompanied by sizable and rapid natriuretic responses [Cogan 1986, Dunn et al 1986, Seymour et al 1985a, Johannessen et al 1986, Biollaz et al 1986a, Cody et al 1986, Weidman et al 1986]. The natriuretic effect is greater when the dietary intake of sodium has been high compared with a sodium-restricted diet [Cuneo et al 1986, Weidman et al 1986]. ANP infusions, causing circulating ANP levels within the physiological or pathophysiological range, elicit delayed renal responses [Anderson et al 1987, Bie et al 1987, Biollaz et al 1986a, Zimmerman et al 1987] or even a lack of natriuresils and diuresis [Debinski et al 1986a, Ishii et al 1986]. Infusions lasting 4 hours still increase the diuresis and natriuresis in sodium loaded male volunteers [Biollaz et al 1986b], whereas infusions of ANP over several days do not appear have any influence on renal function [Granger et al 1986, Janssen et al 1988].

Atrial appendectomy in rats, dogs and monkeys demonstrate the rellationship between volume expansion induced natriuresis and diuresis and ANP [Villarreal et al 1986, Schwab et al 1986, Benjamin et al 1987, Benjamin et al 1988]. The importance of ANP in controlling renal excretory functions was stressed again with the inhibition of the natriuretic and diuretic responses to whole blood volume expansion in anesthetized rats, immunized with monoclonal antibodies raised specifically against ANP(5-27) [Hirth et al 1986].

Crude atrial extracts [Currie et al 1983] and partially purified ANP [Garcia et al 1983,1984, Grammer et al 1983] possess vasorelaxant properties on the precontracted aorta in vitro. After synthetic analogues became available, extensive studies on the structure of various ANP analogues were conducted in vascular preparations and other assays. Presence of Phe-Arg-Tyr at the carboxyl terminal is critical in vascullar preparations. Deletion of amino terminal amino acids gradually diminishes relaxant properties to Ser-103. When Ser103 and 104 are removed, relaxant properties are regained [Thibault et al 1984, Fok et al 1985, Garcia et al 1985a, Olins et al 1986]. In smaller arteries [Faison et al 1985], veins [Holtz et al 1985] and 
resistance arteries [Osol et al 1986], ANP has little or no relaxant effect. Only in renal and mesenteric arteries, ANP exerts relaxant. effects [Mulvany et al 1985, De Mey et al 1987]. The mechanism of vasorelaxation appears to be endothelium independent [Winquist et al $1984 \mathrm{~b}$ ] and is likely to be mediated via cGMP (fig 1.2).

Acute hemodynamic effects of ANP in vivo
Efrects of acute ANP infusion on the regionall circulation

Chronic hemodynamic effects of ANP
When ANP is infused intravenously, total peripheral resistance remains constant [Sasaki et al 1985, Waeber et al 1986] or even increases [Breuhaus et al 1985, Lappe et al 1985b, Goetż et al 1986]. This is associated with a hypotensive effect. The reduction in blood pressure is ascribed to a fall in cardiac output [Ackerman et al 1984, Breuhaus et al 1985, Lappe et al 1985b]. Cardiac output is not reduced by negative inotropy or chronotropy [Hiwatari et al 1986], although results on heart rate in vivo are inconsistent. Decreased [Allen et al 1987, Ackerman et al 1988, Gellai et al 1986], unchanged [Bie et al 1988, Goetz et al 1986, Hintze et al 1985, Seymour et al 1987] and slightly increased heart rates [Breuhaus et al 1985, Drexler et al 1987, Hofbauer et al 1986, Lappe et al 1985b] during ANP infusion have all been reported. The fall in cardiac output has been ascribed to a reduction of cardiac filling pressures [Breuhaus et al 1985, Lappe et al 1985b, Trippodo et al 1987]. It has been suggested that reduced venous tone and decreased blood volume may contribute to the reduction of filling pressure [Lappe et al 1985b, Almeida et al 1986, Flückiger et al 1986, Weidman et al 1986]. The latter indicates that a shift of circulating fluid to the interstitial space is likely to occur. This might be caused by an increase in postcapillary resistance [Trippodo et al 1986, Faber et al 1988], increase in resistance to venous return [Chien et al 1987] and an increase in capillary bydraulic conductivity [Huxley et al 1987].

Regional hemodynamic studies indicate that the fall in cardiac output is expressed mainly by a reduced renal and mesenteric blood flow [Lappe et al 1985a,b,1986, Hofbauer et al 1986]. The associated increase in resistance has been demonstrated to be dependent on a baroreflex mediated increase in sympathetic tone [Lappe et al 1985a].

Short term and chronic low dose infusions in experimental animals, elevating plasma ANP levels within the physiological or pathophysiological range, have been reported to evoke hemodynamic responses. In normotensive dogs $50 \mathrm{ng} / \mathrm{kg}$.min over one hour 
Henodynamic effects of several synthetic ANP analogues

Acute bemodynamic. effects of ANP in humans evoked an essentially similar decrease in arterial pressure, cardiac filling pressures and cardiac output as did pharmacological doses [Bie et al 1988]. In rats; the fall in cardiac output and blood pressure to $330 \mathrm{ng} / \mathrm{kg}$.min ANP(5-27) during 2 hours was accompanied by a bradycardia [Allen et al 1987]. Chronically administered atrial peptides in normotensive animals caused a fall [Hofbauer et al 1986, Parkes et al 1988, Kondo et al 1986, Granger et al 1986] or no change in blood pressure [De Mey et al 1987, Garcia et al 1986a,b,1987a,b, Cachofeiro et al 1989, Fenoy et al 1989]. Cardiac output initially falls but returns to basic values after two or three days [Parkes et al 1988, Fenoy et al 1989].

Several synthetic analogues have been subjected to hemodynamic studies. ANP (5-28), (5-27) and (4-28) have been systematically studied in conscious rats [Lappe et al 1986] and ANP (5-25), (5 27) and (5-28) have been investigated in dogs [Hintze et al 1985]. These analogues, varying on the carboxyl terminal part of the peptide, have clearcut differences in vasorelaxant properties in vitro. However, removal of amino terminal residues proved to be critical for vasorelaxant activity too. This strongly suggests the need for systematic experiments with synthetic ANP analogues in vivo.

Hemodynamic effects in man are somewhat different. Hypotensive effects have been repeatedly reported [Richards et al 1985, Weidman et al 1986, Biollaz et al 1986b, Fujio et al 1986, Bussien et al 1986, Larochelle et al 1987b, Janssen et all 1986, 1989]. Sodium status does not seem to interfere with the hypotensive activity of ANP [Weidmann et al 1986]. In contrast to observations in experimental animals, heart rate consistently increases in humans during ANP administration. However, large decreases in blood pressure are accompanied by a vagal reaction and bradycardia [Biollaz et al 1986b, Bussien et al 1986, Janssen et al 1986]. Reduction of forearm vascular resistance and cutaneous vasodilation during ANP administration into the brachial artery and the antecubital vein respectively [Bolli et al 1987, Fujita et al 1987, Bussien et al 1986], imply that atrial peptides are potent vasodilators in normal human subjects. Cardiac output has been reported not to change [Cody et al 1986, Allen et al 1989] or to fall [Ebert et al 1988] in human volunteers during ANP infusion. 
Chronic hemodynamic effects in humam
In humans chronic ANP administration resulted in a gradual decrease of blood pressure over 5 days accompanied by an increase in heart rate [Janssen et al 1989].

\subsection{ANP and cardiovascular pathophysiology}

\subsubsection{Hypertension}

Plasma ANP levels in hypertensive animals

Renal excretory effects of ANP in hypertensive animals

Hemodynamic effects in hypertensive animals
Because of its hypotensive properties, ANP has been studied extensively in several experimental hypertensive models, such as SHR, stroke prone SHR, $2 \mathrm{~K}-1 \mathrm{C}$ hypertension, $1 \mathrm{~K}-1 \mathrm{C}$ hypertension, DOCA-salt hypertension and Dahl salt sensitive hypertension. In all the models of hypertension mentioned above, plasma ANP was demonstrated to be increased (table 1.1) [Garcia et al 1985b,c, 1987a,b,c, Morii et al 1986, Hirata et al 1984, Snajdar and Rapp 1985, Sugimoto et al 1986]. However, for SHR not all investigators can demonstrate elevation of plasma ANP [Pettersson et al 1985 , Haass et al 1986]. Increased plasma ANP is generally accompanied by a decrease in atrial content, except in $2 \mathrm{~K}-1 \mathrm{C}$ hypertension [Garcia et al 1987c].

In spontaneously hypertensive rats, the natriuretic and diuretic response is slightly elevated, in comparison with normotensive rats [Gellai et al 1986, Kondo et al 1985]. Two kidney, one clip hypertensive rats, exhibit the greatest natriuretic response to ANP and chronic ANP administration also induces enhanced natriuresis [Seymour et al 1985b, Garcia et al 1985], whereas mineralocorticoid salt- and salt-sensitive Dahl hypertensive rats show normal and even depressed natriuretic responses respectively [Seymour et al 1985b, Hirata et al 1984].

Seymour et al [1985b] demonstrated a huge hypotensive effect in DOCA-salt hypertension. Volpe et al [1986] showed that the hypotensive response was greater in $2 \mathrm{~K}-1 \mathrm{C}$ animals which were saralasin responsive and $1 \mathrm{~K}-1 \mathrm{C}$ animals only respond when they were sodium depleted and thus renin dependent [Volpe et al 1986]. This indicates that angiotensin II induced hypertension is counteracted by ANP. In most of the hemodynamic studies, no differences in central and regional hemodynamics have been demonstrated between normotensive animals and SHR [Lappe et al 1985a,b, 1986, [Seymour et al 1985b]. In one kidney, one clip hypertension, acute 
Plasma ANP levels in hypertensive bumans

Renall excretory effects in hypertensvie humans

Hemodynamic effects in hypertensive humans
Marsh et al 1985, Pettersson et al 1986]. However, De Mey et al [1987] showed a marked difference in blood pressure response to a bolus ANP(5-28). When ANP is administered chronically, hypertensive animals respond with a persistent fall in blood pressure [e.g. De Mey et al 1987, Garcia et al 1985b,c].

In mild hypertensive humans, no elevation of plasma ANP was demonstrated [Larochelle et al 1987a, Zachariah et al 1987, Hedner et al 1989]. In groups without specifically defined type and severity of hypertension, no change in plasma ANP was demonstrated [Naruse et al 1986, Andersson et al 1986, Hedner et al 1986], whereas in similar groups of hypertensive subjects, without specially described type and severity of hypertension or with essential hypertension, other studies found slightly elevated plasma ANP levels [Sugawara et al 1985, Richards et al 1986a,b, Sagnella et all 1986, Arendt et al 1986, Taylor et al 1989].

The renal responses to $\alpha$-hANP are greater in essential hypertensives than in normotensives [Richards et al 1985, 1989, Weidman et al 1986]. Natriuresis is even continued after sodium depletion [Janssen et al 1986]. This may be related partly to the baseline level of arterial pressure.

A bolus of 50 and $100 \mu \mathrm{g}$ ANP [Larochelle et al 1987b, Sugawara et al 1986] and ANP infusion at a rate of $6.5 \mathrm{ug} / \mathrm{min}$ [Weidman et al 1986] induced a significant fall in blood pressure. Sodium restriction enhanced the hypotensive action of infused ANP [Janssen et al 1986], in contrast to its hypotensive activity in healthy volunteers [Weidmann et al 1986]. Lower doses [Larochelle et al 1987b, Cusson et al 1987, Genest et al 1988], did not lead to hemodynamic changes. In a recent study in hypertensive patients [Richards et al 1989], it was demonstrated that a low dose of hANP(1-28) over 3 hours, raising plasma ANP by approximately 3 -fold, did not change blood pressure and heart rate. However, the renin-angiotensinaldosterone system was suppressed. Hence, essential hypertension may be characterized by a relative resistance to the depressor action of ANP [Richards et al 1989]. 


\subsubsection{Congestive heart failure}

Plasma levels in experimental heart

failure

Renal excretory and hemodynamic effect of ANP in experimental heart failure

Plasma ANP' levels in humans having fheart failure

Renal excretory and hemodynamic effects of ANP in humans having heart failure
Plasma ANP levels have been demonstrated to be markedly elevated in experimental congestive heart failure in rats, dogs and hamsters [e.g. Ding et al 1987, Drexler et al 1987, Franch et al 1986, Riegger et al 1988, Holmer et al 1987], which could be related to an increase in cardiac filling pressures [Cantin et al 1973a, Riegger et al 1988]. The elevated plasma ANP levels are parallelled by an increased synthesis and secretion of ANP in the ventricles [Franch et al 1988], possibly contributing to the elevated plasma ANP.

The effects of ANP on renal function appear to be reduced. The natriuretic and diuretic effects of ANP are markedly reduced or are even absent, compared to responses in normal animals [Kohzuki et al 1989, Scriven et al 1985, Tikkanen et al 1987a, Riegger et al 1988]. Administration of antibodies, raised against ANP, in anesthetized animals with experimental heart failure, depresses absolute and fractionall sodium excretion without affecting blood pressure [Awazu et al 1989]. ANP binding sites in renal medulla are decreased in rats with congestive heart failure [Tsunoda et al 1989] suggesting that down regulation of ANP receptors may contribute to the hyporesponsivemess in experimental heart failure. Hemodynamic effects are also attenuated. ANP infusions in animals with congestive heart failure result in small decreases in blood pressure [Kohzuki et al 1989, Drexler et al 1987, Riegger et al 1988, Tikkanen et al 1987b] and no changes in cardiac output [Drexler et al 1987, Riegger et al 1988].

Plasma ANP in humans suffering from congestive heart failure, are also elevated [e.g. Nakaoka et al 1985, Burnett et al 1986, Cody et al 1986, Raine et al 1986, Hirsch et al 1989]. The increase in plasma ANP is parallel to the severity of the congestive heart failure as measured by the New York Heart Association classification [Genest et al 1988].

ANP administration in patients with congestive heart failure still causes natriuresis and diuresis [Riegger et al 1986, Cody et al 1986] although the response appeares to be attenuated [Cody et al 1986, Crozier et al 1986]. ANP administration to patients with congestive heart failure evoked inconsistent hemodynamic responses. Decreased [Molina et al 1988, Serizawa et al 1988a, 1988b] and unchanged 
[Cody et al 1986] blood pressure have been reported. Cardiac index is unchanged during infusion of ANP [Serizawa et al 1988a, 1988b] or even increased [Cody et al 1986, Molina et al 1988] although the pulmonary wedge pressure decreases. A reduction in preload may decrease ventricular distention, with improvement of cardiac function. Variable results have been reported for PRA and aldosterone.

Function of circulating ANP in heart lailure

In a correlation study in patients with congestive heart failure, Hirsch et al [1989] found that ANP is a relatively weak counterregulatory hormone to vasoconstrictor hormones in regional hemodynamic regulation. This suggests that elevated plasma ANP is not relevant in congestive heart failure [Hirsch et al 1989]. The blunted renal and hemodynamic responses to ANP administration confirm these findings.

\subsection{Aim of this thesis}

Diagrammatic summary of the role of ANP in cardiovascular homeostasis

Situdy on renal effects of ANP

Sitwdy on hemodynamic effects of ANP analogues under several conditions
On the basis of the existing knowledge, a theoretical role of ANP in cardiovascular homeostasis is summarized in figure 1.5. The goal of the investigations, described in this thesis, is to further elucidate the role of atrial natriuretic peptides in the cardiovascular homeostasis in normal rats and in rats with hypertension and experimental heart failure.

Contrasting results and a lack of studies in intact and conscious animalls, gave rise to controversial views of the renal function of ANP. Therefore, we investigated the effects of ANP(5-27) on renal hemodynamics and renal excretory functions (chapter 3 ).

In heart failure and hypertension, elevated circulating ANP levels have been demonstrated. Therefore, we decided to study these pathophysiological conditions in rats in parallel to normotensive control rats in several hemodynamic protocols. Firstly, because of the lack of knowledge of the hemodynamic effects of ANP analogues, differing at the amino terminal part of the chain in conscious animals, several ANP analogues were studied with regard to their regional and central hemodynamic effects in the rat models mentioned above. Secondly, long term effects of ANP(5-28) on central hemodynamics in SHR were studied (chapter 4). 
fig 1.5

ANP in cardiowascular homeostasis.
Study of the effects of ANP on microwascular level
The physiological and pathophysiological cardiovascular role of ANP

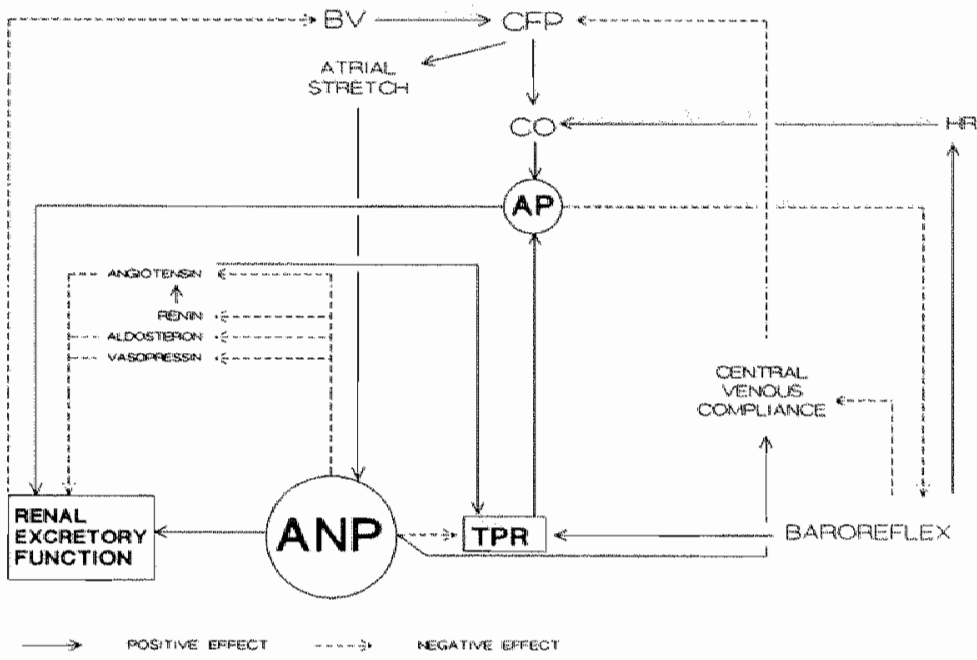

$\mathrm{BV}=$ blood volume

CFP = cardiac filling pressures

$A P=$ arterial blood pressure

$\mathrm{TPR}=$ total peripheral resistance

$\mathrm{CO}=$ cardiac output

The fall in cardiac output during ANP administration is a well documented phenomenon and is mainly due to a reduction in blood volume. However, the precise mechanism has not yet been

elucidated. Therefore, regional albumine clearance, which is used as a parameter for the microcirculatory filtaration, was measured in conscious animals during a blood pressure lowering dose of ANP(128) (chapter 5). In order to study microvascular effects of ANP, related to the extravasation, conscious spontaneously hypertensive rats, equipped with a dorsal skin chamber, were infused with ANP(1-28) (chapter 6).

With surgical bilateral atrial appendectomy, we were able to reduce circulating ANP markedly. In this model, the physiological role of ANP on renal function was studied under basal and volume expanded conditions (chapter 7 ). To elucidate the physiological role of ANP in central hemodynamics, normotensive rats, spontaneously hypertensive rats and rats with heart failure were investigated after monoclonal antibody administration (chapter 8). Finally, all data will 
ANP in cardiovascular homeostasis

be placed in the perspective of recent international literature, thus redefining the rolle of ANP in cardiovascular homeostasis (chapter 9.) 


\section{Materials and methods}

\subsection{Animals}

Male normotensive Wistars (W), Wistar-Kyoto (WKY) and Spontaneously Hypertensive Rats (SHR) were used throughout the studies. The animals, aged between 10 and 16 weeks, weighed 275 to $325 \mathrm{~g}$ before the first surgery.

Origin of the animals

The WKY rats were obtained from the original WKY strain and the SHR from the original SHR strain bred at the Central Animal Facilities of the University of Limburg, Maastricht, The Netherlands. The Wistar rats were obtained from Winkelmann, Borchen, West Germany. The animals had free access to standard lab food (Hope Farms, type RMH-TM, Woerden, the Netherlands) and tap water before and during the experiments. After surgery the animals were housed separately.

\subsection{Surgery}

In this section, all surgical methods used, will be described with their practical implications in the experiments as described in the experimental chapters. The catheters, described in 2.2.1, 2.2.2 and 2.2.3, were implanted at least one day before the experiments were started.

\subsubsection{Arterial blood pressure measurement}

Catheters To perform direct measurement of blood pressure, animals were equipped with a catheter constructed from a $9 \mathrm{~cm}$ piece of $\mathrm{PE}-10$ tubing, heat-sealed to a $12-\mathrm{cm}$ piece of PE-50 tubing and the latter to a $1-\mathrm{cm}$ piece of $P E-100$ tubing. A $3-\mathrm{cm}$ piece of vinyl tubing (Serva TT63) was slid over the PE-100 tubing and fixed tightly with 3-0 silk. Finally, the PE-10 tubing was bent in a J-shape after dipping into near-boiling water.

Surgery In order to cannulate the abdominal aorta, the left or right femoral artery was separated from the connective tissue under ether anesthesia. After clamping, a small hole was cut in the vessel, the PE-10 catheter was inserted and advanced approximately $4 \mathrm{~cm}$ into the 
abdominal aorta. The tip of the catheter was positioned below the bifurcation of the aorta and above the left renal artery. The catheter was secured to the artery with 3-0 silk sutures and behind the Jshape to the hindlimb muscle with 2-0 silk sutures. It was guided subcutaneously to the neck where it was exteriorized and secured to the neck muscle with silk 2-0. The catheter was filled with heparinized saline $(50 \mathrm{IU} / \mathrm{ml}$ in $0.9 \% \mathrm{NaCl})$ and closed with a metal plug.

Measurements For measurement of blood pressure, the rats were placed in plastic experimental cages $(22 \times 13 \times 13 \mathrm{~cm})$. The catheter was connected to a low-volume displacement pressure transducer (type CP O1, Century Technology Company, Inglewood, CA, USA). The transducers were calibrated from 0 to $200 \mathrm{mmHg}$ using a mercury manometer. The signal was recorded on a Grass model 7D, polygraph (Grass Instruments, Quincy, Mass, USA) or on a computerized system (University of Limburg, Maastricht, The Netherlands) [Schoemaker 1989]. Low-pass filtering $(0.5 \mathrm{~Hz})$ of the pulsatile pressure signal resulted in the mean arterial pressure (MAP). In some experiments, heart rate (HR) was obtained from the pulsatile signal using a tachograph (Grass polygraph).

\subsubsection{Central venous pressure measurement}

Catheters To measure central venous pressure (CVP), the rats were equipped with a catheter, constructed of an 8-cm piece of Silastic tubing (602175 ), slid over a $16-\mathrm{cm}$ piece of PE-50 tubing. The PE-50 tubing was bent at the end in a $\mathrm{J}$-shape as described above. Two small rims were made $12 \mathrm{~cm}$ from the J-shape in order to suture the catheter to the neck muscle.

Surgery The thoracic vena cava was cannulated by an approach through the right or left femoral vein. Under ether anesthesia, a small incision was made in the groin and the femoral vein was freed from connective tissue. After clamping, a hole was cut in the vessel. The Silastic tubing was cut to the appropriate length, measured from the lower point of the sternum to the hole in the vessel. Then the Silastic tubing was gently inserted, the cannula was fixed to the vessel and the hindlimb muscle and was guided subcutaneously to the neck where it was exteriorized and fixed. The catheter was filled with heparinized saline and closed with a metal plug. 
Measunements The procedure of CVP-measurements was similar to arterial blood pressure measurements. The catheter was connected to an identical low-volume displacement transducer, which was calibrated for central venous pressure with a water manometer from 0 to $15 \mathrm{~cm}$ water. Recordings of the signals were made on a Grass model $7 \mathrm{D}$, polygraph or on computerized sytems for measurements. Mean pressure was obtained by low-pass filtering $(0.5 \mathrm{~Hz})$ of the pulsatile signal.

\subsubsection{Intravenous administration of drugs or volume load}

Catheters For intravenous infusions or injections of drugs or volume loading, the animals were instrumented with one or two catheters, constructed of a $4-\mathrm{cm}$ piece of PE-10 tubing, heat-sealed to a $16-\mathrm{cm}$ piece of PE-50 tubing. The PE-10 tubing was bent in a J-shape. Two small rims were made $12 \mathrm{~cm}$ from the PE-10/PE-50 seal in order to suture the catheter to the neck muscle.

Surgery The catheters were implanted via the femoral vein by making a small incision in the groin and freeing the vessel from the connective tissue. After clamping, a hole was made in the vessel and the PE-10 catheter was inserted. It was fixed to the vessel and the hindlimb muscle, guided subcutaneously to the neck, exteriorized and sutured to the neck muscle. The catheter was filled with heparinized saline and closed with a metal plug.

\subsubsection{Bladder catheter for renal function measurements}

Catheters For renal function measurements, animals were instrumented with a bladder catheter. This catheter was implanted 3-4 days before the experiments were executed. The catheter consisted of two $20 \mathrm{~cm}$ pieces of PE-50 tubing inserted in two snugly fitting holes made in a small ethylene-vinyl-acetate co-polymer (EVA) cup (diameter 5.5 $\mathrm{mm}$; removable flow moderator cup from Alzet 2001 osmotic minipump; Alza corporation, Palo Alto, Ca, USA). The catheter system was then sterilized with ethylene oxide.

Surgery For the implantation of the catheter under ether anesthesia, a small suprapubic incision was made, the bladder was exteriorized and a round 6-0 silk purse-suture was made at the apex. A $6 \mathrm{~mm}$ incision was made in the apex, taking care not to damage any blood vessels. 
fig. 2.1

Bladder calheter as used in our experiments.s
The vinyl cup was inserted and the bladder wall was closed with the ligature. The abdominal wall was closed with 3-0 silk and the PE-50 tubing was tunneled subcutaneously to the neck, where it was sutured to the neck muscle. The bladder catheter system was carefully flushed with sterile $0.9 \% \mathrm{NaCl}$ solution, using one of the tubes as an inlet and the other one as an outlet. The catheters were then closed with metal plugs.

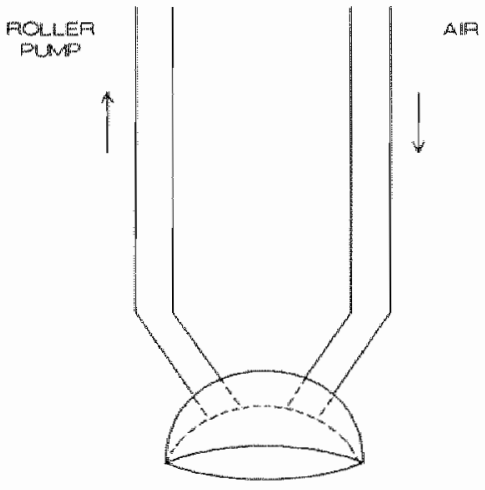

Urine sampling The outlet of the bladder catheter was connected to a peristaltic pump for urine sampling (P-3, Pharmacia Fine Chemicals, Sweden). The open inlet prevents the formation of a vacuum in the bladder, by passively sucking air.

\subsubsection{Doppler flow probe implantation and regional flow measurement}

Probes and surgery Regional blood flow was measured with a $20 \mathrm{MHz}$ directional pulsed Doppler system with small Doppler probes [Haywood et al 1981]. At least 4 days before the start of the experiments, animals were anesthetized with sodium pentobarbital $(60 \mathrm{mg} / \mathrm{kg}$ i.p.) and the abdomen was opened. Intestines were carefully put aside in saline- 
fig 2.2

The lay out of animal preparation used in regional hemodynamtic studies. wetted gauze. The left renal artery, the superior mesenteric artery and the abdominal aorta, distal to the iliolumbar arteries, were carefully dissected. Doppler flow probes were placed around these arteries and the cables were guided out of the abdomen after being fixed to the abdominal wall. The cables of the kidney flow probe were also fixed on the renal capsule. Cables were guided subcutameously to the neck, where they were soldered to a miniature conmector which was mounted on the rat's skull with jeweller's screws and dental cement.

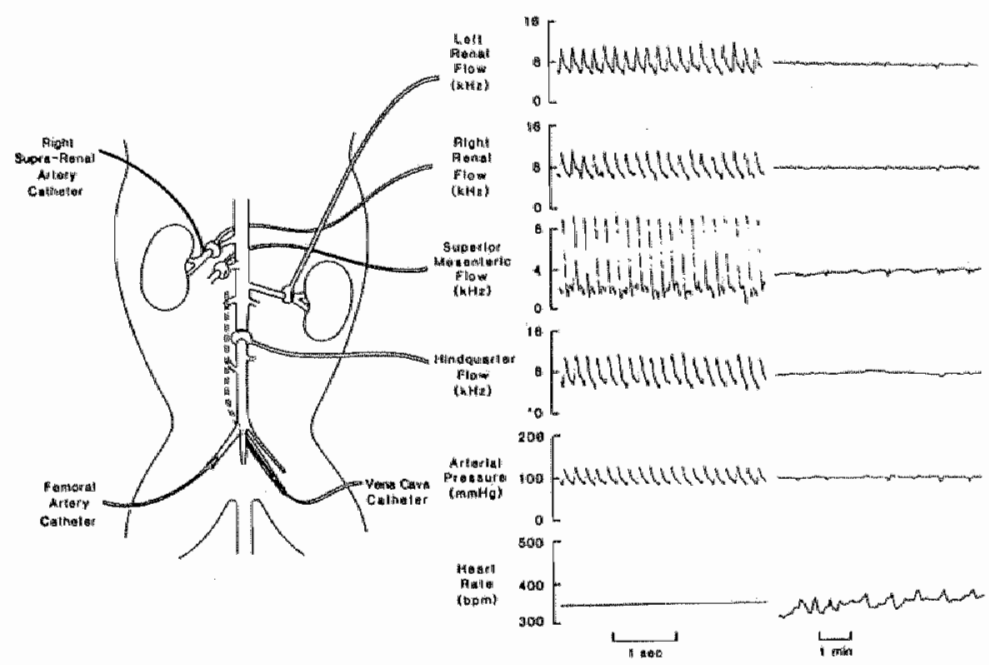

Measurements Renal, mesenteric and hindquarter (which is predominantly the skeletal muscle flow) blood flow, was measured by the flow probes placed around the left renal, mesenteric and abdominal aorta respectively, as $\mathrm{kHz}$ Doppler shift, using a 4-channel $20 \mathrm{MHz}$ directional pulsed Doppler system (Bioengineering Department, University of Iowa, Iowa City, Ia, USA). The Doppler shift is directly and linearly proportional to volume flow [Haywood et al 1981]. Zero 
blood flow was determined electronically and mean flows were obtained by low-pass filtering. Recordings were made on a computerized processing system.

\subsubsection{Electromagnetic Now probe implantation and cardiac output measurement}

Surgery At least 5 days before performing central hemodynamic experiments, rats were anesthetized with sodium pentobarbital $(60 \mathrm{mg} / \mathrm{kg}$ i.p.) and the trachea was intubated for artificial ventilation (60 stro$\mathrm{kes} / \mathrm{min}, 2.5 \mathrm{ml}$ tidal volume) with a respiration pump (model 680 , Harvard Milles, Mass, USA). The skin was opened over the third right intercostal space and the underlying muscles $(\mathrm{m}$. pectoralis profundus and $\mathrm{m}$. rectus abdominus) were cut. A hole was made in the intercostal muscle and pleurae, and they were carefully cut over approximately $15 \mathrm{~mm}$, taking care not to damage the lungs. Then the ribs were spread with a miniature retractor and the aorta was dissected. An electromagnetic flow probe (i.d. 2.6-2.7 mm, Skalar, Delft, The Netherlands) was placed around the ascending aorta. The probe was carefully fixed at the third rib and the thorax was closed. Muscles were sutured separately with 5-0 silk and the cable was tunneled subcutaneously to the neck where the cable was fixed. The connector was sutured to the skin on the head. Negative intrathoracic pressure was restored by inserting a silastic drain between the 6th and 7 th rib and the application of a negative pressure of $10 \mathrm{~cm} \mathrm{H} \mathrm{O}$. Further details of the procedure have been described elsewhere [Smits et al 1982].

Measurements In order to measure cardiac output $(\mathrm{CO})$, the ellectromagnetic flow probe was connected to a sine-wave electromagnetic flowmeter (Skalar, model 400, Delft, The Netherlands). Late diastolic flow was taken to be zero and mean blood flow was used as a measure of $\mathrm{CO}$. In experiments, where $\mathrm{CO}$ was measured, HR was obtained from the flow signal. Signals were recorded on a Grass 7D polygraph (Grass Instruments, Quincy, Mass USA) or by a real-time data processing system (Department of Instrumental Services, University of Limburg, Maastricht, the Netherlands). Mean signals were obtained by low-pass filtering of the signal. 
Calculations The total peripheral resistance was calculated from MAP and CO according to TPR = MAP / CO $(\mathrm{mm} \mathrm{Hg} \cdot \mathrm{min} / \mathrm{ml})$. Stroke volume (SV) was calculated according to SV $=\mathrm{CO} / \mathrm{HR}(\mu \mathrm{l} /$ beat $)$.

fig 2.3

The lay-out of animal preparation used for central hemodyamic studies.
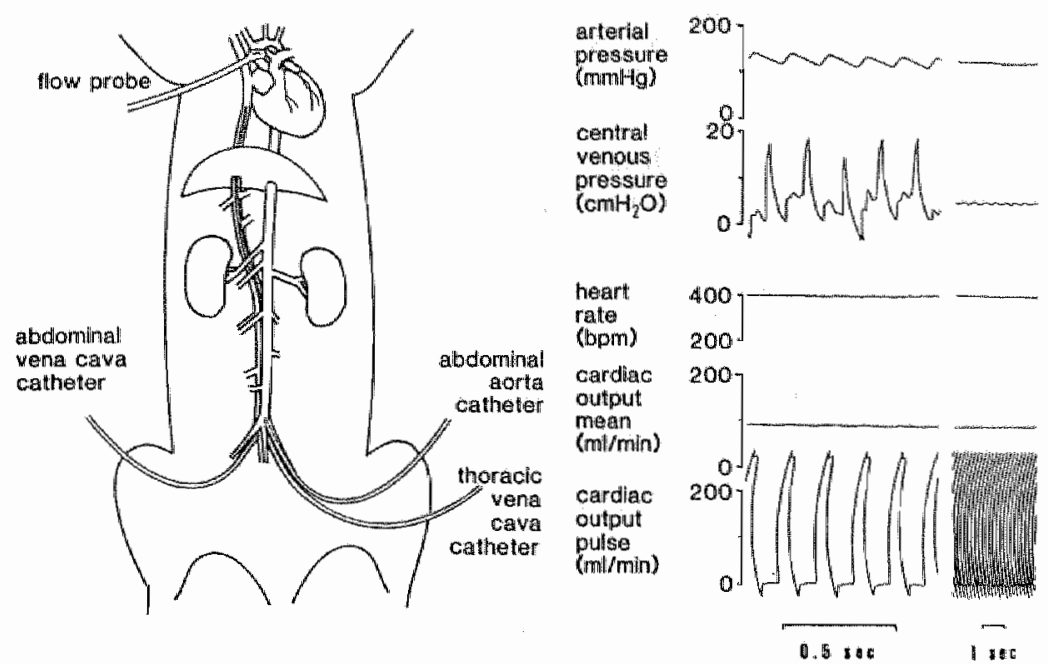

\subsubsection{Atrial appendectomy}

Surgery Atrial appendectomy was performed in male WKY. Rats were anesthetized with sodium pentobarbital $(60 \mathrm{mg} / \mathrm{kg}$ i.p.) and intubated for artificial respiration ( 60 strokes/min, $2.5 \mathrm{ml}$ tidal volume). Median sternotomy was performed and both left and right atrial appendages were exposed. Loop ligatures (5-0 silk) were tightened around the bases of the appendages and both were excised. Then the thorax was closed with six 3-0 silk ligatures. Sham appendectomy was performed similarly but the ligatures were not tightened and atrial appendages were not removed. In animals for renal function studies atrial appendectomy was directly followed by a bladder catheter implantation.

\subsubsection{Infarction}

Surgery Myocardial infarction was produced by left coronary arterial ligation, as previously described [Fishbein et al 1978, Schoemaker 1989]. W 
or WKY were anesthetized with sodium pentobarbital $(50 \mathrm{mg} / \mathrm{kg}$ i.p.), intubated (PE-240) and artificially ventilated (60 strokes/min, $2.5 \mathrm{ml}$ tidal volume). The animals received $2 \mathrm{mg} / \mathrm{kg}$ lidocaine i.m. prophylactically. A thoracotomy was performed in the left 4th intercostal space and the left descending coronary artery was ligated with 6-0 silk near its origin (WI or IWKY). In the sham operated animals, the left coronary artery was not ligated. Twenty four hour mortality for infarcted animals was approximately $30 \%$. Four weeks after infarction, the animals were instrumented with an electromagnetic flowprobe as described in section 2.2.6.

\subsubsection{Dorsal microcirculatory chamber}

Skin chamber

The study presented in chapter 6 is based upon experiments with a two sided muscle layer preparation as originally described by Smith et al [1985]. However, in our experiments, one muscle layer was studied. The chamber (Carolina Medical Electronics, King, NC, USA) is described in detail by le Noble [1987]. During the preparation of the chambers, care was taken to smoothen sharp edges, in order to prevent irritation to the animals or tissue damage. Before implantation the chambers were gas sterillized.

Surgery After anesthesia with pentobarbital $(60 \mathrm{mg} / \mathrm{kg}$ i.p.) the hair of the back of the animal was removed using a chemical depilatory agent (Oplica, Olivin, Hamburg, FRG) over a surface of approximately 6 $\mathrm{cm}$ length and width, from about $1 \mathrm{~cm}$ below the spine of the scapula. Then the rat was placed ventral side down on a special surgery board and four 3-0 silk ligatures were inserted through the skin and underlying muscle along the length of the vertrebral column and fixed to a supporting D-shaped frame. After rotating the animal on its left side, the skin was punched and muscle and skin were dissected. The right side of the chamber was positioned and screws needed to fix the chamber parts together, were placed. Then the animal was turned over on its right side. The window opening on the left side was marked and skin was carefully dissected from the underlying muscle. The left side of the chamber was placed and fitted to the right window with stainless steel nuts. The supporting sutures were removed from the D-shaped frame and the animal was placed ventral side down on the surgery board. Air was emmited by injecting sterile saline into the chamber. Antibiotic ointment (Chloramphenicol, AUV, Cuyk, the Netherlands) was applied topically a- 
round the edges of the chamber to prevent infection. Then the chamber was sealed. In order to protecte the chamber and to improve healing of the wound, a protective aluminum hood was placed over the chamber.

Recordings For studies on conscious animals, a modified Zeiss microscope was used with the stage attached to a heavy stable plate and mounted vertically. The skin muscle was transilluminated using a fiber optic light guide system and a Tungsten halogen lamp (150 W) with a heat absorbing filter. The preparation was studied with a $10 \mathrm{X}(\mathrm{Nu}$ merical Aperture 0.22) objective and recordings were made with a video camera (Philips Video 40, videobuis) and a video recorder (Phillips Video recorder 6561).

Measurements of vessel diameters

\subsection{Determination of plasma immuno-reactive ANP}

Blood sampling Blood samples were drawn into chilled tubes, containing EDTA $(100 \mathrm{mg} / \mathrm{ml})$ and aprotinin $(500 \mathrm{KIU} / \mathrm{ml})$, centrifuged at $4^{\circ} \mathrm{C}$ to separate plasma from blood cells, and frozen in polystyrene tubes at $-20^{\circ} \mathrm{C}$ until assayed.

Extraction of plasma At the time of determination, plasma samples were assayed as described by Rosmalen et al [1987]. Seppak C-18 cartridges were activated with $5 \mathrm{ml}$ of $4 \%$ acetic acid in $86 \%$ ethanol $(\mathrm{v} / \mathrm{v})$, methanol, water and $4 \%$ acetic acid respectively. Then $0.40 \mathrm{ml}$ plasma was acidified with $1 \mathrm{ml} 4 \%$ acetic acid, and applied to Seppak C-18 cartridges (Waters Associates, Harrow, Middx, UK). The Seppak C18 cartridges were washed twice with $5 \mathrm{ml}$ destilled water. After elution with $4 \%$ acetic acid in ethanol $86 \%(\mathrm{v} / \mathrm{v})$ and evaporation under nitrogen stream $\left(37^{\circ} \mathrm{C}\right)$ the extract was dissolved in $500 \mu \mathrm{l}$ RIA buffer (ITS, Wychen, Netherlands, containing $0.2 \mathrm{~mol} / 1$ sodium borate ( $\mathrm{pH} 8.4$ ), $10 \mathrm{mmol} / \mathrm{I}$ EDTA, $0.1 \%$ Triton $\mathrm{X}-100$ detergent and $2 \mathrm{~g} / 1 \mathrm{BSA}$ ) and subsequently subjected to radio immuno assay (RIA). 
Radia immuno assay For RIA a standard curve of rANP (1-28) $(0.78,1.56,3.13,6.25$, $12.5,25,50,100$, and $200 \mathrm{pg} /$ tube was prepared. One hundred $\mu \mathrm{l}$ standard of ANP or plasma extract was pipetted in duplicate into correspondingly labelled tubes. For non-specific binding (NSB) 300 $\mu l$ assay buffer was added to the NSB (blank) tubes. To each tube, except blank and total count tubes (TC), $200 \mu 1$ of r-ANP antiserum (ITS, Wychen, The Netherlands) was added. The tubes were vortexed and incubated for $24 \mathrm{~h}$ at $4^{\circ} \mathrm{C}$. Then $200 \mu \mathrm{l}$ of rANP ${ }^{12} \mathrm{I}$ tracer was added to all tubes. The tubes were vortexed and incubated for $18 \mathrm{~h}$ at $4^{\circ} \mathrm{C}$. To separate bound from non bound tracer, $1 \mathrm{ml}$ sheep anti-rabbit precipitating reagent (SAR/PPT) was added to all tubes except to total count tubes, vortexed and incubated 30 minutes at room temperature. All tubes were centrifuged for $30 \mathrm{~min}$ at $3,000 \mathrm{~g}$ at $20 \pm 5^{\circ} \mathrm{C}$. Supernatant was immediately aspirated and the pellet was counted for $2 \mathrm{~min}$ in a gamma counter. Recovery after extraction was tested with ${ }^{12}$ I-tracer and with $\operatorname{rANP(1-28)}$ in separate samples. Recovery averaged $95 \%$. Specific binding was 27.2 $\pm 0.9 \%$ and nonspecific binding was $5.6 \pm 0.2 \%, \mathrm{ED}_{s 0}$ was $10.3 \pm$ $0.4 \mathrm{pg} /$ tube; sensitivity of the assay was $0.73 \pm 0.05 \mathrm{pg} /$ tube; intraand interassay variation was $4 \%$ and $12 \%$, respectively.

\subsection{Measurement of infarct size}

Removing of the heart

Determination of infurct stixe
After hemodynamic measurements, rats were anesthetised with pentobarbital $(60 \mathrm{mg} / \mathrm{kg}$ i.v. $)$ and killed with potassium chloride i.v. to obtain maximal ventricular dilatation. Hearts were excised and atrial appendages were removed. The ventricles were blotted dry and frozen at $-70^{\circ} \mathrm{C}$ until the analysis of infarct size.

Frozen hearts were cut in slices of approximately $1 \mathrm{~mm}$ thickness and immediately incubated in Sörensen buffer $\left(0.103 \mathrm{M} \mathrm{Na} \mathrm{HPO}_{4}\right.$, $0.015 \mathrm{M} \mathrm{KH}_{3} \mathrm{PO}_{4}, \mathrm{pH}=4$ ) with $1 \mathrm{mg} / \mathrm{ml}$ nitro blue tetrazolium (Sigma) at $37^{\circ} \mathrm{C}$ for approximately $10 \mathrm{~min}$. Slices were washed with destilled water and right ventricle outer walls were excised. From the slices of all infarcted left ventricles, photographs were made to measure epicardial (A), endocardial (B) wall circumferences and outer (C) and inner (D) infarcted part of the ventricle wall for each slice. Infarct size per ventricle was calculated as $1 / 2(\Sigma \mathrm{A} / \mathrm{\Sigma} \mathrm{C}+\Sigma \mathrm{B} / \mathrm{\Sigma D})^{*} 100$ [Schoemaker 1989]. 


\subsection{Substances}

\subsubsection{Atrial natriuretic peptides}

The structures of the different forms of atrial natriuretic peptides used in the experiments described in this thesis are presented in fig 1.2. ANP was always dissolved in $0.9 \% \mathrm{NaCl}$ when used for infusion protocols. Rat-ANP was obtained from Nova Biochem in vials of 1 mg protein containing 76\% ANP. ANP(5-27) was obtained from Peninsula. ANP(3-28)(APIII) was kindly provided by Dr J. De Mey. Concentrations of ANP were calculated from the amount of ANP dissolved in a known amount of saline, assuming that ANP disolved fully. Solutions were always prepared in poly-propylene tubes to avoid adsorption of ANP to the wall.

\subsubsection{Antibodies}

The monoclonal antibodies used, were raised against Atriopeptin III (ANP II, amino acid sequence: Ser-Ser-Cys-Phe-Gily-GLy-Arg-lleAsp-Arg-Ile-Gly-Ala-Gln-Ser-Gly-Leu-Gly-Cys-Asn-Ser-Phe-Arg). They were kindly provided by Dr. D. Neuser (Bayer AG, Institute of Pharmacology and Unit for Analytical Therapy Research, Wuppertal, F.R.G.). The antibody reacts equally with ANP(5-25), ANP(5-27), ANP(5-28) and $\alpha \operatorname{rANP}(1-28)(2)$ and was not diluted for use in experiments. The ascites had a titer of 250.000 , indicating that binding capacity of undiluted ascites was high enough to bind circulating ANP, For the control experiments, mouse serum was used from Swiss mice (Central Animal Facilities, University of Limburg, Maastricht, the Netherlands).

\subsubsection{Radio active tracers for renal function and clearance studies}

The radio-active substances, ${ }^{9} \mathrm{Cr}$-EDTA and ${ }^{125} \mathrm{PAH}$ were obtained from Amersham (). ${ }^{131} \mathrm{I}-$, ${ }^{123} \mathrm{I}$-albumine and were obtained from $\mathrm{Me}$ dgenix (IRE, Fleurus, Belgium). All tracers were used within two weeks of delivery. 


\subsection{Statistics}

Analysis of the Results of the renal study were analysed with a two way ANOVA, renal study in which drug administration was used as source of between subjects variance. The dose of saline or ANP administered was used as the source of within subject variance. Differences between saline and ANP for different dose administrations were tested with a Student's t-test modified according to Bonferroni.

Analysîs of hemodynamic effects of acute ANP infusion

Anallysils of hemodynamic effects of long term ANP infusions

Analysils of effects of ANP infusion on albumin clearance and skin muscle microcirculation

Analysis of effects of matrial appendectomy in acute volume expansiton
Results of the hemodynamic studies with the synthetic ANP analogues were analysed with a two-way ANOVA. Depending on the interest, ANP analogues or the rat models were used as sources of between subject variance in ANOVA. Doses were used as sources of within subject variances. To compare individual points between dose response curves or between rat models, Student's t-test modified according to Bonferroni was used.

The longterm infusion studies were analysed with a two-way ANOVA, using administered drugs as the source of between subject variance and the time as the source of within subject variance. A Student's t-test modified according to Bonferroni was used to compare individual observations between curves.

The observations from the albumin clearance studies were analysed with a Student's t-test for paired observations. The results of the microcirculatory effects of ANP were analysed with a one-way ANOVA. The dose of ANP administered was used as the source of within subjects variance.

The results of acute volume expansion in atrial appendectomized rats were analysed with a two way ANOVA, using atrial appendectomy as the source of between subject variance and the time as the source of within subject variance. Again, individual observations between appendectomy or sham were compared with a Student's ttest modified according to Bonferroni. 
Analysis of effects Statistical significance within groups were analyzed using one-way of antibodies of ANOVA with Dunnett's multiple range test. Comparison between cemtral hemodynamics groups was performed on changes by two-way ANOVA with repeated measures (34). Responses to mouse serum were used as controls for responses to monoclonal antibodies. Each model was compared to its own control.

Levels of In all studies significance was accepted if $P \leq 0.05$. Only if ANOVA significance resulted in $P \leq 0.05$ further analysis with a Student"s $t$-test modified according to Bonferroni was done. 


\section{Renal effects of atrial natriuretic peptide in conscious rats}

\subsection{Introduction}

Renall excretion and renall hemodynamic effect of ANP

Intrarenal sites of activity for ANP

Aim of this study
The natriuretic and diuretic properties were the first effects demonstrated of the atrial natriuretic peptide [De Bold et al 1981]. However, the mechanism is still debated. In a previous study, in conscious, intact spontaneously hypertensive (SHR) and normotensive rats, infusions of ANP(5-27) resulted in a consistent decrease, rather than an increase of renal blood flow as measured with implanted Doppler flowprobes [Lappe et al 1985]. Intra-renal infusion of ANP(5-27) into SHR failed to affect renal blood flow [Smits et al 1986]. Thus, in conscious unrestrained rats, ANP does not act as a renal wasodilator and therefore an increased renal blood flow can not account for the massive diuresis and natriuresis.

Several intrarenal sites of action have been demonstrated for ANP [Leckie 1987]. ANP is able to dilate afferent arterioles and constrict efferent arterioles [Marin-Grez et al 1986]. Furthermore, ANP might antagonize the angiotensin II mediated constriction of mesangial cells [Appel et al 1986]. The change in filtration pressure through afferent arteriolar dilation and efferent arteriolar constriction and the change in glomerular surface area have been postulated as responsible for an increased glomerular filtration rate as demonstrated in anesthetized dogs [Maack et al 1984, Wakitani et al 1985] and conscious rats [Huang et al 1985, Beasley and Malvin 1985]. However, contrasting results have been obtained in conscious dogs [Seymour at el 1985] and rats [Pollock and Banks 1983, Sonnenberg et al 1982]. A change in distribution of flow toward the inner cortex and medulla, thus reducing inner medullary hypertonicity, might also contribute to increased renal excretion [Fujioka et al 1985, Hansell and Ulfendahl 1986].

This study was performed to further characterize the intra-renal mechanisms of atrial natriuretic peptide (5-27) induced urine, sodium and potassium excretion in conscious rats. 


\subsection{Materials and methods}

Animals For this study, male adult SHR were used as described in section 2.1 .

Surgery All surgery was performed under ether anesthesia. Catheters were implanted in the femoral vein as described in section 2.2 .3 for ANP(5-27) infusions. In the SHR, in which renal hemodynamics were to be studied, a second i.v. catheter was implanted into the same vein for infusions of tracer substances (see below) and an arterial catheter was placed in the abdominal aorta through the left femoral artery for blood sampling.

Bladder catheter

Measurement of renal excretion

All animals were implanted with a special catheter in the bladder, as described in section 2.2.4 (fig 2.1), to allow continuous urine sampling in conscious animals. Animals were allowed to recover 4-6 days, during which period the catheters remained closed. During this period, animals voided by the natural route.

On the experimental day, both ends of the bladder catheter were opened. One end was connected to a roller pump, whereas the other end was left open to let air flow in freely. The roller pump was set to pump $0.5 \mathrm{ml} / \mathrm{min}$ out of the bladder, which was $30-100$ times higher than the basal urine production rate. The venous infusion catheter was then filled with the infusion solution $(0.9 \%$ $\mathrm{NaCl}$ or $100 \mu \mathrm{g} / \mathrm{ml} \mathrm{ANP}(5-27)$ in $0.9 \% \mathrm{NaCl})$. Before infusions were started, urine flow was collected in pre-weighed tubes during $15 \mathrm{~min}$ periods. Following urine collection during a control period, infusions of saline or ANP(5-27) were started. ANP(5-27) infusions started at a rate of $0.25 \mu \mathrm{g} / \mathrm{kg}$.min. The infusion rate was doubled every $15 \mathrm{~min}$ up to the highest rate of $4 \mu \mathrm{g} / \mathrm{kg}$. min. Saline was infused in control experiments to obtain an identical intravenous volume flow. Saline and ANP(5-27) infusions were randomized. After the last infusion period was finished, urine was collected for two more 15 min periods. Before closing the catheters, they were flushed with $0.5 \mathrm{ml} 0.9 \% \mathrm{NaCl}$.

Urine samples were weighed and sodium and potassium concentrations determined by flame photometry. 
Measurement of remal hemodynamics

Renal hemodynamics were measured in 8 animals during a control period and during infusion of $0.5,1,2$ and $4 \mu \mathrm{g} / \mathrm{kg} \cdot \min \mathrm{ANP}(5-27)$ and in 8 control animals during salline infusions, following an identical protocol. The bladder catheter was connected to a roller pump as described above. Before urine flow was allowed to stabilize, one venous catheter was filled with the solution to be infused, as above. Through the other catheter, a bolus injection of $0.5 \mu \mathrm{Ci}$ ${ }^{s} \mathrm{Cr}$ EDTA and $1 \mu \mathrm{Ci}{ }^{18}$ I-hippurate (CJP respectively IM315P, the Radionuclide Centre, Amersham) was given, followed by an infusion of a mixture of both tracer substances to deliver ${ }^{s 1} \mathrm{Cr}$ EDTA and ${ }^{12}$ I-hippurate at rates of $0.6 \mu \mathrm{Ci} / \mathrm{h}$, respectively $1.8 \mu \mathrm{Ci} / \mathrm{h}$. Urine collection was started after $1.5 \mathrm{~h}$ to reach a steady state for the tracer substances in plasma. As above, control and ANP(5-27) infusions steps lasted $15 \mathrm{~min}$. In these experiments, urine produced in the first 5 min was discarded to eliminate interference of washout phenomena. Thus, urine was collected only during the last 10 min of infusions. Half-way in this latter period, a $200 \mu \mathrm{l}$ arterial blood sample was taken. Urine was weighed and concentrations of tracers were determined in urine and plasma in an LKB gammacounter corrected for overlap between counting channels. Glomerular filtration rat (GFR) and effective renal plasma flow (ERPF) were calculated from urine and plasma concentrations. Filtration fraction (FF) was calculated as GFR/ERPF. Fractional water excretion $\left(\mathrm{FE}_{\mathrm{H} p)}\right.$ ) was calculated as urine volume flow/GFR. At the end of the experiments, the urinary tract of animals was inspected for signs of obstruction. In none of the animals, this was noted.

Statistics Statistical analysis is performed as described in section 2.6 .

\subsection{Results}

Effects on renal excretory functions
Figure 3.1 summarizes the effect of saline and ANP(5-27) on urine flow (V), sodium excretion $\left(U_{\mathrm{N} x} V\right)$ and potassium excretion $\left(U_{\mathrm{K}} V\right)$. During control periods, no differences were observed between saline- and ANP(5-27)- infused groups with regard to $\mathrm{V}, \mathrm{U}_{\mathrm{N}_{0}} \mathrm{~V}$ and $U_{\mathrm{K}} V$. As may be seen in figure 3.1, infusion of saline did not affect renal excretory function. Infusion of ANP(5-27) increased $V, U_{N a} V$ and $U_{k} V$. Already during infusion of $0.5 \mu \mathrm{g} / \mathrm{kg} . \mathrm{min}$, the differences between saline- and ANP(5-27)-infused animals were statistically significant. Maximal values for $\mathrm{V}, \mathrm{U}_{\mathrm{Na}} \mathrm{V}$ and $\mathrm{U}_{\mathrm{k}} \mathrm{V}$ were observed 


\section{fig 3.1}

Renal excretory effects of ANP (5-27) infitision in conscious rats.

* statistically significant differences between ANP(5-27) and saline responses. during infusion of $2 \mu \mathrm{g} / \mathrm{kg}$.min. Increasing the dose of ANP(5-27) to $4 \mu \mathrm{g} / \mathrm{kg} \cdot \mathrm{min}_{\mu}$ decreased $\mathrm{V}, \mathrm{U}_{\mathrm{Ha}_{\mathrm{t}}} \mathrm{V}$ and $\mathrm{U}_{\mathrm{K}} \mathrm{V}$ again. Following termination of $\mathrm{ANP}(5-27)$ infusion $U_{\text {ma }} \mathrm{V}$ remained elevated during one more $15 \mathrm{~min}$ period. Thereafter, it was returned to control values. $V$ and $U_{k} V$ did no longer differ from control values immediately after the termination of ANP(5-27) infusion.
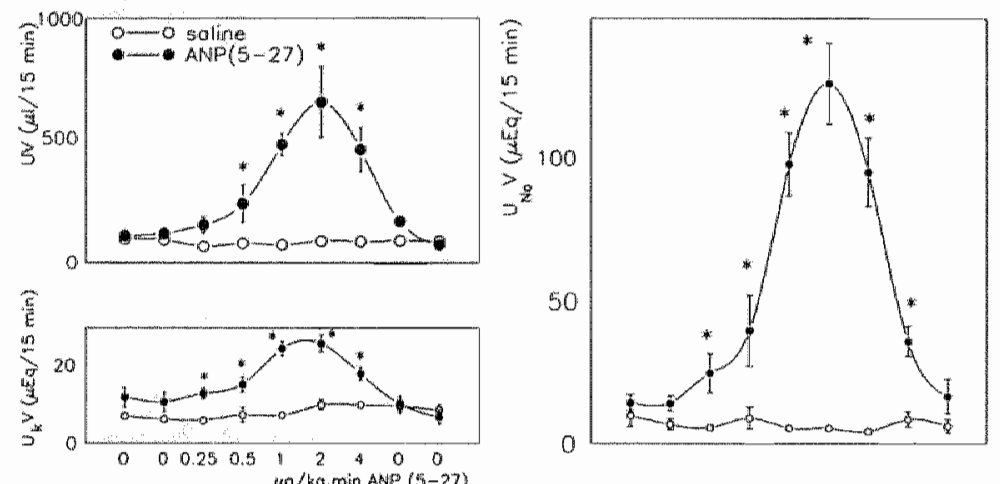

Diuresis in renal hemodynamic studies

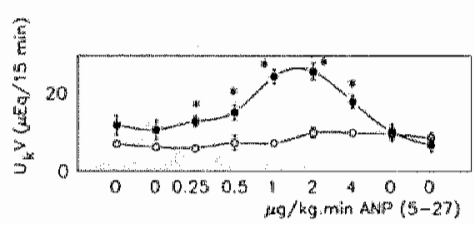

Effects of saline and ANP(5-27) on renal hemodynamic are summarized in figure 3.2. Basal $\mathrm{V}$ in these animals was higher than in the experiments described above, but they were not significantly different from each other. Part of the higher diuresis may be accounted for by the fact that these animals, in contrast to the ones above, received a sustained tracer infusion $(10 \mu \mathrm{l} / \mathrm{min})$. In these experiments, also $\mathrm{V}$ increased during infusion of ANP(5-27). Statistical significance differences between saline- and ANP(5-27)infused animals were obtained only during infusion of 1 and 2 $\mu \mathrm{g} / \mathrm{kg}$.min. Again, as above, a higher infusion rate of $4 \mu \mathrm{g} / \mathrm{kg} \cdot \mathrm{min}$ decreased diuresis.

Ghomerular GFR was similar in both groups during control periods. Saline nttration rate infusion did not affect GFR. During infusion of ANP(5-27), GFR changed maximally at $1 \mu \mathrm{g} / \mathrm{kg}$.min. However, the changes in GFR were not statistically significant when compared to control animals. 
Effective renal plasma t1ow
ERPF was similar in both saline- and ANP(5-27)-infused groups during control periods. Saline infusion did not consistently affect ERPF, whereas ANP(5-27) led to a dose-dependently decrease in ERPF. During infusion of $4 \mu \mathrm{g} / \mathrm{kg} \cdot \mathrm{min}$, it was reduced by $26.5 \pm 7.9 \%$ compared to control values. The effect was, however, not statistically different from that in saline-infused animals, because of the relatively large standard error in the latter.

fig 3.2

Effects of saline and ANP (5-27) on renal hemodynamics in conscious rats.

- Statistically significant differences in responses between saline and ANP(5-27).

Filtration fraction

Fractional water excretion
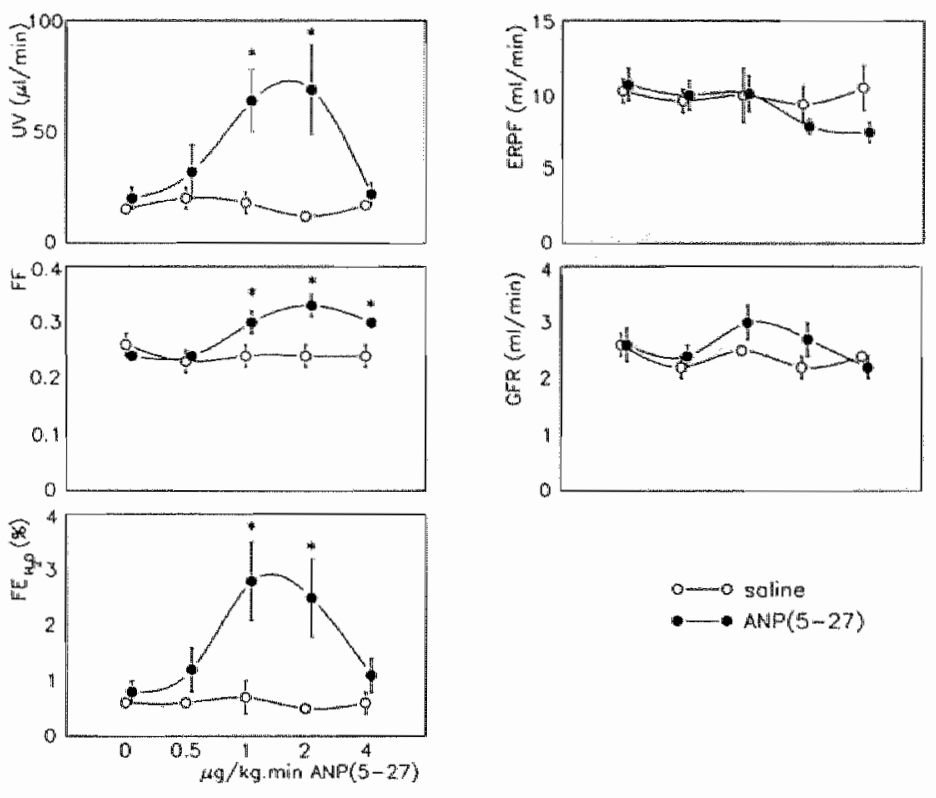

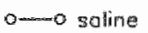

$-\quad \operatorname{ARP}(5-27)$
During control periods, FF in saline infused animals and ANP(5-27) infused animals were not different. Again, This parameter was not affected during saline infusion and increased significantly $(37.5 \%)$ during infusion of $2 \mu \mathrm{g} / \mathrm{kg} \cdot \min$ ANP(5-27).

$F E_{H \rho}$, calculated from $V$ and GFR, did not differ in the two groups during the control periods. ANP(5-27) infusion dosedependently and significantly increased $\mathrm{FE}_{\mathrm{H}, \mathrm{p}}$ during infusion of 1 and $2 \mu \mathrm{g} / \mathrm{kg}$.min. During infusion of $4 \mu \mathrm{g} / \mathrm{kg} \cdot \mathrm{min}$, it declined again. Saline did not affect $\mathrm{FE}_{\mathrm{H}, \mathrm{O}}$. 


\subsection{Discussion}

Background of In a previous study, it was shown that short term infusions of this study ANP(5-27) in conscious, normotensive rats and SHR caused a reduction of blood pressure by reducing cardiac output [Breuhaus et al 1985, Lappe et al 1985]. In contrast to reports in anesthetized animals [Koike et al 1984, Maack et al 1984, Oshima et al 1984, Wakitani et al 1985], we were never able to observe renal vasodilation. In contrary renal vasoconstriction occurred [Lappe et al 1985, Smits et al 1986]. Since then, others have confirmed this observation in rats [Sonnenberg et al 1986] and dogs [Seymour et al 1985]. In this study, we investigated the role of ANP on renal function in detail in conscious unrestrained SHR, equipped with an indwelling bladder catheter, using the same infusion protocol that we have used previously.

Diuretic and natriuretic effects of ANP

Comparable diuretic effects in renal hemodynanic studies

Intrarenal mechanism underlying dinnesis and natriunesis
In the first series of experiments, where we studied the effects of ANP(5-27) on renal excretory function, infusion of ANP(5-27) at rates of $0.5-4 \mu \mathrm{g} / \mathrm{kg} \cdot \min$ significantly increased $\mathrm{V}, \mathrm{U}_{\mathrm{Na}} \mathrm{V}$, and $\mathrm{U}_{\mathrm{K}} \mathrm{V}$. The highest values for all three parameters were observed during infusion rate of $2 \mu \mathrm{g} / \mathrm{kg}$.min when $U_{\mathrm{Na}} \mathrm{V}$ had increased 8.9 -fold. $\mathrm{V}$ and $U_{k} V$ increased respectively $5.5-$ and 2.4 fold. During infusion of

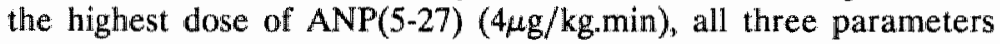
declined again which may be related to the drastic fall in blood pressure noted before [Lappe et al 1985] or to a compensatory response due to fluid volume depletion.

The same pattern of response was observed for $V$ in the experiments, where renal hemodynamics were studied. Because urine from these experiments contained ${ }^{31} \mathrm{Cr}$ and ${ }^{125} \mathrm{I}$, it was impossible to quantitate $\mathrm{Na}$ and $\mathrm{K}$ in these experiments. The maximal urine output was, again, observed at a dose of $2 \mu \mathrm{g} / \mathrm{kg} . \mathrm{min}$, when it was comparable to $\mathrm{V}$ in the first group of animals. Basal urine output in the clearance experiments, however, was higher. This can partly be accounted for by the sustaining tracer infusion these animals received.

In order to investigate which renal hemodynamic changes underlie the natriuretic and diuretic responses, clearances of ${ }^{51} \mathrm{Cr}$ EDTA and ${ }^{12}$ I-hippurate were measured. ERPF declined in a dose-dependent manner. At the highest dose, it was reduced to $7.5 \pm 0.7 \mathrm{ml} / \mathrm{min}$ 
from a control value of $10.7 \pm 1.1 \mathrm{ml} / \mathrm{min}$. Due to the variance in the control group, this effect did not reach statistical significance. However, the $27 \pm 8 \%$ reduction compared to control levels $s_{\text {is }}$ similar to the $25 \pm 5 \%$ reduction of renal blood flow that was measured in a previous study, using Doppler flow probes [Lappe et al 1985]. In conscious rats, 8 Koike et al [1984] noticed an increase in renal blood flow following bolus injections of ANP, whereas others found no change [Huang et al 1985]. In both cases, however, animals were subjected to surgery within $24 \mathrm{~h}$ of the experiments. Therefore, surgical stress may have interfered with experimental results. Similarly, in anesthetized rats [Borenstein et al 1983, Oshima et al 1984] and dogs [Maack et al 1984, Wakitani et al 1985], ANP increases renal blood flow. Others found an unchanged [Pollock et al 1983, Seymour et al 1985] or slightly decreased blood flow [Burnett et al 1984].

Comparison with existing litterature
GFR, ERPF and the role of ANP in diuresis and natriuresis
In our infusion study in conscious rats, no increase in GFR was noticed during ANP infusion, whereas the filtration fraction and fractional water excretion increased significantly during ANP infusion. Reports on the effect of ANP(5-27) on GFR have been as variable as those on renal blood flow. Thus, GFR has been found to increase [Burnett et al 1984, Huang et al 1985, Maack et al 1984], or not to change [Pollock et al 1983, Seymour et al 1985, Sonnenberg et al 1982]. The latter was confirmed in our study. Although, there is no consistant relationship between studies with regard to effects on renal blood flow and GFR, all studies do report an increased filtration fraction. This is again confirmed in the present study.

The combination of unchanged GFR and decreased ERPF as reported here and in other studies, might indicate disturbance of the balance between afferent and efferent arteriolar resistances. Indeed, a combination of afferent arteriolar vasodilation and efferent arteriolar vasoconstriction was demonstrated [Marin-Grez et al 1986, Zeidel et al 1987]. Alternatively, the glomerular filtration coefficient may have increased, either through a direct effect or through interaction with other systems such as the renin-angiotensin system. ANP antagonizes the contractile response of the glomerular mesangial cells to angiotensin II, thus increasing the filtration surface of the glomerulus [Appel et al 1986]. 
Tubular effects Furthermore, ANP affects tubular function by antagonizing the angiotensin II mediated sodium reabsorption in the proximal tubule [Harris al 1987], although contradictory results have been reported [Liu and Cogan 1988]. At the distal tubule, it is able to counteract sodium reabsorbtion induced by aldosteron [Leckie 1987]. At the level of the collecting ducts it antagonizes the effects of vasopressin, thus decreasing water reabsorption [Dillingham et al 1986].

Mechanism tor increased Iractional water excretion

Redilstribution of renal blood now

Conclusion
From GFR and $V$, fractional water excretion was calculated. In ANP infused animals $\mathrm{FE}_{\mathrm{H} \rho}$ increased from $0.79 \pm 0.20 \%$ to $2.81 \pm-$ $0.69 \%$. Although fractional sodium excretion could not be measured, the correlation between water and sodium excretion in the first part of the study suggests that fractional sodium excretion is also increased. In the absence of increased GFR and ERPF, this suggests primarily a reduced tubular reabsorption, which confirms previous micropuncture studies in anesthetized rats [Pollock et al 1983, Sonnenberg et al 1982].

A possible mechanism, through which these effects might occur, is a redistribution of renal blood flow from outer to inner cortex [Fujioka et al 1985, Takezawa et al 1987, Salazar et al 1988]. In the present study, it is not clear, whether a redistribution of flow occurs also, since total renal blood flow decreased drastically. On the contrary, the fact that effects on renal blood flow, measured as clearance of hippurate and as changes in total renal blood flow [Lappe et al 1985], are similar, suggests a lack of intrarenal flow redistribution, although this assumption has been questioned [Stein et al 1976].

In conclusion, as a result of administration of ANP(5-27), urinary excretion of water, sodium and potassium increased and GFR did not change, in spite of an increased FF. This suggests that in these animals a primary tubular mechanism is involved in the renal excretory effects of pharmacological doses of ANP(5-27). 


\section{Hemodynamic effects of ANP $(1-28)$ and ANP (5-28) in conscious normotensive, spontaneously hypertensive rats and in experimental heart failure}

\subsection{Introduction}

In vitro vascular effects of ANP analogues

In vivo hemodyramilc effects of ANP analogues

Erfects of ANP analogues with various amino terminal chains

Sensitivity to ANP analogues in heart railure
Investigations on precontracted blood vessels have demonstrated vasorelaxant properties of atrial natriuretic peptides [Genest et al 1988, Winquist et al 1984]. From the rapid progress in biochemical research on ANP, many analogues have become available for research purposes. Removal of carboxyl or amino terminal amino acids of the peptide variably affects vasorelaxant properties, dependent on the number of amino acids removed. The analogue lacking Ser-Leu-Arg-Arg at the amino terminal part of the chain (ANP(528 )) is 2 to 10 times less potent in vitro than the parent compound [Garcia et al 1984, Olins et al 1985].

Several in vivo hemodynamic studies have been performed with different ANP analogues [Genest and Cantin 1988, Goetz al 1988]. In vivo, high doses of ANP cause an acute hypotensive effect. Furthermore, a marked decrease in cardiac output (CO) has been demonstrated during ANP infusions, which is parallelled by reductions in stroke volume (SV) and central venous pressure (CVP) [Breuhaus et all 1985, Lappe et al 1985b]. Investigations in rats have demonstrated a decreased renal flow [Criscione et all 1987, Hofbauer et al 1986, Lappe et al 1985a,b, 1986]. Significant differences in regional hemodynamic responses to the different ANP analogues (5-27,3-28,1-28) have not been found in SHR [Lappe et al 1986].

The in vitro and in vivo studies with ANP analogues, differing in the number of carboxyl terminal amino acids, and in vitro studies with ANP analogues differing in the number of amino terminal amino acids [Fok et al 1985, Olins et al 1986] suggest that the latter might unduce different hemodynamic responses in normotensive and hypertensive rat models, in comparisson to their native peptide.

In chronic heart failure, elevated plasma ANP levels have been demonstrated [Cody et al 1986, Drexler et al 1987, Hirsch at al 1989, Holmer et al 1987, Johnston et al 1987, Riegger et al 1988 , Tikkanen et al 1987]. The increase in preload is the main cause of 
Alm of this study The aim of this study was to investigate the relevance of the amino terminal amino acids of ANP on hemodynamic response. Firstly, hemodynamic responses to exogenous ANP(1-28) and ANP(5-28) were compared in normotensive (W), spontaneously hypertensive (SHR) and experimental heart failure rats (IW). Secondly, the central hemodynamic responses in different pathologies, i.e. spontaneous hypertension and heart failure, were compared with central hemodynamic responses in normotensive rats. Thirdly, the central hemodynamic effects of longterm low dose infusions of ANP(5-28) were studied in spontaneous hypertension.

\subsection{Material and methods}

Animals For this study male normotensive Wistar Kyoto (WKY), Wistar rats (W) and spontaneously hypertensive rats (SHR) were used as described in section 2.1 .

Doppler now probes For measurement of regional blood flow, rats were instrumented with Doppler probes as described in section 2.2.5.

Electromagnetic At least 5 days before executing central hemodynamic experiments, now probes rats were instrumented with electromagnetic flow probes as described in section 2.2.6.

Myocurdial infarction

Myocardial infarction was produced by left descending coronary artery ligation, as described in section 2.2.8. Four weeks after infarction, the animals were instrumented with an electromagnetic flowprobe as described in section 2.2.5.

Catheters At least one day before experiments were executed, the animals were instrumented with catheters, inserted into the abdominal aorta for direct measurement of blood pressure, the abdominal vena cava for infusion and the thoracic vena cava for direct measurement of 
Removal of the heart and determination of infarct size

Flow measurements

Pressure measurements

Calculations.

Experimental protocol of acute infusions

Experimental protocol of long term linfusions

Statistics central venous pressure as described in sections $2.2 .1,2.2 .2$ and 2.2 .3 respectively.

After central hemodynamic measurements $\mathrm{W}$ and IW were anesthetized with pentobarbital $(60 \mathrm{mg} / \mathrm{kg}$ i.v.) and killed with potassiumchloride in order to remove the heart as described in section 2.8. Infarct size was determined as described in section 2.8. Coronary ligation resulted in a $33 \pm 3 \%$ myocardial infarct of the left ventricle wall in rats used for hemodynamic measurements.

Renal, mesenteric and hindquarter muscle blood flow, obtained from the flow probes, placed around the left renal, mesenteric and abdominal aorta respectively, were measured as $\mathrm{kHz}$ Doppler shift as described in section 2.2.5. Cardiac output (CO) was measured as described in section 2.2.6. In $\mathrm{CO}$ experiments, $\mathrm{HR}$ was obtained from the flow signal.

Blood pressure and central venous pressure were measured as described in section 2.2.1. and 2.2.2.

Total peripheral resistance was calculated from MAP and $\mathrm{CO}$ as $\mathrm{TPR}=\mathrm{MAP} / \mathrm{CO}(\mathrm{mm} \mathrm{Hg} \cdot \mathrm{min} / \mathrm{ml})$. Stroke volume (SV) was calculated as $\mathrm{SV}=\mathrm{CO} / \mathrm{HR}(\mu \mathrm{l} /$ beat $)$.

On the day of the experiment, the animals were connected to the measuring devices and allowed to habituate for at least one hour to the experimental conditions. ANP(1-28) and ANP (5-28) $(0.25,0.50$, 1.0 , and $2.0 \mu \mathrm{g} / \mathrm{kg} \cdot \mathrm{min})$ dissolved in saline or saline $(0.625,1.25,2.5$ and $5.0 \mu \mathrm{l} / \mathrm{min}$ ) were infused intravenously in a randomized sequence. The dose was increased at 15 -minute intervals over the entire dose range and hemodynamic measurements were made after a steady state condition was obtained with each dose.

In a separate study 6 hour infusions of ANP (5-28) $(0.2 \mu \mathrm{g} / \mathrm{kg}$.min) or saline were performed in SHR. Cardiac output, blood pressure, central venous pressure and heart rate were recorded continuously.

Data are presented as means \pm SEM. Results were analysed as described in section 2.6 . 


\subsection{Results}

\subsubsection{Regional hemodynamics}

Baseline hemodynamic values trom reglonal hemodyonaic studies
Baseline measurements of mean arterial pressure (MAP) and heart rate (HR) in the regional hemodynamic experiments are presented in table 4.1. No significant differences were observed between the saline, ANP(1-28) and ANP(5-28) infused groups. SHR had significantly higher baseline MAP. Heart rate was similar in all groups.

Table 4.1 Basic hemodynamic values in the regional hemodynamic experiments

\begin{tabular}{lcccccc} 
& \multicolumn{3}{c}{ WKY } & \multicolumn{3}{c}{ SHR } \\
saline & ANP1-28 & ANP5-28 & saline & ANP1-28 & ANP5-28 \\
& $(9)$ & $(6)$ & $(9)$ & $(5)$ & $(5)$ & $(5)$ \\
\hline $\begin{array}{l}\text { MAP } \\
(\mathrm{mmHg})\end{array}$ & $125 \pm 3$ & $111 \pm 2$ & $120 \pm 5$ & $165 \pm 5$ & $155 \pm 9$ & $156 \pm 10$ \\
$\begin{array}{l}\text { HR } \\
(\mathrm{bpm})\end{array}$ & $363 \pm 8$ & $348 \pm 16$ & $352 \pm 12$ & $351 \pm 19$ & $358 \pm 25$ & $358 \pm 10$ \\
\hline
\end{tabular}

Regional hemodynamic Figure 4.1 summarizes the regional hemodynamic effects of both ANP analogues. Blood pressure responses to both analogues in WKY were not significantly different from saline. In SHR, MAP decreased significantly in respons to both analogues. HR did not change during infusion of any ANP analogue in neither of the rat models used. ANP(1-28) and ANP(5-28) exerted similar responses in renal and mesenteric flows in both WKY and SHR, although the renal vascular response in WKY to ANP(1-28) was not significantly different from saline. The hindquarter flow decreased significantly in the SHR in reaction to both analogues. Comparison of responses to infusions between WKY and SHR, revealed no significant differences, except for the HQF. Changes in HQF in response to ANP(5-28) were greater in SHR than in WKY. 
fig 4.1

Effects of ANP(1-

28) and ANP(5-28)

on meant arterial

blood pressure

(MAP), lefi renal

flow (LRF),

mesenteric flow

(MF) and hind

quarter frow (HQF)

in $W K Y$ and $S H R$.

- statistical

significant

difference $(P<0.05)$

between responses

vo saline and ANP

as analysed by

ANOVA.
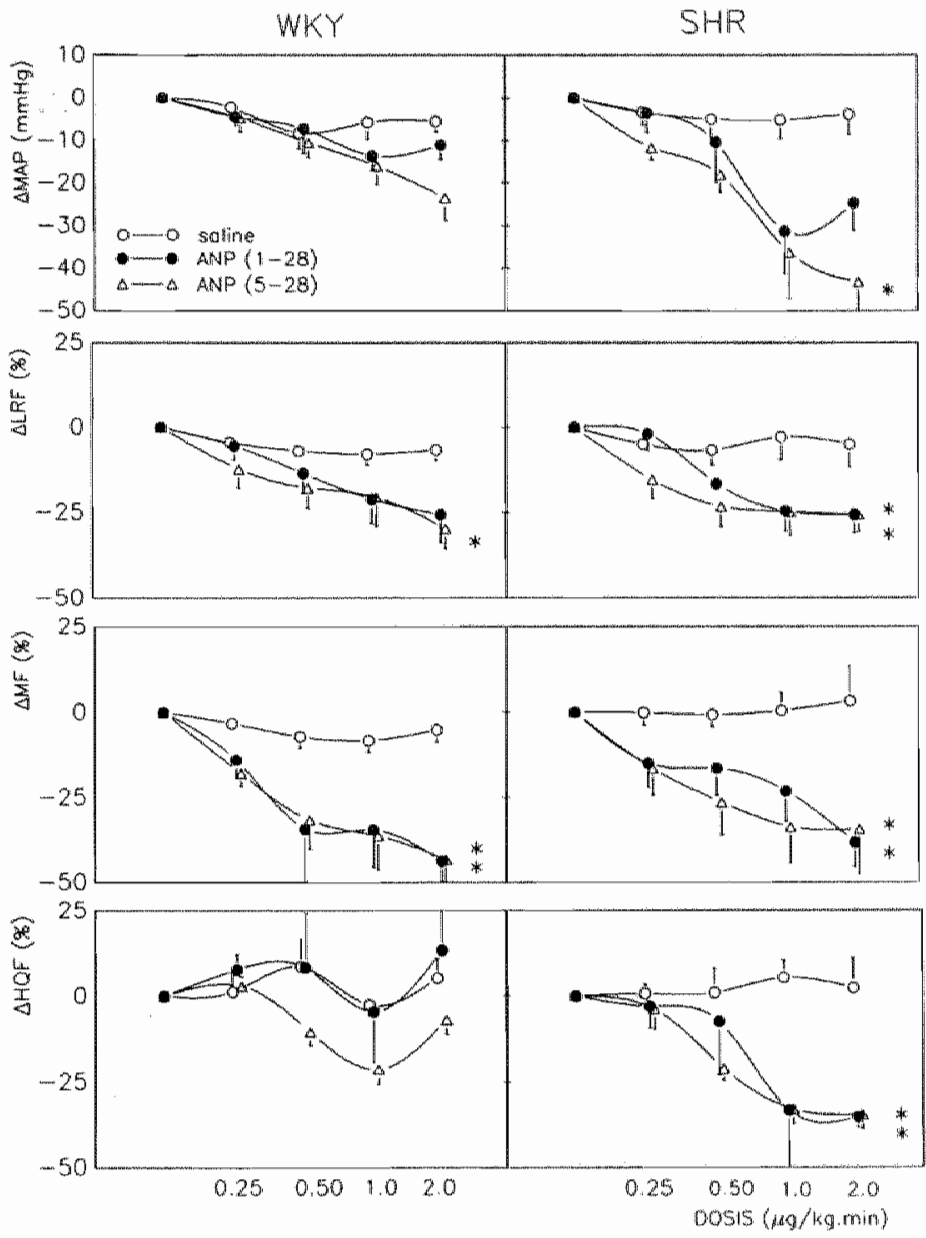

\subsubsection{Central hemodynamics.}

Baseline hemodynamic Baseline central hemodynamics are presented in table 4.2. Changes walues in central in MAP, CO, SV and TPR are shown in fig 4.2. MAP decreased hemodynamic studies significantly in W to both $\mathrm{ANP}(1-28)$ and $\mathrm{ANP}(5-28)$. No significant 
change was observed in IW and SHR. In SHR, MAP decreased significantly in time to saline as well as to both ANP analogues. HR did not change in response to both ANP analogues in either of the rat models. CO increased significantly to both ANP analogues in SHR and $W$. Changes in CO in IW reached $p$-values of $p<0.05$ for ANP(1-28) and $p=0.07$ for ANP(5-28). SV decreased significantly to both ANP analogues in SHR and W. Changes in SV

Table 4.2 Baseline hemodynamics in central hemodynamic experiments

\begin{tabular}{|c|c|c|c|c|c|c|c|c|c|}
\hline & $W$ & & & IN & & & SHR & & \\
\hline$n=$ & $\begin{array}{c}1 \\
(13)\end{array}$ & $\begin{array}{c}2 \\
(17) \\
\end{array}$ & $\begin{array}{c}3 \\
(15) \\
\end{array}$ & $\begin{array}{c}1 \\
(6)\end{array}$ & $\begin{array}{c}2 \\
(8) \\
\end{array}$ & $\begin{array}{r}3 \\
(8) \\
\end{array}$ & $\begin{array}{r}1 \\
(7) \\
\end{array}$ & $\begin{array}{r}2 \\
(8) \\
\end{array}$ & $\begin{array}{c}3 \\
(7) \\
\end{array}$ \\
\hline $\operatorname{MAP}(\mathrm{mmH} H)$ & 105 & 103 & 110 & 97 & 103 & 104 & 142 & 137 & 138 \\
\hline sem & 4 & 4 & 3 & 5 & 3 & 4 & 5 & 4 & 4 \\
\hline $\mathrm{HR}(\mathrm{bpm})$ & 390 & 357 & 396 & 396 & 411 & 369 & 368 & 368 & 349 \\
\hline sem & 12 & 10 & 10 & 19 & 11 & 16 & 11 & $\mathbb{1 1}$ & 14 \\
\hline $\mathrm{CO}(\mathrm{ml} / \mathrm{min})$ & 91 & 96 & 90 & 75 & 82 & 77 & 95 & 83 & 84 \\
\hline sem & 4 & 3 & 5 & 6 & 4 & 4 & 4 & 3 & 5 \\
\hline $\operatorname{SV}(\mu \mathrm{l} / \mathrm{b})$ & 236 & 272 & 229 & 194 & 199 & 211 & 260 & 226 & 244 \\
\hline sem & 12 & 11 & 12 & 21 & 10 & 12 & 11 & $\mathbb{1 1}$ & 20 \\
\hline TPR (mmHg/min.ml) & 1.18 & 1.08 & 125 & 1.33 & 1.27 & 1.37 & 1.50 & 1.68 & 1.68 \\
\hline sem & 0.07 & 0.04 & 0.06 & 0.11 & 0.05 & 0.10 & 0.05 & 0.08 & 0.11 \\
\hline
\end{tabular}

$W=$ Wistar Rats

IW $=$ Wistar Rats with 5 week old myocardial infarction $(33 \pm 3 \%)$

SHR = Spontaneously Hypertensive Rats

$\operatorname{sem}=$ standard error of the mean

1 - Before saline infusion

2 : Before ANP(1-28) infusion

$3=$ Before ANP(5-28) infusion 

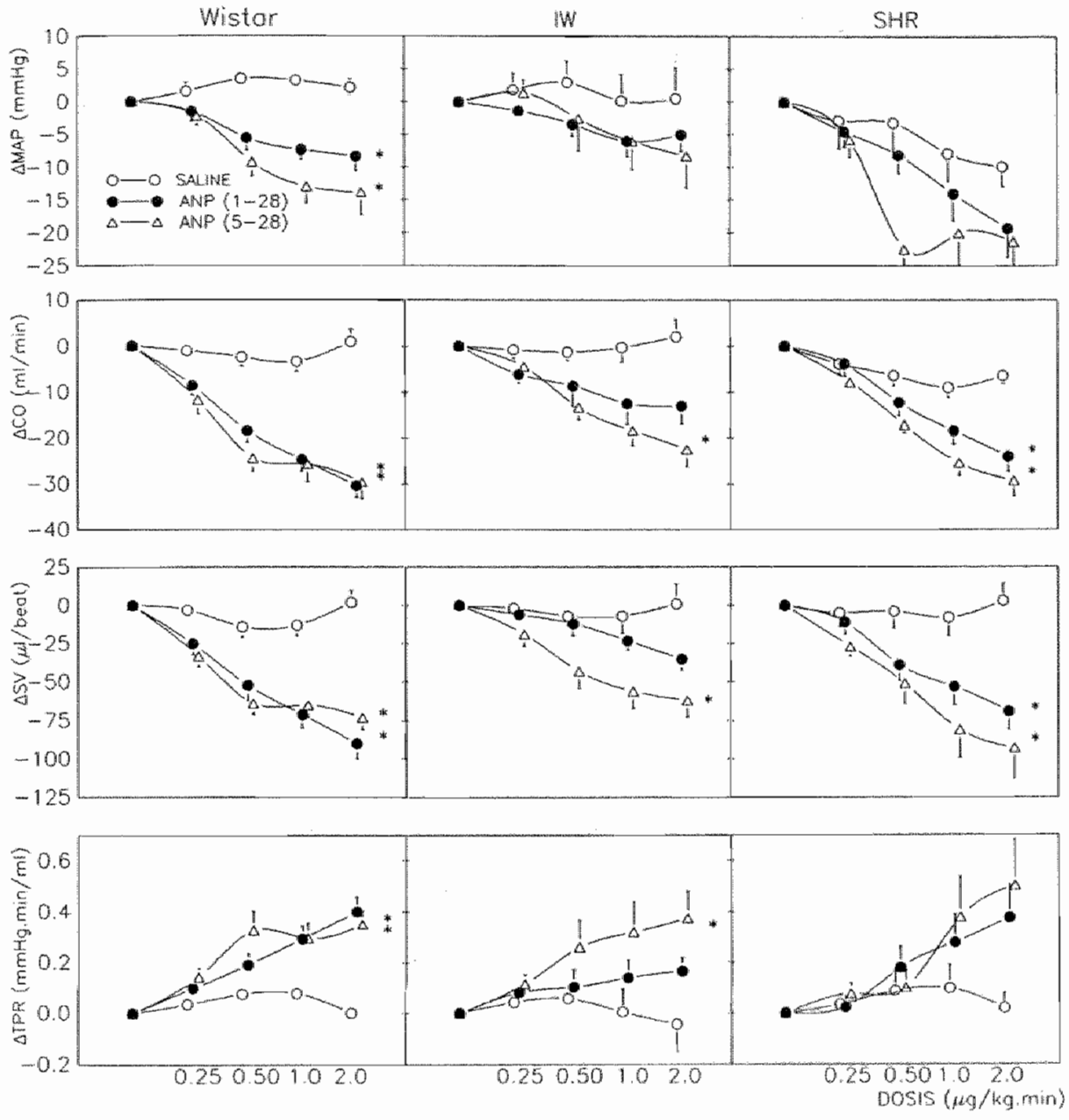

fig 4.2

Effects of ANP(1-28) and ANP(5-28) on mean arterial pressure (MLAP), cardiac outptu (CO), stroke volume (SV) and total peripherial resistance (TPR) in Wistor, inforcted wistar and SHR.

* statistically signifrcant difference between responses to ANP and saline as analysed with ANONA. 
in IW reached $p$-values of $p<0.05$ for $A N P(1-28)$ and $p=0.13$ for ANP(5-28). TPR increased significantly to both ANP(1-28) and ANP (5-28) in $W$ whereas the difference was only significant for ANP(528) in IW. No statistically significant increase in TPR was observed in $\mathrm{SHR}$.

In $W$ the decreas in $C O$ and $S V$ to $A N P(1-28)$ were significantly greater than in IW.

\subsubsection{6 hour infusion.}

Baseline hemodynamic values in loing term infusion study
Baseline hemodynamics in rats used in the 6 hour infusion study are presented in table 4.3. No preinfusion differences were observed. Six hour infusions with low doses of $\operatorname{ANP}(5-28)$ resulted in a significant decrease in CO and SV, and an increase in TPR (fig 4.3.). MAP decreased to ANP(5-28) but the effect did not differ significantly from the effect of saline infusion.

Table 4.3 Basic central hemodynamics before start of 6 hour infusion of ANP(528) in $S H R$

\begin{tabular}{lcc} 
& $\begin{array}{c}\text { Saline } \\
\mathbf{n}=\end{array}$ & $\begin{array}{c}\text { ANP(5-28) } \\
(6)\end{array}$ \\
\cline { 2 - 3 } MAP(mmHg) & $145 \pm 4$ & $(9)$ \\
HR(bpm) & $355 \pm 17$ & $146 \pm 4$ \\
$\mathrm{CO}(\mathrm{ml} / \mathrm{min})$ & $76 \pm 3$ & $351 \pm 14$ \\
$\mathrm{TPR}$ & $1.93 \pm 0.07$ & $70 \pm 3$ \\
$\mathrm{SV}(\mu \mathrm{l} / \mathrm{b})$ & $218 \pm 15$ & $2.07 \pm 0.10$ \\
\hline
\end{tabular}

\subsection{Discussion}

In the present study, hemodynamic effects of two ANP analogues, ANP(1-28) and ANP(5-28), were investigated in a normotensive rat model and two pathophysiological rat models: spontaneous hypertension and experimental heart failure. 
fig 4.3

Effects of 6 hour infusion of ANP(5-

28) on meast anterial pressure (MAP), cardiac output (CO), stroke wolume (SV) and total peripheral resistance (TPR) in SHR.

* statistically significant difference between responses to saline and ANP as analysed by ANOKA.
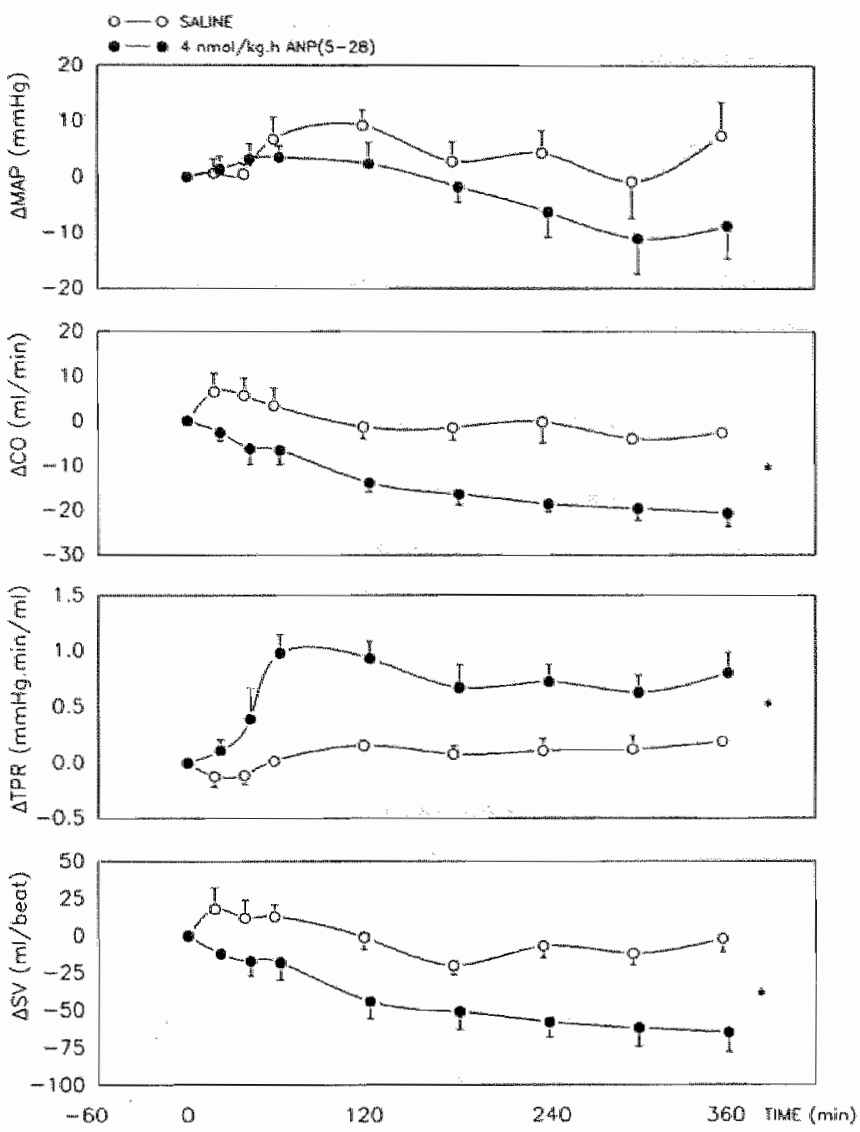

Plasma ANP levels In the hemodynamic studies plasma ANP levels were not deterIn the warious rat mined. This choice was made to avoid taking blood samples which models could possibly interfere with hemodynamics in the rats under investigation, since the amount of blood, necessary for radio immuno assay, is approximately $5 \%$ of the total blood volume. Previous experiments in our own laboratory (de Vries et al, submitted for publication) and others, demonstrated markedly elevated plasma ANP in infarcted rats [Drexler et all 1987, Genest et al 1988, Holmer et al 1987, Riegger et al 1988, Tikkanen et al 1987], 
whereas elevated [Morii et al 1986] or unchanged [Pettersson et al 1985] lewels of circulating ANP in SHR have also been found.

Results of the acute infusien protoculs

Comparison between the ditferent ANP anallogues
Our studies show a similar pattern of acute regional and central hemodynamic changes to ANP(1-28) and ANP(5-28) infusion. Blood pressure decreased in a dose dependent fashion with both analogues, although the changes were not significant in the WKY in regional hemodynamic studies and not in SHR and IW in the central hemodynamic studies. The lack of statistical significance in these studies may be caused by the method of statistical analysis in which the analysis of variance was applied to the whole doserespons curve. This analysis included all doses and as a result, also the low ones, which do not cause any change. The highest rates of ANP infusions consistently lowered blood pressure. Renal and mesenteric flows decreased in both WKY and SHR, whereas the hindquarter flow decreased only in SHR. Mean arterial pressure, cardiac output and stroke volume decreased dose dependently and calculated total peripheral resistance increased in W, IW and SHR. The changes in TPR were not significant in the SHR, due to the variation. Cardiac output and stroke volume declined gradually over the total infusion period with the prolonged low dose infusions. Total peripheral resistance increased during the first hour of infusion and remained unchanged thereafter. No changes in heart rate and central venous pressure were observed.

Our hemodynamic studies demonstrate that, despite the reduced vasorelaxant properties of ANP(5-28) in vitro [Garcia et al 1985, Olins et al 1985, Thibault et al 1984] no difference can be demonstrated in vivo between the two ANP analogues. Comparative studies using a bolus of the ANP analogues (5-25,5-27,5-28) in conscious dogs showed that removal of carboxyl terminal residues did not result in altered regional hemodynamic properties [Hintze et al 1985]. In the SHR, Lappe et al [1986] demonstrated that infusion of rANP $(5-25,1-28)$ and hANP(3-28,1-28) increased mesenteric and renal resistance independent of the structure. However, in vitro, these analogues have similar vasorelaxant properties [Genest et al 1988]. In conscious intact animals, the vasodilating capacity of ANP does not play an important role in cardiovascular homeostasis. In contrast, infusion of ANP induces an increase regional and peripheral resistance, thus increasing sympathetic tone [Lappe et al 1985a, Breuhaus et al 1985]. 
Effects of long term infusion of ANP

The role of ANP in hypertension
Infusion of ANP(5-28) over a 6 hour period demonstrates that a dose, below the dose used in acute infusions, which increases plasma ANP leveis within the physiological range [De Mey et al 1987], reduces cardiac output in parallel to a decrease in stroke volume. The gradual fall in cardiac output and stroke volume indicates that the acute effects of high doses can also be obtained with low doses, infused over a longer period. This effect is unlikely to be an effect of the accumulation of ANP in the circulation because of the very short half life of ANP $( \pm 30 \mathrm{sec}$ ) [Murthy et al 1986]. A possible fall in arterial blood pressure, as a result of the decrease in cardiac output, seems to be effectively counteracted by an increase in sympathetic tone, thus increasing peripheral resistance. Two hour infusions in rats [Allen et al 1987] and one hour infusions in dogs [Bie et al 1988] showed similar hemodynamic responses with respect to cardiac output and stroke volume. However, left atrial pressure was reduced and arterial blood pressure declined significantly in comparison to vehicle infusions in dogs [Bie et al 1988]. In rats arterial blood pressure was also reduced, parallelled by a reduction in heart rate [Allen et al 1987].

We did not find elevated plasma ANP in our SHR (unpublished results). Circulating ANP has been reported to be increased in. several models of hypertension. In man, increased [Richards et al 1986] as well as unchanged [Larochelle et al 1987a] plasma ANP levels have been reported. Plasma ANP in man seems to depend on the severity of hypertension [Genest and Cantin 1988]. In SHR, plasma ANP is increased [Gutkowska et al 1986]. Our SHR had a rather mild hypertension. This might explain the similar ANP levels as in WKY. Because ANP could play a role in the hemodynamic regulation in several models of hypertension, this has been subject of many investigations [Genest and Cantin 1988, Goetz et al 1988, Lang et al 1987]. Hemodynamic changes in the SHR were similar to those in W and WKY. Only in the hindquarters, blood flow was decreased in comparison to WKY. The results from previous animal studies demonstrate that the acute hemodynamic effects may depend on the model of hypertension [Volpe et al 1986]. In the SHR, the ANP-induced effects are quite variable. No changes in cardiac output with decreased peripheral resistance [Fujioka et al 1985] and reduced cardiac output [Lappe et al 1985b] to ANP administration have been reported. 
The role of ANP in heart failure

Conclusilion
In another group of infarcted rats (unpublished results) plasma ANP was approximately trippled, despite the rather mild form of myocardial infarction (infarct size in left ventricle: $32 \pm 2 \%$ ). In the animals used in our study, similar increases in plasma ANP might be expected because of the size of myocardial infarction in the left ventricle was similar. Plasma ANP levels in clinical and experimental heart failure have been reported to be markedly elevated [Cody et al 1986, Drexler et al 1987, Hirsch et al 1989, Holmer et al 1987, Riegger et al 1988, Tikkanen et al 1987]. As recently reported in experimental heart failure [Drexler et al 1987, Riegger et al 1988], the responsiveness to ANP(1-28) is reduced. It has been hypothesized that chronically elevated plasma ANP in experimental heart failure reduces the responsiveness to exogenously administered ANP [Tsunoda et al 1989]. Down regulation of receptors is thought to be the cause. The fact that renal arteries from experimental heart failure rats did not differ in responsiveness to $\mathrm{ANP}(1-28)$ in vitro (personal communication JG de Mey) pleads against the idea of receptor down regulation. In humans suffering from congestive heart failure, ANP infusions improves cardiac performance [Cody et al 1986, Molina et al 1988] due to a fall in pulmonary wedge pressure. However, the improvement of cardiac performance may depend on the severity of the heart failure because in explicitly severe heart failure, no alteration in cardiac output has been observed [Serizawa et al 1988a, Serizawa et al 1988b]. In the present study, blood pressure, cardiac output, stroke volume and total peripheral resistance are similarly changed after $\operatorname{ANP}(5-28)$ infusion in normal and infarcted rats, although the change in blood pressure was not significant. However, the changes in cardiac output and stroke volume to $\mathrm{ANP}(1-28)$ were significantly reduced.

In conclusion, the results from this study indicate that the length of the amino terminal part of the peptide does not play a crucial role in its hemodynamic properties in conscious rats. Hemodynamic effects of ANP in spontaneous hypertension and experimental heart failure do not differ from those in normotension. Furthermore ANP appears to have important hemodynamic regulating properties within several hours of infusion. 


\section{Atrial natriuretic peptide (ANP) increases albumin ex- travasation in conscious rats}

\subsection{Introduction}

ANP induces nuid shifft from the circulation

Aim of this study

The role of ANP in cardiovascular homeostasis is the subject of considerable scientific investigation. Apart from vascular and renal actions, an effect of ANP on the control of body fluid volume has been suggested. Several authors have noted a decreased plasma volume during ANP infusion. This decrease is also observed in anephric animals, indicating a fluid-shift from the intra- to the extravascular space [Almeida et al 1986, Flückiger et al 1986] through effects at the level of the microcirculation.

The present study was designed to investigate the effects of ANP on regional clearances of albumin in conscious rats, using a doublelabel tracer technique. The dose of ANP was chosen whereby that blood pressure and cardiac output were decreased and were stabilized within 15 minutes, as based upon previous studies [Lappe et al $1985 b]$.

\subsection{Material and methods}

Animals For this study male Wistar rats were used as described in section 2.1.

Surgery On the day before the experiments, the animals were equipped with an arterial catheter for blood sampling and two venous catheters for injections and infusions. Operations were caried out as described in section 2.2 .

Experimental On the experimental day, one venous catheter was connected to an protocol infusion pump. After the animals were accustomed to the experimental conditions, ANP ( $\alpha$-rANP, Nova Biochem, Switzerland; $1 \mu \mathrm{g} / \mathrm{kg}$. $\mathrm{min})$ or saline at an equivalent rate $(20 \mu \mathrm{l} / \mathrm{min})$ were infused. At the same time $(\mathrm{t}=0 \mathrm{~min})$ a bolus of $\approx 3 \mu \mathrm{Ci}{ }^{125} \mathrm{I}$-human serum albumin (i2 I-A; IRE, Fleurus, Belgium) was injected through the other venous catheter in a volume of $100 \mu$, followed by a 100 $\mu l$ saline flush. Fourty min later $(\mathrm{t}=40 \mathrm{~min})$, an arterial blood sample $(100 \mu \mathrm{l})$ was taken. This volume was not replaced. Immediately after that, another i.v. bolus of $\approx 3 \mu \mathrm{Ci}{ }^{\text {131 }}$ I-human 
serum albumin ( ${ }^{131} \mathrm{~L}-\mathrm{A}$; IRE, Fleurus, Belgium) was again injected. Twenty min later $(t=60 \mathrm{~min})$, after obtaining a second blood sample, animals were killed with an i.v. injection of pentobarbital. Within $4 \mathrm{~min}$, brain, lungs, right gastronemicus muscle, a $5 \mathrm{~cm}$ piece of ileum and an approximately $1 \mathrm{~cm}^{2}$ patch of skin from the right hind leg were removed. Tissues were blotted dry and the piece of ileum was washed and blotted. After weighing, they were placed in an LKB scintillation counter, programmed for simultaneous determination of ${ }^{125} \mathrm{I}$ and ${ }^{131} \mathrm{I}$. Duplicate plasma samples obtained at 40 and 60 minutes were also counted for radioactivity.

Calculations Plasma volume (PV) was calculated according to Trippodo et al [1979] from the amount of ${ }^{125} \mathbb{I}-\mathrm{A}$ injected and the concentration of i2s $\mathbb{1}$-A at $\mathrm{t}=0$, which in turn was calculated from log-linear extrapolation of values at 40 and $60 \mathrm{~min}$. From a pilot study with 5 animals log-linear relation was evaluated by measuring plasma [ ${ }^{125} \mathrm{I}$ $\mathrm{A}]$ and $\left[{ }^{131} \mathrm{I}-\mathrm{A}\right]$ at $\mathrm{t}=20,40$ and $60 \mathrm{~min}$. Correlation between $\log$ $\left[{ }^{13} \mathrm{I}-\mathrm{A}\right]$ and time and $\log \left[{ }^{134} \mathrm{I}-\mathrm{A}\right]$ and time were $0.97 \pm 0.02$ and $0.95 \pm 0.02$ respectively whereas disappearance rates of ${ }^{125} \mathrm{I}-\mathrm{A}$ and ${ }^{131}$ I-A were $4.31 \pm 0.79 \% /$ hour and $3.98 \pm 0.75 \% /$ hour respectively.

In the subsequent studies ${ }^{131}$ I-A was used as a marker for intravascular space. Thus, the amount of extravascular ${ }^{125} \mathrm{I}-\mathrm{A}$ ( ${ }^{125} \mathrm{I}-\mathrm{A}$, extra) in tissues could be calculated as:

$$
X=A-(B / C)^{*} D
$$

$X={ }^{125} \mathrm{I}-\mathrm{A}$, extra $; A={ }^{124} \mathrm{I}-\mathrm{A}$ in tissue ;

$B=\left[{ }^{125} I-A\right]$ plasma, $t=60 ; C=\left[{ }^{131} I-A\right]$ plasma, $t=60$;

$\mathrm{D}={ }^{n+1} \mathbb{I}-\mathrm{A}$ in tissue

Clearance was calculated per tissue from extravascular ${ }^{125} \mathrm{I}-\mathrm{A}$ and the area under the time concentration curve (AUC) for $\left[{ }^{125} \mathrm{I}-\mathrm{A}\right]$ in plasma from 0 to $60 \mathrm{~min}$, using standard pharmacokinetic methods.

$$
\text { Clearance }=\frac{125 \mathrm{I}-\mathrm{A}, \text { extra }}{\mathrm{AUC}\left[^{125} \mathrm{I}-\mathrm{A}\right] \text { in plasma }}
$$


Plasma volumes were normalized for body weight and expressed as $\mathrm{ml} / 100 \mathrm{~g}$ body weight. Clearances were normalized for tissue weight, and expressed as $\mu \mathrm{l} / \mathrm{min} . \mathrm{g}$ tissue.

Statistics Groups consisted of 8 animals each. Data are given as means \pm SEM. Results were evaluated as described in section 2.5. Statistical significance was accepted at the $5 \%$ level.

\subsection{Results}

Plasma Volume The two groups of rats were comparable with regard to body weight ( $365 \pm 5 \mathrm{~g}$ and $361 \pm 8 \mathrm{~g}$ in ANP and saline infused animals resp.) Plasma volume was lower in ANP infused rats $(3.20 \pm 0.06 \mathrm{ml} / 100 \mathrm{~g}$ b.w.) in comparison to saline infused animals $(3.58 \pm 0.07 \mathrm{ml} / 100 \mathrm{~g}$ b.w.). The difference was statistically significant $(\mathrm{p}<0.005)$.

Albumin In control rats the lowest clearance was observed in braintissue, the Clearance highest in ileum (table 5.1). ANP affected clearances in different ways (cf. table 5.1). Significant differences between groups were noted in muscle and ileum tissue (table 5.1). In brain, lung and skin tissue, no differences were found, although clearance tended to be higher in the latter in ANP-infused animals.

Table 5.1 Regional clearances of ${ }^{125}$ I-human serum albumin in conscious rats ( $\mu \mathrm{l} / \mathrm{g}$ tissue.min).

saline

\begin{tabular}{lll} 
& \multicolumn{1}{c}{ saline } & \multicolumn{1}{c}{ ANP } \\
\hline & & \\
muscle & $0.050 \pm 0.013$ & $0.105 \pm 0.015 *$ \\
ileum & $0.248 \pm 0.015$ & $0.324 \pm 0.026 *$ \\
skin & $0.069 \pm 0.008$ & $0.114 \pm 0.029$ \\
lung & $0.261 \pm 0.037$ & $0.249 \pm 0.032$ \\
brain & $0.010 \pm 0.002$ & $0.011 \pm 0.003$
\end{tabular}

* Statistically significant difference between saline and ANP-infused animals $(p<0.05)$ 


\subsection{Discussion}

Possilule role of extravasation in cardiovaseular homeogtasis

Reduction of plasma volume

Tissues used for measurement of regilonal albumin clesirance
The reduction of cardiac output by ANP has been shown to be associated with decreased cardiac filling pressures [Lappe et al 1985b]. The dose used reproducibly lowered left atrial pressure, central venous pressure, arterial blood pressure and cardiac output in previous studies [Lappe et al 1985b]. Several studies indicate that reduced plasma volume contributes to these hemodynamic changes [Almeida et al 1986, Flückiger et al 1986]. Furthermore, this effect is not dependent upon diuresis, because it persists in bilaterally nephrectomized animals [Almeida et al 1986, Flückiger et al 1986]. This suggests an effect at the microcirculatory level. ANP increases hematocrit without affecting red blood cell volume, as measured with labelled erythrocytes [Flückiger et al 1986]. Circulating volume was decreased only through the change in plasma volume, suggesting that albumin filtration and hydraulic conductivity (i.e. endothelial permeability) are increased. This is supported by Huxley et al [1987], who have reported an increased hydraulic conductivity following addition of ANP in frog mesentery vessels in vitro, which corroborates with increased water extravasation. As filtration does not depend upon conductivity alone, but also on arterial and venous pressures and flow, this result cannot simply be extrapolated to the in vivo situation. The present study used an experimental design which allowes the in vivo measurement of albumin extravasation.

The reduction of plasma volume found in the present study corroborates with findings in other studies [Almeida et al 1986, Flückiger et al 1986]. Our way of calculating PV implicitly assumes that changes take place within the first $40 \mathrm{~min}$ of infusion. This assumption is based on hemodynamic studies in which ANP effects were present within 15 min after starting the infusion [Lappe et al 1985b]. If plasma volume changes further after 40-60 min with ANP-infusion, our values will be an over-estimation, making the effect even greater.

The choice of tissues for the regional albumin clearances was based on the large contribution of these tissues to the total blood flow. Kidneys were excluded because glomerular filtration of albumin, which may also be affected by ANP [Fried et al 1986], would result in seemingly high tissue concentrations of albumin by the presence of residual urine. In control animals, albumin clearance in the brain 
Filtration pressure and conductivity

Contribution of regional now

Arteriolar and venular resistance was lowest, which is consistent with the presence of the blood-brainbarrier. In lung tissue clearance was as high as in ileum tissue but did not chage on ANP infusion. Infusion of ANP increases the clearance of albumin in skeletal muscle and ileum, but not in the other 3 tissues. Thus, vascular leakage during ANP-infusion is not a generalized phenomenom.

Albumin clearance, as measured here, depends, among others, on blood flow, filtration pressure and conductivity of the microcirculation. Our method cannot differentiate between increased filtration pressure and conductivity. The latter would be consistent with direct observations on water conductivity in frog mesentery [Huxley et al 1987]. If such a direct interaction of ANP with blood vessels is the basis of increased clearance, this would suggest differential properties of the various vascular ANP-receptors in the circulation [Schiffrin et al 1988].

Flow changes do not seem to contribute to the observed phenomena. Since ANP decreases blood flow in both hindquarters and splanchnic circulation [Lappe et al 1985b], this would oppose increased clearance. The same would hold for lungs, in view of the decreased cardiac output during ANP infusion [Lappe et al 1985b]. Blood flow through skin and brain are not affected [Drexler et al 1987].

The concomitant increase in resistance [Lappe et al 1985b] and clearance is also consistent with recent observations by Faber et al [1988]. These authors showed that, in cremaster muscle, there is a differential distribution of $\alpha_{i}$ and $\alpha_{2}$-adrenocepters on arterioles and venules, with a more predominance of $\alpha_{2}$ receptors on the venular side of the circulation. In that preparation, ANP inhibits $\alpha_{1}$-mediated but not $\alpha_{2}$-mediated constriction. Since the vasoconstriction during ANP infusion is sympathetically mediated [Lappe et al 1985a], this would result in a greater venular constriction than arteriolar constriction, decreasing tissue flow and increasing filtration pressure at the same time. If this is the mechanism of increased albumin clearance, then the tissue selectivity of increased clearance may reflect the distribution of $\alpha_{1}^{-}$and $\alpha_{z}$ adrenoceptors over tissues. Such a localization of $\alpha$-adrenoceptors has indeed been found [Langer et al 1984]. There are, however, no data in rats on other tissues than skeletal muscle. 
Conclusion In conclusion, ANP in a dose that acutely lowers blood pressure and cardiac output, decreases plasma volume and increases albumin clearance in skeletal muscle and ileum tissue of rats. In skin, brain and lung tissue, however, no changes in clearance were observed. So far, ANP has been suggested to be involved in circulatory homeostasis by effecting renal function and vascular tone. The present study indicates that it may also involve another, powerful mechanism, i.e. control of intra- and extravascular fluid volumes. 


\section{Effects of ANP on the microcirculation of the cuta- neous skeletal muscle in conscious rats}

\section{1 introduction}

Milcrocirculatory changes, responsible for hemodynamic effects

Administration of ANP results in a number of cardiovascular effects. The first documented cardiovascular action of ANP was its hypotensive activity [De Bold et al 1981]. Although it was originally shown that ANP dilated precontracted isolated arteries, the fall in blood pressure is now usually attributed to a decrease in cardiac output [Breuhaus et al 1985, Lappe et al 1985b]. The fall in cardiac output is very likely induced by a decrease in blood volume [Trippodo et al 1987, Flückiger et al 1986, Almeida et al 1986]. Experiments in conscious rats with albumin tracers suggest that the decrease in blood volume is caused by plasma extravasation, predominantly in the ileum and skeletal muscle [de Vries et al 1990]. In anesthetized rats ANP(5-27) induced regional plasma extravasation in even more tissues [Williamson et al 1989]. The enhanced plasma extravasation could be caused by an increase in post capillary resistance [Trippodo 1987, Chien et al 1987]. Faber et al [1988] showed that in denervated cremaster muscle of anesthetized rats, ANP antagonizes the contraction of small arterioles induced by $\alpha_{i}$ but not by $\alpha_{i}$ adrenoceptor stimulants. The $\alpha_{\bar{x}}$-adrenoceptor mediated vasoconstriction was predominantly located in the venules. This differential microvascular action could be responsible for plasma extravasation.

Aim of the study The purpose of the present study was to investigate microvascular actions of ANP by means of direct microscopic observation, using a newly developed preparation to study the skeletal muscle microcirculation in conscious rats.

\subsection{Material and methods}

Animals The spontaneously hypertensive rats used in this study were obtained from the Central Animal Facilities (University of Limburg, Maastricht, the Netherlands). At the time of surgery, their age was 5-6 weeks. Four weeks later experiments were performed.

Surgery The study presented here is based upon a method using a two sided muscle layer preparation originally described by Smith et al [1985] and adapted by Le Noble et al [1990]. Chambers (Carolina 
Usabillty of the preparation
Experimentall proflocell
Catheters At least one day before the experiments were performed, the animals were equipped with an arterial and a venous catheter, as described in sections 2.2 .1 and 2.2 .3 , in order to measure arterial blood pressure and to infuse the drug, respectively.

Medical Electronics, King NC, USA) were used, after slight modifications [Le Noble et al 1990]. Before implantation the chambers were gas sterilized. The surgical method of implantation is described in section 2.2.9.

One day before the experiments were performed, the preparations were judged on their usability. The preparations were considered to be good when 1) no major bleeding during surgery and no microbleeding during recovery were observed; 2) no signs of inflammation were found; and 3) no excessive leucocyte rolling and sticking at venular walls was present. The entire microvasculature in areas with optimal clarity was documented with low magnification (X10). Arterioles and venules were selected.

On the day of the experiment the animals were placed in a restrainer and connected to the measurement devices. They were allowed to habituate for at least one hour to experimental conditions. ANP(1-28) (Doses: $0.25,0.50,1.0$, and $2.0 \mu \mathrm{g} / \mathrm{kg} . \mathrm{min}$ ) dissolved in saline or saline alone $(30 \mu \mathrm{l} / \mathrm{min})$ was infused intravenously. The dose ANP(1-28) was increased at 15-minute intervals over the entire dose range whereas saline was infused over 30 minutes. Mean arterial pressure and heart rate were measured continuously as described in section 2.2.1. In the last 7 minutes of each infusion period, recordings were made from consecutive segments of the vascular tree for off-line diameter measurements. The types of vessels were grouped according by the functional branching order and classified alphanumerically. Thus, primary perfusing arterioles were designated as first-order arterioles (A1) with their branches designated second-order (A2). The branches of second-order and third-order arterioles are referred to as $\mathrm{A} 3$ and $\mathrm{A} 4$ respectively. The same vessel classification was used for the venous side (V1-V4). Measurement of vessel diameter by image splitting, using a shearing monitor [Intaglietta and Tompkins 1973] were performed from video tape. Total optical magnification used for vessel diameter measurements was $\mathrm{X} 40$. 
Statistics Results are presented as mean \pm standard error of the mean and were analysed with a one way ANOVA. Individual points of the dose response curve against saline response were analysed as described in section 2.6 .

\subsection{Results}

Baseline values

fig 6.1

Changes of mean arrenial pressure (DMAP) and heart rate (DHR) during 30 minules of saline (Cross hatched bars) inficion and ANP infusion (Filled doss, in indicated doses.

Effects of ANP on arterioles and venules
Baseline mean arterial pressure and heart rate were $173 \pm 7$ and $363 \pm 22$ respectively. Changes in mean arterial pressure and heart rate are given in figure 6.1. Mean arterial pressure decreased dose dependently. The decrease was statistically significant. Heart rate increased dose dependently but the change did not reach statistical significance.
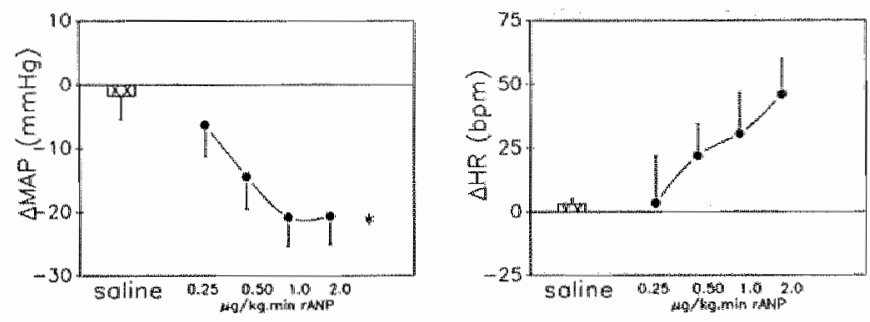

Mean resting vessel diameters are presented in table 6.1. Figure 6.2 summarizes the results of saline infusion (cross hatched bars) and the doses-responses curves of ANP(1-28) in A1, A2, A3/A4, V3/V4, $\mathrm{V} 2$ and $\mathrm{V} 1$ vessels respectively (filled dots). The effects of ANP(128) on $\mathrm{A} 1$ and $\mathrm{A} 2$ diameters were smaller than $5 \%$ and did not reach statistical significance. The effects on $\mathrm{A} 3$ diameters were more variable, but were also not significant. The $V 3$ vessels only responded significantly to the lowest dose of ANP(1-28) with vasoconstriction, whereas no effect was demonstrated during the other infusion rates. Both $V_{2}$ and $V 3$ vessels responded significantly with a vasoconstriction to all doses of ANP(1-28). 
Table 6.1 Resting diameters of microcirculatory vessels in cutaneous skeletal muscle of conscious SHR

vessel

$A_{1}$

$A_{2}$

$A_{3} / A_{4}$

$\mathrm{V}_{3} / \mathrm{V}_{4}$

$\mathrm{W}_{2}$

$V_{1}$ diameter $(\mu \mathrm{m})$

$89.5 \pm 5,9$

$43.0 \pm 3.6$

$21.0 \pm 1.7$

$26.6 \pm 2.6$

$50.6 \pm 4.5$

$122.9 \pm 11.9$

fig 6.2

Changes in diamerer of arterioles (A1, A2, A3) Ad) and venules ( $V I$, $\left.v 2, V_{3} / v^{4}\right)$ during 30 minutes saline infusion (Crons hatched bars) and to ANP infusion
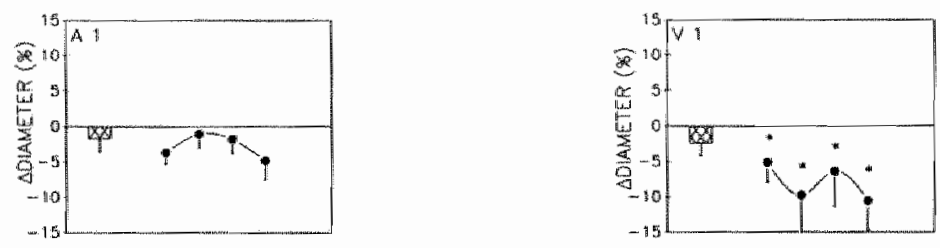
(filled dows) in different doses.
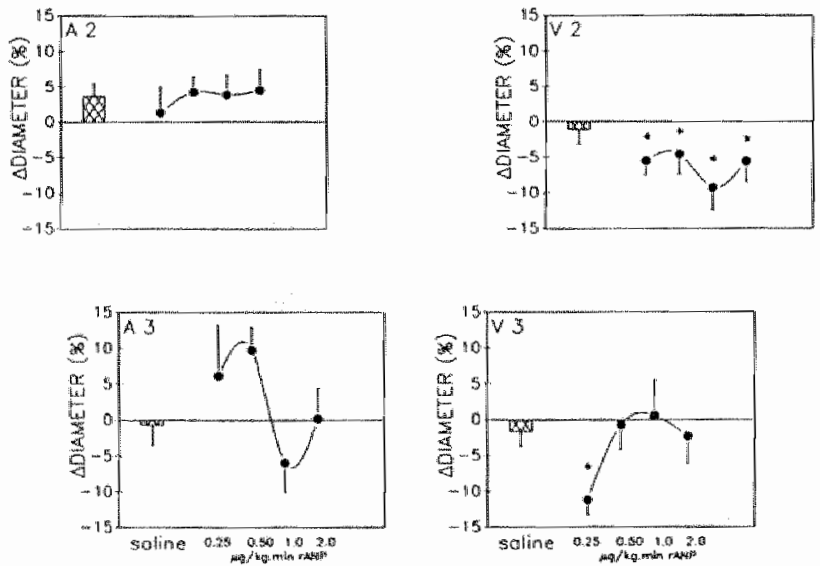


\subsection{Discussion}

Purpose of the study In the present study, we investigated microvascular responses to ANP(1-28) infusion in conscious unrestrained rats. For this purpose, we used SHR, equipped with a dorsal microcirculation chamber. A1, $A 2, A 3 / A 4, V 3 / V 4, V 2$ and $V 1$ vessels were monitored during resting situations, saline infusion and different rates of ANP(1-28) infusion.

ANP induces vemular constriction

Decrease in blood volume by microcirculatory changes
Infusion of ANP(1-28) resulted in a dose dependent decrease of the mean arterial pressure, without a significant change in heart rate, although a dose dependent increase can be observed. No effects of ANP(1-28) on arterioles in the skin muscle of conscious unrestrained SHR were demonstrated, whereas medium sized and large venules (V2 and V1 vessels resp.) constricted in response to ANP(128 ). The smallest venules, V3/V4 vessels only constricted with the lowest dose of ANP(1-28).

The decrease in blood pressure to ANP(1-28) infusion confirms many previous investigations, reviewed recently [e.g. Genest and Cantin 1988, Needleman et al 1989]. This has been attributed to a decrease in cardiac output [Breuhaus et al 1985, Lappe et al 1985b]. A decrease in circulating blood volume was demonstrated to be the main cause of the decrease in cardiac output [Flückiger et al 1986, Almeida et al 1986]. In a previous study, we [de Vries et al 1990] demonstrated that infusion of $1 \mu \mathrm{g} / \mathrm{kg} \cdot \mathrm{min}$ ANP(1-28) in conscious rats. This dose reproducibly lowers mean arterial pressure and cardiac output [Lappe et al 1985b] and decreased plasma volume with approximately $10 \%$. This was parallelled by an increased plasma albumine clearance in skeletal muscle and ileum. In anesthetized Sprague Dawley rats $0.3 \mu \mathrm{g} / \mathrm{kg}$ min ANP(5-27) decreased plasma volume in combination with an increase in albumine clearance in several tissues, such as skeletal muscle, ileum, skin [Williamson et al 1989]. It is suggested that this phenomenon is likely to take place at the level of the microcirculation because circulating volume is mainly decreased through a change in plasma volume [Flückiger et al 1986, Williamson et al 1989]. Possible mechanisms for this effect are increased albumine filtration rate through increasing resistance to venous return [Chien et al 1987] and increased hydraulic conductivity (i.e. endothelial permeability) [Huxley et al 1987]. 
ANP and adremergic receptors in the milerocirculation
The increased clearance is consistent with microcirculatory observations in denervated cremasier muscle from anesthetized rats [Faber et al 1988]. A differential distribution of $\alpha_{i}$-and $\alpha_{i}$ adrenoceptors on arterioles and venules was demonstrated. $\alpha_{2}$ adrenoceptors are predominently present on the venular side of the circulation. In the cremaster muscle, ANP inhibits $\alpha_{1}$-mediated but not $\alpha_{2}$ mediated constriction. Vasoconstriction during infusion of atrial natriuretic peptides is sympathetically mediated [Lappe et al 1985a]. The results in the cremaster muscle preparation indicate that ANP infusion results in a greater venular constriction than arteriolar constriction. Evidence for this differential effect is supported by the direct microcirculatory observations in the present study.

Conclusion In conclusion, infusion of ANP(1-28) in conscious SHR does not affect vascular tone in the arteriolar part of the microcirculatory bed. On the venular side of the microcirculation, the vessels constricts in response to ANP(1-28) at V2 and V1 level. This mechanism contributes to the reduction in blood volume and an increase in resistance to venous return during infusion of atrial natriuretic peptides and may thus be the primary cause of the fall in cardiac output and mean arterial pressure in conscious rats. 


\section{Physiological role of ANP under resting and volume expanded conditions in normotensive rats}

\subsection{Introduction}

Physiological role of ANP in renal excretion

Aim of this study

\subsection{Materials and methods}

Animals For this study male Wistar Kyoto rats were used as described in section 2.1 .

Bilateral atrial Rats for bilateral appendectomy (BAP) were anesthetized with appendectomy pentobarbital $(60 \mathrm{mg} / \mathrm{kg}$ i.p.) and intubated for maintainance of respiration (60 strokes/ min, $2.5 \mathrm{ml}$ tidal volume). Operations were performed as described in section 2.2.7. 
Bladder catheter For diuresis and natriuresis measurements, animals were immediately instrumented with a urinary bladder catheter as described in section 2.2 .4 .

Arterilal and venous catheters

Experimental protocol
Plasma ANP determination
At least one day before experiments started, catheters were inserted into the femoral artery and vein and advanced into the abdominal aorta, thoracic inferior vena cava and abdominal vena cava for direct measurements of arterial blood pressure, central venous pressure and infusion or injection of drugs respectively. Surgery and measurements were performed as described in section $2.2 .1,2.2 .2$ and 2.2.3. respectively

On the day of the experiment, the outlet of the bladder catheter was connected to a peristaltic pump (P-3, Pharmacia Fine Chemicals, Sweden) and the inlet was opened to the air, to avoid the bladder of becoming vacuum. The arterial and venous pressure catheters were connected to low volume displacement pressure transducers (CP-01, Century Technology Company, Inglewood, CA, USA) to measure arterial and central venous pressure respectively. After stabilization, a $1 \mathrm{ml}$ blood sample was taken for the determination of plasma ANP and replaced with fresh donor blood from. conscious animals. Urine collection was started with two control periods of 15 minutes. Then a volume load of $6 \mathrm{ml}$ iso-oncotic albumin solution (6\% BSA in Ringer) was infused over a $15 \mathrm{~min}$ period during which urine was collected. Again, a blood sample of 1 $\mathrm{ml}$ was taken and replaced with fresh donor blood, taken from conscious unstressed animals. Urine collection was continued over two periods of $15 \mathrm{~min}$, followed by a third blood sample. Urine volume (UV) was determined by weighing collecting tubes before and after collection of urine. Urine was analysed for sodium (U$\left.V_{N}\right)$ by flame photometry. Mean arterial pressure, heart rate and central venous pressure were continuously recorded.

Blood samples were drawn into chilled tubes, containing EDTA $(100 \mathrm{mg} / \mathrm{ml})$ and aprotinin $(500 \mathrm{KIU} / \mathrm{ml})$, centrifuged at $4^{\circ} \mathrm{C}$ to separate plasma from blood cells. Plasma was frozen in polystyrene tubes at $-20^{\circ} \mathrm{C}$ until assayed. Plasma samples were assayed as described in section 2.3.1. 
Statistics Results are reported as mean \pm SEM. Data were evaluated as described in section 2.6 .

\subsection{Results}

Hemodynamics, ANP levels and renal excretion before and during vollume expansion

fig. 7.1

Hemodynamics, plasnua ANP, wrinary voInome and writary sodiwn excretion before, during and affer a volume load with $6 \mathrm{ml}$ iso-oncotic Ringer's solution.
Hemodynamics, plasma ANP and renal excretions are shown in figure 7.1. No differences were observed between BAP and SHAM with respect to basal levels of all hemodynamic parameters measured. Plasma ANP in BAP was significantly lower than in SHAM $(95 \pm 11 \mathrm{pg} / \mathrm{ml}$ and $153 \pm 15 \mathrm{pg} / \mathrm{ml}$ resp). During the volume load, CVP increased markedly in both SHAM and BAP. CVP was higher in BAP than in SHAM. MAP and HR responses did not differ. SHAM responded by clearly increasing UV and UV whereas UV and $U_{\mathrm{ns}}$ were not increased in BAP. These responses significantly differed between BAP and SHAM.
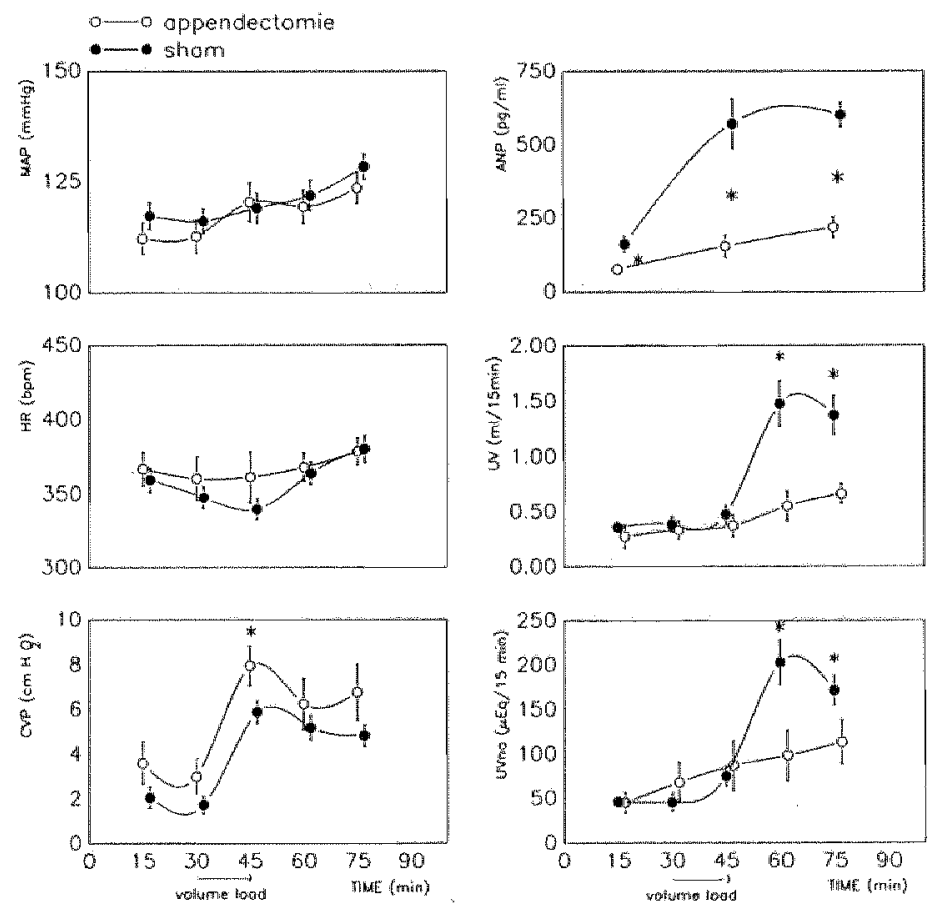
Relationsilup betweten ANP and CVP, retiat excretion fig. 7.2

A) plasma ANP related to central verlous pressure, $B$ ) Urine volume related to plasma ANP and C) urinary sodium excrelion related to plasma ANP.
ANP plotted against CVP (fig 7.2a) indicates strongly reduced ANP release in BAP. In both groups, ANP release is not solely dependent on central venous pressure. UV and UVna plotted against ANP (fig 7.2b, 7.2c) demonstrates a non linear dependency of renal excretion on ANP.
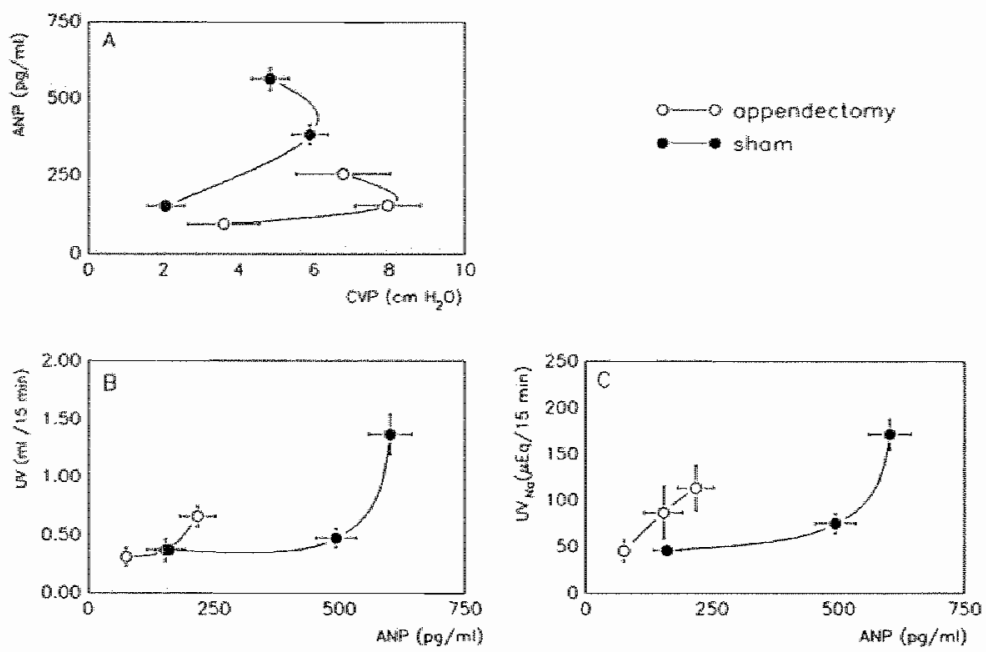

\subsection{Discussion}

Does ANP plity a physitologloal irole Ia renal excretion?

Atrial appendectomy affects stinulated renal excretion
The present study examined the role of endogenous ANP in the control of renal excretory function in rats under normal and volume stressed conditions. We used surgical bilateral atrial appendectomy to reduce circulating ANP. Volume expansion was induced by infusion of $6 \mathrm{ml}$ iso-oncotic Ringer's solution, containing $6 \%$ BSA.

A significant decrease in both basic and stimulated plasma ANP was found, indicating the effectiveness of the bilateral appendectomy in this study. In contrast, basic urine and sodium excretion were not significantly decreased. Renal excretory functions were significantly depressed after volume expansion in bilateral appendectomized rats. 
Atrial appendectomy reduces circulating. ANP

Filling pressure is not the only factor, stimulating $A N P$ relemse

Circulatimg ANP in relation to basal renal excretory functions

ANP levels and renal excretion during volume expansion
The purpose of bilateral atrial appendectomy was to reduce circulating ANP as effectively as possible. Total reduction of plasma ANP by surgical methods is not possible. ANP producing cells are located all over the atria and ventricles and even over part of the central venous system [Genest and Cantin 1988]. However, in contrast to previous studies [Schwab et al 1986, Villarreal et al 1986b], a significant decrease in basic plasma ANP was demonstrated following atrial appendectomy.

ANP release dependends on cardiac filling pressures [Lang et al 1985]. Our results demonstrate a non-linear dependency in sham animals, indicating that ANP release is not solely due to atrial stretch. When CVP decreases, plasma ANP still rises (fig 7.2a). This is in agreement with in vitro studies showing hormonal effects due to ANP release [Ruskoaho 1989]. Furthermore, CVP was slightly though not significantly increased in BAP but was significantly higher during volume load than in SHAM animals. This was parallelled by an attenuated ANP release and may indicate a functional role for ANP in controlling filling pressure. Therefore, the capacity of ANP release in BAP can be considered to be strongly reduced. Bilateral atrial appendectomy can reduce basic and stimulated circulating ANP.

With the surgical method, it was not possible to reduce circulating ANP below detectable levels, but a significant reduction was demonstrated. Despite reduced basal plasma ANP, basal renal excretory functions in BAP did not differ from SHAM animals. This is consistant with results from experiments using antibodies, raised against ANP [Greenwald et a] 1988, Hirth et al 1986, Itoh et al 1989], although conflicting data have also been reported [Naruse et al 1985, Sasaki et al 1987, Rudd et al 1989].

In SHAM animals, urine and sodium excretion were markedly increased during volume expansion with iso-oncotic albumine solution, although the effects were of late onset (fig 7.2b, 7.2c). This is in conflict with the quick onset of diuresis and natriuresis following pharmacological doses of ANP by injection or infusion [Goetz 1988, Lang et al 1987]. However, when infusions, resulting in plasma ANP levels within the physiological range, are used, diuresis and natriuresis are also of late onset [Bie et al 1988]. Removal of atrial appendages attenuated the late diuretic and natriuretic response to volume expansion. The difference did not parallel the 
reduction of ANP, indicating that other mechanisms, such as the activation of cardiopulmonary receptors are of importance in renal excretory functions. In volume expanded situations, ANP appears to play a role in renal excretory functions which is initiated by other, as yet not elucidated mechanisms.

Conelusion In conclusion, these studies with bilateral atrial appendectomy indicates that basal circulating ANP does not influence renal excretory functions in rats under basal conditions but is important in volume expanded conditions. This study also suggests that ANP is not directly responsible for the diuretic and natriuretic effects after volume expansion with iso-oncotic Ringer's solution. 


\section{Physiological role of atrial natriuretic peptide in normal and pathophysiological rat models}

\subsection{Introduction}

Changes induced by ANP

Atrial appendectomy as tool to elucidate physiological role of ANP

Antibodies used as an alternative for antagonists
Circulating atrial natriuretic peptides (ANP) are thought to have an important regulatory function in cardiovascular homeostasis [Lang et al 1987, Needleman et al 1989]. Infusion of ANP induces hemodynamic, hormonal and renal excretory changes. Venous return is decreased, thus reducing cardiac output (CO) and mean arterial pressure (MAP) [Lappe et al 1985]. Aldosterone production [Vari et al 1986] and renin secretion [Villarreal et al 1986a] are inhibited by ANP infusion, whereas diuresis and natriuresis are stimulated [Burnett et al 1984].

To elucidate the physiological role of atrial natriuretic peptides, surgical atrial appendectomy was performed. This procedure reduces the natriuretic and diuretic effects of an acute volume load [Kobrin et al 1985, Schwab et al 1986, Veress et al 1984, Villarreal et al 1986b] as well as the increase of ANP induced by such a load [Schwab et all 1986, Veress et al 1984]. However, despite removal of most of the ANP producing tissue, basic ANP levels are not reduced in the studies presented thus far.

Specific ANP antagonists are not yet available in the study of the role of endogenous ANP. Administration of antibodies raised against ANP, can reduce urinary output and sodium excretion [Naruse et al 1985, Rudd et al 1989] and can increase plasma renin activity in rats [Naruse et al 1985], although a lack of effects on renal excretion has also been observed [Greenwald et al 1988, Itoh et al 1989]. Diuretic, natriuretic, renin and aldosterone responses after an acute volume load are blocked by ANP antibodies [Hirth et al 1986, Stasch et al 1988]. In chronically ANP blocked SHR and deoxycorticosterone acetate (DOCA) hypertensive rats, development of hypertension is accelerated [Itoh et al 1989]. In contrast, autoimmunity to ANP, induced by ANP (1-28) bound to thyroglobulin [Greenwald et al 1988] in SHR or DOCA hypertensive rats does not accelerate the development of hypertension. In anesthetized rats, short term increases in MAP and CO have been demonstrated after antibody administration [Sasaki et al 1987], whereas blood pressure did not change in conscious rats [Naruse et al 1985]. 
Alm of this study In view of the conflicting and incomplete data above on the function of ANP in cardiovascular homeostasis, the present study was designed to investigate the contribution of ANP to hemodynamic homeostasis in two pathophysiological situations; spontaneous hypertension in rats and herart failure due to myocardial infarction. Central hemodynamics were monitored in chronically instrumented conscious rats before and during blockade of circulating ANP with monoclonal antibodies raised against ANP(5-27). Effects were compared to those of mouse serum and effects in control Wistar Kyoto (WKY) rats.

\subsection{Materials and methods}

Animals For this study, male spontaneously hypertensive rats (SHR and normotensive Wistar Kyoto rats (WKY) were used as described in section 2.1. WKY rats were used in myocardial infarction experiments.

Myocardial infaretion

Myocardial infarction was produced by left descending coronary artery ligation, as described in section 2.2.8. Four weeks after infarction, the animals were instrumented with an electromagnetic flowprobe as described in section 2.2.6.

Electromagnetic now probe:

Catheters

Measurement of cardllac output
At least 5 days before executing central hemodynamic experiments, rats were instrumented with electromagnetic flow probes as described in section 2.2.6.

At least one day before experiments were executed, the animals were instrumented with catheters inserted into the abdominal aorta for the direct measurement of blood pressure, the thoracic vena cava for the direct measurement of central venous pressure and the abdominal vena cava for the infusion of ANP as described in sections 2.2.1, 2.2.2 and 2.2.3 respectively.

On the days of the experiments, the flow probe was connected to an electromagnetic flowmeter (Skalar, MDL 400, Skalar, Delft, The Netherlands). The arterial and venous pressure catheters were connected to low volume displacement pressure transducers ( $\mathrm{CP}-01$, Century Technollogy Company, Inglewood, CA, USA). All signals were recorded by a real-time data processing system (Instrumental 
Services, University of Limburg, Maastricht, the Netherlands). Cardiac output was determined from the flow-signal, by setting the baseline at late diastolic flow. HR was derived from the cardiac output signal.

Measurement of blood pressures

Experimental protocol

Removal of the heart and determination of infarct size

Blood sampling and plasma ANP determination
Mean arterial pressure and mean central venous pressure were derived from arterial pressure and central venous pressure signals respectively.

On the first day of measurements, the animals were allowed to adapt to the experimental conditions for at least $60 \mathrm{~min}$. In this period hemodynamic parameters stabilized. Then, a blood sample of $1 \mathrm{ml}$ was taken over a 30 second period for the determination of plasma ANP levels. The animals were allowed to recover for at least 30 min during which period baseline hemodynamics recovered and stabilized again. Then they were slowly injected with a bolus of $150 \mu \mathrm{l}$ mouse serum. The cannulas were flushed with $0.2 \mathrm{ml}$ saline over 15 seconds. Hemodynamic parameters were recorded contimuously over 60 minutes. After this period, $2 \mu \mathrm{g} / \mathrm{kg}$.min rANP(128) dissolved in saline, was infused intravenously for $15 \mathrm{~min}$ as hemodynamic control for the response to ANP. Hemodynamic measurements were made after a steady state condition was obtained. Hemodynamics were compared to the hemodynamics $60 \mathrm{~min}$ after mouse serum. On the second day, the same experimental protocol was used, but instead of mouse serum injection, ascites with monoclonal antibodies raised against ANP(5-27) were administered.

After completing the hemodynamic measurements, the rats were anesthetized with pentobarbital $(60 \mathrm{mg} / \mathrm{kg}$ i.v.) and killed with potassium chloride i.v. to obtain maximal ventricular dilatation. Hearts were excised and atrial appendages were removed. The ventricles were blotted dry and frozen at $-70^{\circ} \mathrm{C}$ for of time measurements of infarct size. Infarct size was measured as described in section 2.4 .

Blood samples were drawn into chilled tubes, containing EDTA (1.5 $\mathrm{mg} / \mathrm{ml})$ and aprotinin $(2.5 \mathrm{KIU} / \mathrm{ml})$ and centrifuged at $4^{\circ} \mathrm{C}$ to separate plasma from blood cells. Plasma was frozen in polystyrene tubes at $-20^{\circ} \mathrm{C}$ until assayed. At the time of determination, plasma samples were assayed as described in section 2.3. 
Monoclonal antibodies The monoclonal antibodies used, were raised against Atriopeptin II (ANP(5-27); amino acid sequence: Ser-Ser-Cys-Phe-Gly-GLy-Arg-IleAsp-Arg-Ile-Gly-Ala-Gln-Ser-Gly-Leu-Gly-Cys-Asn-Ser-Phe-Arg). They were kindly provided by Dr. D. Neuser (Bayer AG, Institute of Pharmacology and Unit for Analytical Therapy Research, Wuppertal, F.R.G.). The antibody reacts equally with ANP (5-25), ANP(5-27), ANP(5-28) and arANP (1-28) (10) and was used undiluted in this experiment. The ascites had a titer of 250.000 . For the control experiments, mouse serum was used from Swiss mice (Central Animal Facilities, University of Limburg, Maastricht, the Netherlands).

Statistics Results are reported as mean \pm SEM. Data were evaluated as described in section 2.6 .

\subsection{Results}

Hemodynamic baseline values

Plasma ANP levels

Response to rANP infusilon after mouse serum or monoclonal antibodies
Baseline values of central hemodynamics are shown in table 8.1. Mean arterial pressure and total peripheral resistance were significantly higher in SHR than in WKY. Mean arterial pressure at the start of mouse serum experiments was lower than before the start of the monoclonal antibody experiments in WKY and higher in SHR. Other hemodynamic variables did not differ significantly (c.f.. table 8.1.)

Plasma ANP levels were significantly higher in IWKY $(249 \pm 20$ $\mathrm{pg} / \mathrm{ml})$ than in WKY and SHR $(132 \pm 30 \mathrm{pg} / \mathrm{ml}$ and $133 \pm 15$ $\mathrm{pg} / \mathrm{ml}$ resp.).

Effects of rANP(1-28) on central hemodynamics following mouse serum and monoclonal antibodies are summarized in figure 8.1. After mouse serum administration, infusion of rANP(1-28) resulted in a significant decreases in mean arterial pressure, cardiac output and stroke volume in all three rat models, whereas heart rate increased in IWKY and SHR and total peripheral resistance increased in WKY and SHR. After monoclonal antibody injection, no significant hemodynamic response to rANP (1-28) infusion were observed (fig 8.1), thus demonstrating a complete block of hemodynamic respons to ANP-infusion. 
Table 8.1 Baseline hemodynamics in antibody experiment before MS or MAB is administered

\begin{tabular}{|c|c|c|c|c|c|c|}
\hline \multirow[t]{2}{*}{ n } & \multirow{2}{*}{$\begin{array}{c}\text { WKY } \\
(8) \\
\text { MS }\end{array}$} & \multirow[b]{2}{*}{ MAB } & \multirow{2}{*}{$\begin{array}{c}\text { TWKY" } \\
\text { (8) } \\
\text { MS }\end{array}$} & \multicolumn{3}{|c|}{$\begin{array}{r}\text { SHR } \\
(6)\end{array}$} \\
\hline & & & & MAB & MS & MAB \\
\hline $\begin{array}{l}\text { MAP } \\
(\mathrm{mmHg})\end{array}$ & $99 \pm 3$ & $108 \pm 3^{*}$ & $103 \pm 3$ & $100 \pm 3$ & $139+4+$ & $12814 *$ \\
\hline $\begin{array}{l}\text { HR } \\
(\mathrm{bpm})\end{array}$ & $361 \pm 8$ & $346 \pm 9$ & $333 \pm 10$ & $331 \pm 10$ & $365 \pm 11$ & $316 \pm 7$ \\
\hline $\begin{array}{l}\mathrm{CVP} \\
\left(\mathrm{cm} \mathrm{H} \mathrm{H}_{2}\right)\end{array}$ & $-0.5 \pm 1.8$ & $-1.5 \pm 0.7$ & $-1.7 \pm 0.6$ & $-1.2 \pm 0.7$ & $-1.1 \pm 0,6$ & $-1.6 \pm 0.5$ \\
\hline $\begin{array}{l}\mathrm{CO} \\
(\mathrm{ml} / \mathrm{min})\end{array}$ & $82 \pm 5$ & $81 \pm 4$ & $78 \pm 9$ & $77 \pm 6$ & $74 \pm 5$ & $67 \pm 5$ \\
\hline $\begin{array}{l}\text { SV } \\
(\mu l / \text { beat })\end{array}$ & $229 \pm 15$ & $237 \pm 14$ & $233 \pm 24$ & $233 \pm 17$ & $203 \pm 15$ & $213 \pm 16$ \\
\hline $\begin{array}{l}\text { TPR } \\
\text { (mmHgmi }\end{array}$ & $\begin{array}{l}1.23 \pm 0.08 \\
\text { nl) }\end{array}$ & $1.35 \pm 0.07$ & $1.44 \pm 0.19$ & $1.41 \pm 0.14$ & $1.92 \pm 0.12+$ & $1.86 \pm 0.15+$ \\
\hline $\begin{array}{l}\text { MS = mon } \\
\text { between } \mathrm{M} \\
\text { basic value } \\
\text { Inffarct si }\end{array}$ & $\begin{array}{l}\text { erum, MA } \\
\text { a MAB in } \\
\text { tween grou } \\
2 \pm 3 \%\end{array}$ & $\begin{array}{l}B=\text { monoc } \\
\text { one group } \\
\text { ps ( } p<0.0\end{array}$ & $\begin{array}{l}\text { clonal antib } \\
(p<0.05) \\
\text { as). }\end{array}$ & $\begin{array}{l}\text { lies } \\
+=\text { sugnif }\end{array}$ & $\begin{array}{l}\text { significant di } \\
\text { ificant differ }\end{array}$ & $\begin{array}{l}\text { fference } \\
\text { nec in }\end{array}$ \\
\hline
\end{tabular}

Respons to mouse serum and monoclonal antibodies in WKY
Effects of mouse serum and monoclonal antibodies on central hemodynamics are shown in figure 8.2 . WKY responded with an increase in MAP as compared to control values at 10 and 20 minutes after mouse serum injection. At 10 and 20 minutes TPR was significantly elevated. After monoclonal antibody administration $\mathrm{CO}$ and SV increased significantly over $60 \mathrm{~min}$ compared to control values as well as to responses to mouse serum administration (fig 2). TPR decreased significantly as compared to the control value only at 60 minutes. All changes were maximal at 60 minutes after monoclonal antibody injection. MAP, HR and central venous pressure (CVP) did not change significantly. 
fig 8.1

Hewhodynamic changes to a 15 min infusion of $2 \mu \mathrm{g} / \mathrm{kg}$ *hin $\mathrm{FANP}(\mathrm{l}$ 28), stanted $60 \mathrm{~min}$ after mouse serum or monoclonal antibody adiministration.
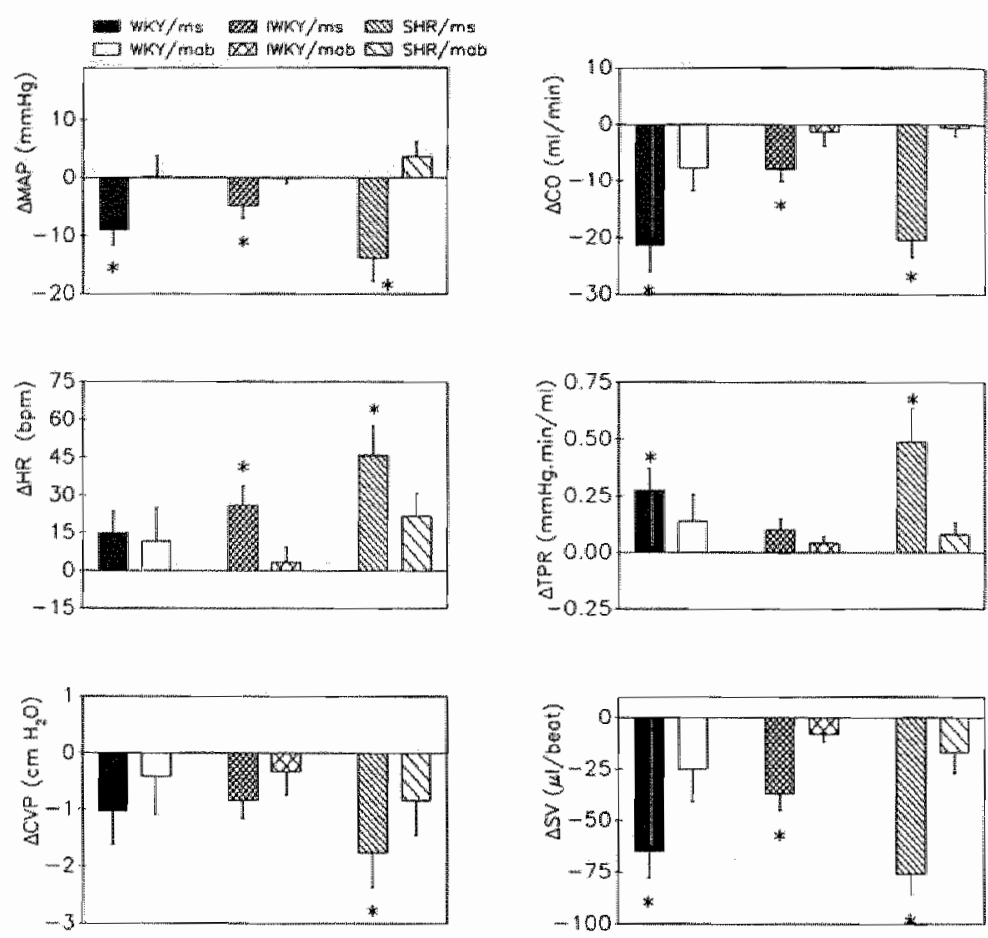

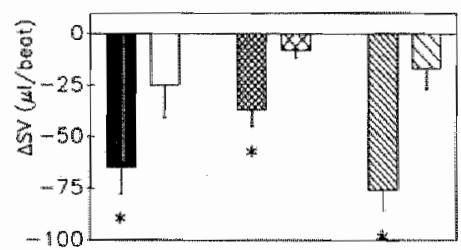

Response to mouse strum and monoclonal antibodies in IWKY
In IWKY CO did not change significantly after mouse serum injection. This was the only time point at which $\mathrm{CO}$ response to mouse senum and monoclonal antibody administration differed significantly. Compared to control values, $\mathrm{CO}$ increased significantly to monoclonal antibody administration after 10,40 and 60 minutes. TPR decreased significantly but the effect did not differ from that of mouse serum. SV increased significantly following monoclonal antibodies as compared to control values. Again, no significant differences were observed between responses to mouse serum and monoclonal antibody administration. No further significant hemodynamic changes were observed compared to responses on mouse serum (fig 8.2). 
Response to mouse serun and monoclonal antibodies in SHR

\subsection{Discussion}

The physiological role of ANP in view of existing literature

ifools to deprive animals from ANP
In SHR mouse serum did not cause any hemodynamic change although SV was quite variable. Injection of monoclonal antibodies induced an increase of $\mathrm{CO}$ which reached its maximal change after 10 minutes. A statistically significant difference in $\mathrm{CO}$ response to mouse serum and monoclonal antibody administration was observed after 10 minutes. Other hemodynamic parameters did not change significantly as compared to responses to mouse serum (fig 8.2).

In the present study we injected monoclonal antibodies against ANP(5-27) in WKY, IWKY and SHR to investigate the role of endogenous ANP in the cardiovascular homeostasis under both normal and pathophysiological conditions. Pharmacological experiments in which ANP was administered, have demonstrated several important effects of ANP. Its major actions are the induction of natriuresis and diuresis, suppression of the RAA-system, modulation of the cardiovascular system and interaction with the autonomic nervous activity to the heart [Reviews: Genest and Cantin 1988, Goetz 1988, Lang et al 1987, Needleman et al 1989]. Conclusions on a possible homeostatic function can be drawn from these experiments only by extrapolation. Antagonizing ANP or deprivation from ANP could be a tool to establish a physiological role more firmly. However, antagonists for ANP are not yet available.

Total deprivation from ANP by surgical methods is not possible. ANP producing cells are located all over the atria and ventricles and even over a part of the venous system [Genest and Cantin 1988]. Using antibodies raised against ANP, it should be possible to entrap circulating endogenous ANP. No immunological evidence can be obtained on whether administration of antibodies indeed deprives the animal from circulating ANP, as circulating antibodies interfere with the methods of determination [Greenwald et al 1988, Hirth et al 1986, Sasaki et al 1987, Stasch et al 1988]. Bioassays, such as renal or hemodynamic responses to exogenous ANP, can give an indication of the degree of deprivation [Greenwald et al 1988, Itoh et al 1989]. 

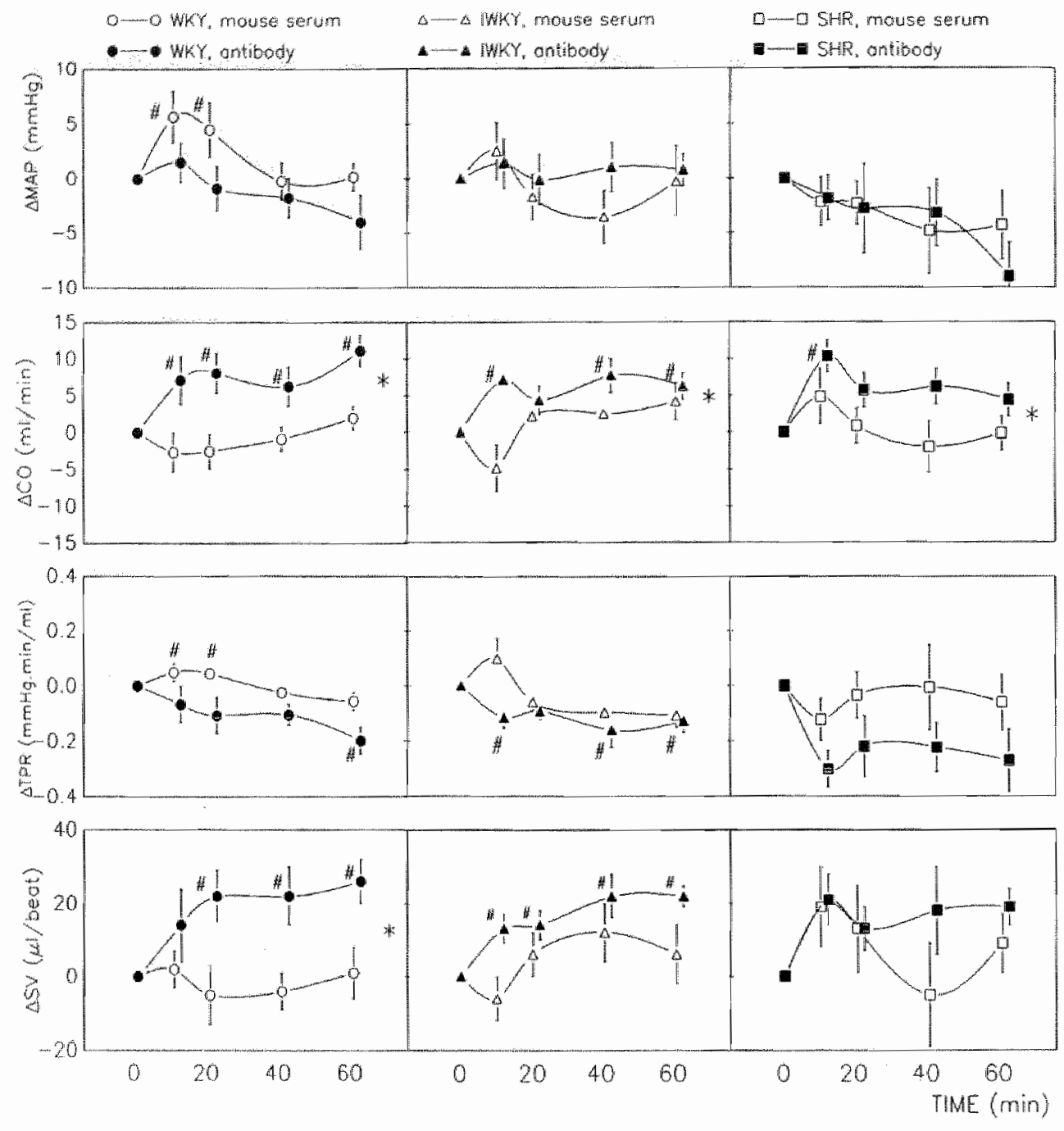

fig 8.2

Hemodynamic changes after mouse senum or monoclonal antibody administration.

* Statistical differences in response between mouse senum and monoclonal antibodies as analyzed by ANOVA. 
Monoclonal antibodies to bind circulating ANP

Mouse serum as control for antibodies

ANP challenge

Responses in WKY

Possible role for ANP in de regulation of cardiac output in WKY
In this study, monoclonal antibodies were used to deprive conscious animals from circulating ANP. Responses were studied in normotensive (sham infarcted) rats, as well as in infarcted and spontaneously hypertensive rats.

In our study, we used mouse serum as a control for monoclonal antibodies. A limitation of the design of the present study could be the fact that use of monoclonal antibodies and mouse serum were not randomized. However, the longterm immunity against ANP following monoclonal antibodies [Itoh et al 1989], makes randomized testing impossible. We, therefore, explicitly chose for the design used.

Effectiveness of deprivation of ANP was checked with rANP infusions. After mouse serum injections, animals responded significantly to control infusions of $\mathrm{AANP}$, whereas responses after monoclonal antibodies were effectively blocked (fig 8.1.). On the basis of these measurements we conclude that infused exogenous rANP and circulating rANP had been effectively bound.

In WKY, CO and SV increased approximately by $10 \%$ after monoclonal antibody administration. Both TPR and MAP decreased slightly. Blood pressure responses to mouse serum and antibody administration did not differ significantly. The observed increase in $\mathrm{CO}$ is consistent with findings in a previous study, using polyclonal antibodies in anesthetized rats [Sasaki et al 1987]. However, in that study the change was only of short duration lasting and was parallelled by an increase in MAP.

Responses to ANP infusion in rats consist of reduced $S V$ and $C O$, and increased TPR [Lappe et al 1985b], probably as a tesult of increased resistance to venous return [Faber et al 1988] and a decrease of blood volume [de Vries et al 1990]. Blockade of ANP in the present study reveals an increase in SV and CO. MAP does not change because of a decreased TPR. Since, during ANP-infusion, TPR changes are reflex in nature [Lappe et al 1985a], we assumed that this also is the case during blockade of ANP. We therefore postulate that, under physiological conditions, ANP tonically inhibits $\mathrm{CO}$. 
Pathophysionlogical changes in heart fallure in relation to ANP

Resporise to monoclonal antibodies in heart rallure

Transient changes are also of physiollogical importance

Plasma ANP in spontaneous hyperttension
In heart failure, sympathetic nervous activity is elevated in combination with activated hormonal vasoconstrictor activity and increased circulating volume [Johnston et al 1987, Remme 1986]. The latter is associated with increased plasma ANP as demonstrated by many authors [Genest and Cantin 1988, Goetz 1988, Johnston et al 1987, Lang et al 1987, Needleman et al 1989]. ANP infusions at doses which result in similar increases of plasma ANP, decrease $\mathrm{CO}$ [Bie et al 1988].

In spite of these increased basal levels, monoclonal antibody administration induced only a slight and short lasting improvement of cardiac output and SV. The response in IWKY tended to be somewhat smaller than in WKY and SHR. A difference between responses to mouse serum and antibodies was only observed at 10 minutes after administration. The observed, but attenuated, changes agree with the attenuated diuretic, natriuretic and hemodynamic response to ANP infusions in patients and animal models for heart failure [Drexler et al 1987, Genest and Cantin 1988, Riegger et al 1988, Tikkanen et al 1987, Tikkanen et al 1989]. The elevated ANP levels do not seem to effectively oppose the increased hormonal vasoconstrictor activity (elevated catecholamines and angiotensin II) present in heart failure. If anything, elevated ANP levels contribute less to the hemodynamic homeostasis in heart failure, than in normal rats.

Effects of monoclonal antibodies in IWKY were relatively shortlasting. Although this seems to be contradictory to the above postulate in normal rats, blockade of ANP may result in a new homeostatis. Transient effects, besides lasting effects, may thus also provide information on possible involvement of ANP in homeostasis, and may therefore not be ignored.

In SHR, sympathetic nerve activity [Aboud 1982] and ANP are increased [Genest and Cantin 1988, Goetz 1988, Lang et al 1987] although circulating blood volume is decreased [Aboud 1982]. A functional relationship between ANP and sympathetic nervous activity has been suggested [Genest and Cantin 1988]. It has been suggested that plasma ANP is increased to compensate increased blood pressure [Greenwald et al 1988, Itoh et al 1989]. In our SHR no elevated plasma ANP could be demonstrated, probably because of a rather mild hypertension. In humans, hypertension is also not 
consistently accompanied with increased plasma-ANP [Genest and Cantin 1988].

Response to monocllonal antibodies in SHR

In SHR, chronic deprivation of ANP with a weekly injection of antibodies, accelerated the development of hypertension [Itoh et al 1989], but this effect was not observed in SHR, made autoimmune for ANP [Greenwald et al 1988]. Deprivation could be proved in both models with bioassay. This contradiction has been attributed to differences in substrain of the SHR used or to differences in experimental protocols. In the present study in SHR, we did not find any effect on MAP in SHR. No statistically significant changes in TPR and SV were observed but CO increased transiently. A difference between responses to mouse serum versus antibodies was only observed at 40 minutes after administration. It appears that ANP does play a minor role in the cardiovascular homeostasis in SHR. No dependency to the increased sympathetic nervous activity can be demonstrated in conscious SHR with $H R$ as indicator.

Conclusion In conclusion, we investigated the hemodynamic consequences of monoclonal antibody administration to deprive rats of ANP. The hemodynamic responses to this passive immunisation in WKY, IWKY and SHR indicates that endogenous ANP possesses no primary blood pressure regulatory properties but does play a role in the regulation of cardiac output. Overall, ANP appears to have an important physiological function in the regulation of central hemodynamics in rats. This function is not exaggerated in bypertension and heart failure. 


\section{ANP: its role in cardiovascular homeostasis}

Aim of this thesis

Postulated physio-

logical functions

of ANP

Main results obtained

from experiments in this thesis
As suggested in the titel of this thesis, we have tried to further elucidate the role of atrial natriuretic peptides, ANP, in cardiovascular homeostasis. Therefore, we used several rat models, Wistar Kyoto rats (WKY), WKY from which the atria were removed, spontaneously hypertensive rats and WKY with heart failure.

Several possible physiological functions of ANP have been suggested. Because of its diuretic and natriuretic properties and hypotensive activity, an important function in blood pressure regulation was put forward [Lang et al 1987]. A possible role in the modulation of cardiovascular function and fluid balance was proposed [Goetz 1988, Blaine 1990]. When a variety of variables is appropriately tuned, sodium excretion could play an important role in body fluid homeostasis. However, evidence against a physiological regulating role in sodium excretion was discussed in concomitance [Goetz 1990]. On the basis of results of the experiments, described in this thesis, we propose that ANP has a role in maintaining circulating blood volume and the regulation of the balance of arteriolar and venular tone. These regulate control of cardiac function through regulation of balance of arteriolar and venous tone, hence, circulatory volume and venous return.

Pharmacological doses of ANP(5-27) induce a bell-shaped renal response (chapter 3) without changing GFR. The renal response is obtained despite marked hemodynamic alterations, such as a decreased cardiac output, blood pressure and renal flow [Lappe et al 1985], which are also described in chapter 4. A reduction in blood volume, induced by ANP through an increase in extravasation of plasma in the intestines and skeletal muscle from the circulation (chapter 5) and increased resistance to venous return, can account for the fall in cardiac output. Microcirculatory observations in skin muscle (chapter 6) suggest that constriction of $\mathrm{V}_{1}$ and $\mathrm{V}_{2}$ vessels is responsible for the increase in resistance to venous return and increase in plasma extravasation.

In rats, with appendectomized atria (chapter 7), reduced circulating plasma ANP did not affect basal renal excretion. In normal rats, a dissociation was observed between renal response and plasma ANP levels during and after acute volume expansion. The renal response to acute volume expansion was diminished. This was parallelled by 
Effects of ANP in renal excretton

Is the diuretic and natriunetic activity of ANP of physiologicall relewance? a decreased ANP release to volume expansion. Blockade of circulating ANP with monoclonal ANP-antibodies (chapter 8), caused an increase in cardiac output in WKY, SHR and rats with heart failure, without affecting mean arterial pressure.

The kidney has an important role in cardiovascular homeostasis [Guyton 1986]. The stimulatory effects of ANP on renal excretory functions, the first effects to be described [De Bold et al 198:1], have been thought to be the most important physiological effects of ANP. Today, the physiological importance of the renal effects is a subject of debate. The mechanisms have still not been elucidated. Pharmacological studies, as described in chapter 3, show that ANP can increase renal excretion in absence of [Seymour et al 1985, chapter 3] or in concert with increased GFR [Maack et a] 1984, Huang et al 1985]. Both increased and unchanged GFR are now accepted as possible reactions to ANP in situations of enhanced renal excretion [Genest and Cantin 1988]. Filtration fractions have consistently been found to be increased [chapter 3, Maack et al 1984, Seymour et al 1985]. Mechanisms at proximal [Burnett et al 1984, Harris et al 1987] and distal [Leckie 1987] tubular level and at the level of the collecting duct [Sonnenberg et al 1986a, Zeidel et al 1986], increasing renal excretion, have been documented. Moreover, ANP consistently decreased inner medullary hypertonicity [Borenstein et al 1983, Sosa et al 1986], due to a redistribution of blood flow toward the inner cortex and medulla [Fujioka et al 1985, Hansell and Ulfendahl 1986].

The physiological relevance of the natriuretic and diuretic effect of a 2 to 13 fold rise in plasma ANP has been extensively discussed by Goetz [1990]. Administration of ANP-antibodies resulted in either no effect [Itoh et al 1989, Greenwald et al 1988] or a depressing effect [Sasaki et al 1987, Rudd et al 1989] on basal renal excretory function. Fourty percent reduction of circulating plasma ANP, obtained by bilateral atrial appendectomy (chapter 7), did not affect basal renal excretion. During and after acute volume expansion, a dissociation was observed between plasma ANP levels and renal excretion. The latter suggests that, in acute volume expanded conditions, ANP does not exert a primary role in renal excretory function. A reduced renal response and plasma ANP response to acute volume load in atrial appendectomized rats indicate that ANP does play a role in the late renal excretion in volume expanded 
Evidence against a physilological function of ANP in renal excretion

Admimistration of ANP-analogues affects central and regilonal hemodynamics conditions. Other factors, such as renal perfussion pressure and renal nerve activity may play an important role in the renal response to ANP [Blaine 1990].

Several lines of evidence argue against a direct role of ANP in renal function. These are; late renal responses to physiologically elevated plasma ANP levels [Goetz 1990], a lack of effect on basal renal excretion when plasma ANP is halved and discrepancies in antibody-experiments argue. Moreover, there is no contribute of importance of renal excretion to the reduction in blood volume, which is obtained by infusion of ANP; in nephrectomized rats equal blood volume reduction after ANP infusion is observed [Flückiger et al 1986]. Thus, it remains to be established if ANP is a hormone which is necessary in renal function.

A second potential site of action is that of the peripheral circulation. Administration of atrial extracts induces a decrease in arterial blood pressure [De Bold et al 1981]. Further investigations demonstrate that ANP is responsible for this decrease [Lappe et al $1985 \mathrm{~b}$, Seymour et al 1985b]. In vitro, atrial natriuretic peptides cause a relaxation of precontracted aorta and mesenteric and renal resistance arteries [Currie et al 1983, Mulvany et al 1985, De Mey et al 1987]. Originally it was thought, that a new powerful antihypertensive agent had been found. Many analogues of ANP have been synthesized and tested as such in vitro [Genest and Cantin 1988]. Analogues with various carboxyl terminal chains, with different vasodilatory activity in vitro, induce equal responses in vivo [Lappe et al 1986]. Our studies in WKY, SHR and WKY with heart failure (chapter 4) demonstrate that analogues with various amino terminal chains and different vasodilatory activity in vitro, also induced equal responses in vivo. Neither could any difference in response to ANP(1-28) and ANP(5-28) be demonstrated between the various rat models, indicating that the response to ANP is independent of cardiovascular pathophysiology. These results indicate that the in vitro obtained vasodilatory differences for several ANP analogues do not predict activity in vivo. It also implies that the vasodilatory activity is not of primary significance in vivo. 
A fall In cardiac output is the casse of hypotension during ANP adminisitiration

Cardiac output reduction is not due to direct action of ANP on the heart

ANP reduces circula ting blood volume through peripheral fuld extrayasation

Extravasation is ohtained by venular constriction and a possible Increase in capillaryt permeability
Hemodynamic responses were equal to responses in earlier inwestigations with synthetic analogues in intact animals [Breuhaus et al 1985, Lappe ell al 1985b]. A decrease in blood pressure was parallelled by a decrease in cardiac output and calculated peripheral resistance was even increased. The increase in peripheral resistance is caused by an increase in sympathetic activity [Lappe et al 1985a]. Thus the fall in blood pressure is not due to the vasodilatory activity of ANP, as suggested by in vitro experiments, but rather by a decrease in cardiac output. Upon comparison of the 6 hour infusions with the short term dose-response infusions, it becomes clear that a dose, which in short term infusions does not give a significant hemodynamic changes, lowers cardiac output as significantly as the highest dose in short term infusions, whereas mean arterial pressure is not significantly reduced. These results suggest, that $A N \mathbb{P}$ is more likely a substance, directly involved in cardiac output regulation rather than in blood pressure regulation.

The mechanisms of cardiac output reduction are not yet clear. A direct cardiodepressive effect us unlikely as isolated perfused and functioning hearts do mot respond to ANP [Hiwatari et al 1986]. Alternatively, according Starling's law of the heart, the primary factor determining cardiac output under steady-state conditions, is the venous return of blood to the heart. Mean circulatory filling pressure, thus circulating volume and resistance to venous return, are factors regulating venous return.

ANP administration reduces circulating blood volume [Flückiger et al 1986, Almeida et al 1986, Williamson et al 1989 , chapter 5], even in nephrectomized animals [Flückiger et al 1986]. It was hypothesized that the reduction in blood volume could be caused by an increase in venous resistance [Trippodo 1987], thus causing extravasation of plasma from the circulation. We demonstrated that a reduction in blood volume of $\pm 10 \%$ was mainly due to plasma extravasation in the illeum and skelletal muscle. But what is the underlying mechanism of peripheral fluid extravasation?

Extravasation can occur when 1) there is an increase in capillary pressure due to a change in balance of arteriolar and/or venular tone and 2) the capillary permeability is increased. An increased capillary permeability [Huxley et al 1987] might contribute to an increased extravasation. A chnage in balance of venular tone has 
been demonstrated in chapter 6 . Because total peripheral resistance is increased, arteriolar constriction is likely to occur. However, we did not find any significant effect of ANP on A. A, and $A_{y / 4}$ vessels in the skin muscle from conscious SHR (chapter 6). On the other hand ${ }_{4}$ constriction of $\mathrm{V}_{2}$ and $\mathrm{V}_{1}$ vessels created a condition for the previously observed extravasation. Our results are consistent with the microcirculatory observations in denervated cremaster muscle of anesthetized rats [Faber et al 1988]. In the cremaster muscle ANP inhibits $\alpha_{1}$-mediated but not $\alpha_{\overrightarrow{2}}$ mediated constriction. Because $\alpha_{z}$-adrenoceptors are more abundant on the venular side of the microcirculation than are $\alpha_{i}$-adrenoceptors [Faber 1988], venous resistance is increased due to sympathetic activation.

Depriving animals from circulating ANP increases cardiac output, stressing the role of ANP in cardiac output regulation

Is blood volume or preload the main target of ANP?
The experiments, described in chapters 3 to 6 , indicate that ANP plays an important role in cardiovascular homeostasis. This role appears to be functionalized by the regulation of venous resistance. But what is the physiological cardiovascular role of ANP under normal and pathophysiological conditions? Pharmacological tools to investigate a possible physiological or pathophysiological role, i.e. antagonists, are not available for ANP. As an alternative to antagonists, ANP-antibodies were used to study the physiological and pathophysiological cardiovascular role of ANP in normotensive rats, in spontaneously hypertensive rats and in rats with heart failure respectively. Administration of antibodies increased cardiac output in all the rat models used in these experiments, rather than mean arterial pressure. Once again, these experiments demonstrate that circulating ANP is not an important arterial blood pressure regulating factor. The importance of circulating ANP lies in the regulation of cardiac function or circulating blood volume under normal physiological conditions as well as under pathophysiological conditions, such as spontaneous hypertension and experimental heart failure.

An important question remains in this discussion. Is the regulation of circulating blood volume the primary target of ANP or is it the primary role of ANP to protect the heart from a working overload? The discrimination between these two possibilities is difficult. Under resting conditions and mild labour, when the heart is in a normal healthy condition, it has a permissive role in the circulation of up to cardiac output values of $10-13 \mathrm{l} / \mathrm{min}$ (in trained conditions even up to $15-201 / \mathrm{min}$ ) [Guyton 1986]. Sympathetic stimulation can approximately double the normal output. Under normal 
physiological conditions there seems no need to protect the heart against overload, because of its broad pumping capacity. On the other hand, it is questionable, if the circulation needs a substance which, as ANP, acutely regulates blood volume by increasing extravascular volume. The kidney itself has a great capacity to regulate a volume overload. However, it seems attractive to assume the existence of a humoral agent, counteracting angiotensin II, vasopressin and aldosterone in the blood volume regulation. Moreover, the regulation of the blood volume and the resistance to venous return implies that cardiac function is controlled indirectly by the action of ANP.

fign 9.1.

Role of ANP in the cardiovascular homeostasis as suggested in our experiments

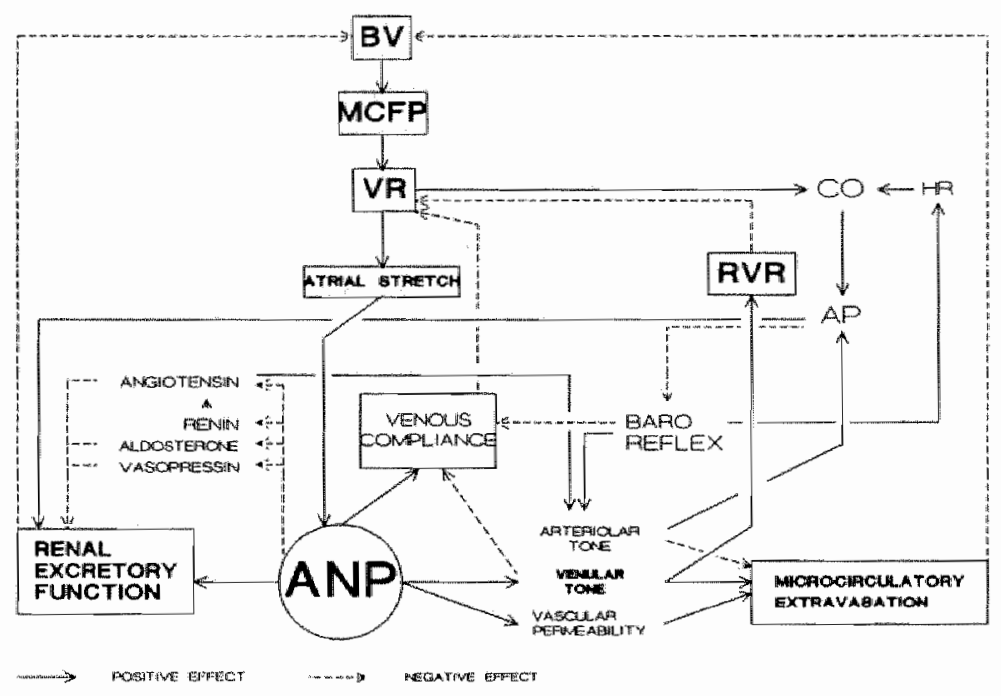

BV $=$ blood wolume

MCFP = mean circulatory filling pressure

$V R=$ wenous return

RVR = resistance to wenous return

$\mathrm{CO}=$ cardiac output

AP arterial blood pressure

$\mathrm{HR}=$ heart rate 
ANP in cardiovascular homeostasüs

On the basis of these considerations, the diagram, presented in chapter 1, can be modified (fig 1). Taking blood volume as a starting-point, the role of ANP in the cardiovascular homeostasis can be described as follows: An increased blood volume (BV), affecting mean circulating filling pressure (MCFP), induces an increase in venous retum (VR) and thus in the preload. This results in an increased release of $A N P$ into the circulation. The increased plasma ANP levels affect several mechanisms. At first venous resistance is increased by a constrictive activity on $V_{a}$ and $V_{1}$ vessels without affecting the tone of arterioles. This results in an increased resistance to venous return and an increased microcirculatory extravasation, thus reducing blood volume. At the level of microcirculatorion ANP might also increase capillary permeability, although no evidence of this in vivo has as yet been published. Secondly, increased plasma ANP might increase renal excretory function. This would also result in a decrease of blood volume. Thirdly, the increased plasma ANP might cause an increased central venous compliance. This results in a changed distribution of circulating blood and a decrease in cardiac filling pressures. Hemodynamic implications are a decrease in cardiac output, which in turn causes a decrease in arterial blood pressure. The total peripheral resistance is increased due to a reflex mediated increase of sympathetic activity. All three mechanisms, induced by elevated plasma ANP, act as a negative feedback to reduce venous return which form the preload of the heart. This is effectuated in a decreased atrial stretch, which in turn causes a decrease in the release of ANP.

Conclusion In this thesis the physiology of ANP in normotensive rats, spontaneously hypertensive rats and rats with experimental heart failure has been further analysed. The studies suggest a role for ANP as an endocrine substance controlling cardiac output, primarily acting on the resistance to venous return and circulating blood volume. 


\section{REFERENCES}

A

Abboud FM. The sympathetic system in hypertension. Hypert. 4(suppl II): 11-208-1225 (1982)

Ackermann $\mathrm{U}$, Irizama $\mathrm{TG}$, Milojevic $\mathrm{S}$ and Sonnenberg $\mathrm{H}$. Cardiovascular effects of atrial extracts in anesthetized rats. Can J Physiol Pharmacol 62: $819-826$ (1984)

Ackermann U, Khanna $J$ and Irizawa G. Atrial natriuretic factor alters autonomic interactions in the control of heart rate in conscious rats. Can J Physiol Pharmacol 66: 930-936 (1988)

Allen DE and Gellai M. Cardioinhibitory effect of atrial peptide in conscious rats. An I Physiol 252: R610-R616 (1987)

Allen MJ, Gilmour SM, Singer M and Bennett DE. Effects of atrial natriuretic peptide on systemic haemodynamics and cardiac function in nomal man. Cardiovascul Res 23: 70-75 (1989)

Almeida FA, Suzuki M and Maack T. Atrial natriuretic factor increases hematocrit and decreases plasma volume in nephrectomized rats. Life Sci 39: 1193-1199 (1986)

Anand-Srivastawa MB, Franks DJ, Cantin $M$ and Genest J. Atrkal natriuretic factor inhibits adenylate cyclase activity. Biochem Biophys Res Commun 121: 855-862 (1984)

Anand-Srivastava MB, Cantin $\mathrm{M}$ and Genest J. Inhibition of pituitary adenylate cyclase by atrial natriuretic factor. Life Sci 36: 1873-1879 (1985)

Anand-Srivastava MB, Vinay P,Cantin $M$ and Genest J. Effect of atrial natriuretic factor on adenylate cyclase in various nephron segments. Am J Physiol 251: F417-F423 (1986)

Anderson JV, Millar ND, O'Hara JP, Mackenzie JC, Corrall RJM and Bloom SR. Atrial natriuretic peptide: Physiological release associated with natriuresis during water immersion in man. Cli Scì Lond 71: 319-322 (1986)

Anderson JV, Donckier J, Payne NN, Beacham J, Slater JDH and Bloom SR. Atrial natriuretic peptide: evidence of action as a natriuretic homone at physiological plasma concentrations in man. Clin Sici 72: 305-312 (1987)

Andersson OK, Persson B, Aurell M, Grnaerus G, Wysocky M, Hedner J and Hedner T. Basal and stimulated levels of immunoreactive atrial natriuretic peptide ( $\alpha$-h.ANP) levels in relation to central venous pressure, renal and central hemodynamics and sodium excretion in normotensive and hypertensive man. J Cardiovasc Pharmacol 8: 1300 (1986)

Appel RG, Wang J, Simonson MS and Dunn MJ. A mechanism by which atriall natriuretic factor mediates its glomerular actions. Am J Physiol 251:F 1036-1042 (1986)

Arendt R, Gerbes AL, Ritter D, Stang1 E, Bach $P$ and Zahringer I. Atrial natriuretic factor in plasma of patients with arterial hypertension, heart failure of cirhosis of the hiver. J Hypert 4 (suppl 2):S131-S135 (1986a)

Arendt RM, Gerbes AL, Ritter D, Stangl E, Bach P and Zahringer I. Alpha-atrial natriuretic factor in cardiovascular disease. J Am Coll Cardiol 7: 75A (1986b)

Arjamaa $O$ and Vuolteenaho $O$. Sodium oin stimulates the release of atrial natriuretic polypeptide (ANP) from rat atria. Biochem Biophys Res Commun 132: 375-381 (1985)

Atarashi K, Mulrow PJ, Franco-Saenz R, Snajdar R and Rapp J. Irihibition of aldosterone production by an atrial extract. Science 224: $992-994$ (1984)

Atarashi K, Mulrow PJ and Franco-Saenz R. Effect of atrial peptides on aldosterone production. J Clin Invest 76: 1807-1811 (1985)

Atlas SA. Atrial natriuretic factor: a new hormone of cardiac origin. Recent Prog Horm Res 42: $207-249(1986 a)$

Atlas SA, Volpe M, Sosa RE, Laragh JH, Camargo MJF and Maack T. Effects of atrial natriuretic factor on blood pressure and the renin-angiotensin-aldosterone system. Fed Prec $45: 2115$. $2121(1986 b)$ 
A wazu M, Imada $T$, Kon $Y$, Inagami " $T$ and Ichikawa $L$. Role of endogenous atrial natriuretic peptide in congestive hean failure. Am J Physiol 257: R641-R646 (1989)

B

Ballerman BJ, Hoover RL., Karnovsjy MJ and Brenner BM. Physiologic regulation of natriuretic peptide receptors in rat renal glomeruli. J Clin Invest 76: 2049-2056 (1985)

Baum $M$ and Toto RD. Lack of a direct effect of atrial natriuretic factor in the rabbit proximal tubule. Am J Physiol 251: F66-F69 (1986)

Beasley D and Malvin RL. Atrial extracts increase glomenular filtration rate in vivo. Am J Physiol 248: F24-F30 (1985)

Beliveau R, Bernier M, Vinay $P$, Tremblay $J$, Pang SC and Hamet P. Atrial natriuretic factor does not alter sodium transport in purified luminal membrane from rat kidney cortex. IRCS Med Sci 13: $402-403$ (1985)

Benjamin BA, Merzler $\mathrm{CH}$ and Peterson TV. Renal response to volume expansion in atrial apendectomized dogs. Am J Physiol 253: R786-R793 (1987)

Benjamin BA, Metzler $\mathrm{CH}$ and Peterson TV. Chronic atrial appendectomy alters sodium excretion in conscious monkeys. Am J Physiol 254: R699 (1988)

Bergey JL, Much DR, Krarunis V and Asaad M. Effects of human ANF (99-126) on sympathetic nerve function, hemodynamic parameters and plasma cGMP levels in anesthetized, ganglionblocked dogs. Eur J Pharmacol 159: 103-112 (1989)

Bianchi C, Gutkowska J, Garcia R, Thibault G, Genest J and Cantin M. Radioautographic localization of ${ }^{125} I$-atrial natriuretic factor (ANF) in rat tissues. Histochemistry 82: 441-452 (1985)

Bianchi C, Gutkowska J, Garcia R, Thibault G, Genest I and Cantin M. Localization of ${ }^{125}$ I-atriall natriuretic factor (ANF)-binding sites in rat renal medulla. $A$ light and electron microscope autoradiographic study. J Histochem Cytochem 35: 149-153 (1987)

Bie P, Wang BC, Leadley RJ and Goetz KL. Hemodynamic and renal effects of low-dose infusions of atrial peptide in awake dogs. Am J Physiol 254: R161-R169 (1988)

Biollaz J, Waeber B, Nussberger J, Porchet F, Brunner-Ferber F, Otterbein ES, Gomez HJ and Brunner HR. Atrial natriuretic peptides: reproducibility of renal effects and response of lower blood flow. Eur J Clin Pharmacol 31: 1-8 (1986a)

Biollaz J, Nussberger J, Porcher M, Brunner-Ferber F, Otterbein ES, Gomez H, Waeber B and Brunner HR. Four hour infusion of synthetic atrial natriuretic peptide in normal volunteers. Hypertension 8 (suppl 2): 96-105 (1986b)

Blaine EH. Atrial natriuretic factor plays a significant role in body fluid homeostasis. Hypertension 15: $2-8(1990)$

Bloch KD, Scott JA, Zistein JB, Fallon JT, Margolies MN et al. Biosynthesis and secretion of proatrial natriuretic factor by cultured rat cardiocytes. Science 230: 1168-1171 (1985)

Bolli P, Muller FB, Linder L, Raine AEG, Resink TJ, Eme P, Kiowski W, Ritz R and Bululer FR. The vasodilator potency of atrial natriuretic peptide in man. Circulation 75: 221-228 (1987)

Borenstein HB, Cupples WA, Sonnenberg H and Veress AT. The effect of a natriuretic atrial extract on renal hemodynamics and urinary excretion in anesthetized rats. J Physiol 334: 133$140(1983)$

Breuhaus BA, Sanci HH, Brandt MA and Chimoskey JE. Atriopeptin II lowers cardiac output in conscious sheep. Am J Physiol 249: R776-R780 (1985)

Bürgisser E, Raine AEG, Erne P, Kamber B and Bühler FR. Human cardiac plasma concentrations of atrial natriuretic peptride quantified by radioreceptor assay. Biochem Biophys Res Com- 
mun 133: $1201-1209$ (1985)

Bumett JC, Granger JP and Opgenorth TJ. Effects of synthetic atrial natriuretic factor on renal function and renin release. Am J Physiol 247: F863-F866 (1984)

Bumett JC, Kao PC, Hu DC, Heser DW, Heublein D, Granger JP, Opgenonh TJ and Reeder GS. Atrial natriuretic peptide elevation in congestive heart failure in the human. Science 231: 1.145-1147(1986)

Bussien JP, Biollaz J, Waeber B, Nussberger J, Turini GA, Brunner HR, Brunner-Ferber F, Gomez HJ and Otterbein ES. Dose-dependent effect of atrial natriuretic peptide on blood pressure, heart rate and skin blood flow of normal volunteers. J Cardiovasc Pharmacol 8: 216 220 (1986)

C

Cachofeiro V, Schiffrin EL, Thibault G, Cantin M and Gatcia R. Effect of a chronic infusion of atrial natriuretic factor on glomerular and vascular receptors in spontaneously hypertensive rats. J Hypert 7: 335-342 (1989)

Cantin M, Forthonme D and Bajusz E. Renal glomerulus in experimental congestive heart failure: ultrastructure and functional studies. In: Cardiomyopathies, vol 2. Edited by Bajusz E. University Park Press, Baltimore, pp 467-492 (1973)

Cantin M, Gutkowska J, Januszewicz P, Thibault G, Garcia R and Genest J. Effect of blood volume expansion on the plasmatic concentration of immunoreactive atrial natriuretic factor. Proc. 10th meeting, Internat Soc Hypertension, Interlaken, June 1984, Abstract.

Casto R, Keiler I, Schroeder G and Stock G. Angiotensin II-induced vasopressin release is attenuated by central atrial natriuretic factor. Clin Exp Theory \& Practice A9: 81-94 (1987)

Chang M, Lowe DG, Lewis M, Hellmiss R, Chen E and Goeddel D. Differential activation by atrial and brain natriuretic peptides of two different receptor guanylate cyclases. Nature 341 : 68-72 (1989)

Chartier L, Schiffrin EL and Thibault G. Effect of atrial natriuretic factor (ANF)-related peptides on aldosterone secretion by adrenal glomerulosa cells: critical role of the intramolecular disulphide band. Biochem Biophys Res Commun 122: 171-174 (1984a)

Chartier L, Schiffrin EL. Thibault G and Garcia R. Atrial natriuretic factor inhibits the stimulation of aldosterone secretion by angiotensin II, ACTH and potassium in vitro and angiotensin IIinduced steroidogenesis in vivo. Endocrinology 115: 2026-2028 (1984b)

Chartier L and Schiffrin EL. Atrial natriuretic peptide inhibits the effect of endogenous angiotensin II on plasma aldosterone in conscious sodium-depleted rats. Clin Sci 72: 31-35 (1987)

Cheung DW. Atriopeptin III depresses the excitability of sympathetic neurones Biochem Biophys Res Commun 154: $411-416$ (1988)

Chien YW, Frohlich ED and Trippodo NC. Atrial natriuretic peptide increases resistance to venous remm in rats. Am J Physiol 252: H894-H899 (1987)

Chinkers M, Garbers DL, Chang M, Lowe DG, Chin H, Goeddel DV and Schulz S. A membrane form of guanylate cyclase is an atrial natriuretic peptide receptor. Nature 333: 78-83 (1989)

Cody RJ, Atlas SA, Laragh JH, Kubo SH, Covit AB, Ryman KS, Shaknovich $A$, Pondolfino K, Clark M, Camargo MJF, Scarborough RM and Lewicki JA. Atrial natriuretic factor in normal subjects and heart failure patients. Plasma levels and renal, hormonal, and hemodynamic responses to peptide infusion. J Clin Invest $78: 1362-1374$ (1986)

Cogan MG. Atrial natriuretic factor can increase renal solute excretion primarily by raising glomerular filtration. Am J Physiol 250: F710-F71: (1986) 
Condra CL, Leidy EA, Bunting $\mathrm{P}$, Colton CD, Nut RF, Rosenblatt $M$ and Jacobs JW. Clearance and bydrolysiss of atrial natruretic factor in vivo. J Clin Invest 81: 1348-1354 (1988)

Criscione $\mathbb{L}$, Burder $R$, Hanni $H$, kamber $B$. Truog $A$ and Hofbauer $K G$. Systemic and regional hemodynamic effects of atriopeptin II in anesthetized rats. J Cardiovasc Pharmacol 9: 135141 (1987)

Crozier IG, Ikram H, Gomex HJ, Nicholls MG, Espiner EA and Wamer NI. Hemodynamic effects of atrial peptide infusion in heart faulure. Lancet it: 1242-1243 (1986)

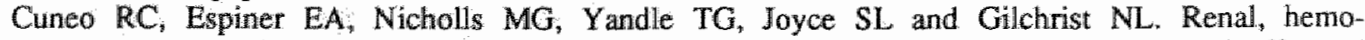
dynamic and hormonal responses to atriall natriuretic peptide in normall man and effect of sodium intake. J Clin Endocrinol Metab: 63: 946-953 (1986)

Currie MG, Geller DM, Cole BR, Boylan JG, Ju Sheng W, Holmberg SW and Needleman P. Bioactive cardiac substances: potent vasorelaxant activity in mammalian atria. Science $211: 71$. $73(1983)$

Currie MO and Newman WH. Evidence for $\alpha_{1}$-adrenergic receptor regulation of atriopeptin release from the isolated rat heart. Biochem Biophys Res Commun 137: 94-100 (1986)

Cusson JR, Hamet P, Gutkowska J, Kuchel O, Genest J, Cantin M and Larochelle P. Effects of atrial natriuretic factor on natriuresis and CGMP in patients with essential hypertension. J Hypertension 5: 435-443 (1987)

D

Day MI, Schwartz D, Rodi C, Rankin A, Needleman P and Wiegand R. Enhanced atriopeptin mRNA and immunoreactivity in atria and ventricles treated with dexamethasone. Fed Proc 45 : Abstract 601 (1986)

Debinski W, Gutkowska J, Kuchel O, Racz K, Buu NT et al. ANF-like peptide(s) in the peripheral autonomic nervous system. Biochem Biophys Res Commun 134: 279-284 (1986a)

Debinski W, Kuchel O, Buw NT, Garcia R, Cantin M and Genest J. Involvement of the adrenal glands in the action of the atrial natriuretic factor. Proc Soc Exp Biol Med 181: 318-324 (1986b)

Debinski W, Gutkowska J, Kuchel O, Racz K, Buu NT et al. Presence of an atrial natriuretic factor-like peptide in the rat superior cervical ganglion. Neuroendocrinol 46: 236-240 (1987)

De Bold AJ, Borenstein HB, Veress AT and Sonnenberg H. A rapid and potent natriuretic response to intravenous injection of atrial myocardial extract in rat. Life Sci 28: 89-94 (1981)

De Bold AJ. Atrial natriuretic factor of the rat heart. Studies on isolation and properties. Proc Sioc Exp Biol Med 179: 133-138 (1982)

De Bold AJ and Fllynn TG. Cardionatrin $\mathbb{I}$ - a novel heart peptide with potent diuretic and natriuretic properties. Live Sci 33: 297-302 (1983)

De Lean A, Racz K, Gutkowska J, Nguyen TT, Cantin M and Genest I. Specific receptor mediated inhibition by synthetic atrial natriuretic factor of hormone stimulated steroidogenesis in cultured bovine adrenal cells, Endocrinology 115: 1636-1638 (1984)

De Lean A, Ong $\mathrm{H}_{*}$ McNicoll N, Racz K, Gutkowska $J$ and Cantin M. Identification of aldosterone secretion inhibitory factor in bowine adrenal medulla. Life Sci 36: 2375-2382 (1985)

De Mey JG, Defreyn G, Lenears $A$. Calderon $P$ and Roba J. Atrial reactivity, blood pressure and plasma levels of atrial natriuretic peptides in nomotensive and hypertensive rats: effects of acute and chronic admistration of atriopeptin III. J Cardiovasc Pharmacol 9: 525-535 (1987)

Deray G, Branch RA. Herzer A, Ohnishi A and Jackson EK. Effects of atrial natriuretic factor on hormone induced renin release. Hypertension 9; 513-517 (1987) 
De Wardener HE, Mils IH, Clapman WF and Hayter CJ. Studies on the efferent mechanism of the sodium diuresis which follows the administration of intravenous saline in the dogg. Clin Sci Lond 21: 249-258 (1961)

Dietz JR. Release of natriuretic factor from rat heart-lung preparation by atrial distension. Am J Physiol 247: R1093-1096 (1984)

Dillingham MA and Anderson RJ. Inhibition of vasopressin action by atrial natriuretic factor. Science 231: $1572-1573$ (1986)

Ding J, Thibault G, Gutkowska J, Garcia $R$, Karabatsos $T$, Jasmin $G$, Genest $J$ and Cantin $M$. Cardiac and plasma atrial natriuretic factor in experimental congestive heart failure. Edocrinalogy 121: 248-257 (1987)

Drexler $H$, Finkh $M$, Höing $S$, Toth $M$, Just $H$ and Lang $R E$. Systemic and regional vascular effects of atrial natriuretic peptide in a rat model of chronic heart failure. Basic Res Cardiol 87: $517-529(1987)$

Dunn BR, Troy JL, Ichikawa I and Brenner BM. Effect of atrial natriuretic peptide (ANP) on hydraulic pressures in the rat renal papilla: implications for ANP-induced natriuresis. Kidney Int 29: 382 (abstract) (1986)

$\mathbf{E}$

Ebert TJ and Cowley AW. Atrial natriuretic factor attenuates carotid baroreflex-mediated car dioaccelaration in humans. Am J Physiol 254: R590-R.594 (1988)

Ebert TJ, Skelton MM and Cowley AW. Dynamic cardiovascular responses to infusions of atriall natriuretic factor in humans. Hypertension 11: 537-544 (1988)

Edwards BS, Zimmerman RS, Schwab TR, Heublein DM and Bumett JC. Atrial stretch, and not pressure, is the principal determinant controlling the acute release of atrial natriuretic factor. Circ Res 62: 191-195 (1988)

$\mathbf{F}$

Faber JE, Gettes DR and Gianturco DP. Microvascular effects if atriall natriuretic factor: Interaction with $\alpha_{1}$ - and $\alpha_{2}$-adrenoceptors. Circ Res 63: 415-428 (1988)

Faber JE. In situ analysis of alpha-adrenoceptors on arteriolar and wenular smooth mucle in rat skeletal muscle microcirculation. Circ Res 62: 37-50 (1988)

Faison EP, Siegl PK, Morgan $G$, Winquist RJ. Regional vasorelaxant selectivity of atrial natriuretic factor in isolated rabbit vessels. Life Sci 37: 1073-1079 (1985)

Fenoy FJ, Quesada T, Garcia-Salom M, Romero JC and Salazar FJ. Hemodynamic effects of chronic infusion of rANP in renal hypertensive rats. Am J Physiol 256: H1393-H1398 (1989)

Fesenko EE, Kolesnikov SS and Lyubarsky AL. Induction by cyclic GMP of cationic conductance in plasma membrane of retinal rod outer segment. Nature 313: 310-313 (1985)

Fishbein MC, Maclean D and Maroko PR. Experimental myocardial infarction in the rat. Am J Path 90: 57-70 (1978)

Flückiger JP, Waeber B, Matsueda $G$, Delaloye B, Nussberger J and Brunner HR (1986) Effect of atriopeptin III on hematocrit and volemia of nephrectomized rats. Am J Physiol 251: H880H883

Flynn TG, De Bold ML and De Bold AJ. The amino acid sequence of an atrial peptide with potent diuretic and natriuretic properties. Biochem Biophys Res Commun 117: 859-865 (1983)

Fok KF, Tjoeng FS, Houbion JA, Spear KL, Nugent ST, Eubariks SR, Zupee ME, Olins GH, Blehm DJ, Adams SP, Wakatani $K$ and Needleman $P$. Structure activity studies of 
arriopeprins. In: Deber CM, Hruby VJ, Kopple KD (eds). Peptides: structure and function. Pierce Chemical Company, Rockford, Illinois, USA (1985), pp 953-956

Forsimann WG, Birr $C$, Carlquist $M$, Christmann $M$, Finke $R$, Henschen $A$, Hock $D$, Hircheim $H$, Kreye $V$, Cottspeich $F$, Metz J, Mutt $V$ and Reineike $M$. The auricular myocardiocytes of the heart constitute an endocrine organ. Characterization of a porcine cardiac peptide hormone. Cell Tissue Res 238: 425430 (1984)

Franch HA, Callatian LI and Blaine EH. Plasma and atrial content of atrial natriuretic factor in cardiomyopathic hamsters. Life Sci 39*1151-1159 (1986)

Franch HA, Dixon RAF, Blaine EH and Siegel PKS. Ventricular atrial natriuretic factor in the cardiomyopathic hamster model of congestive heart failure. Circ Res 62: 31-36 (1988)

Freeman $\mathrm{RH}$, Davis JO and $\mathrm{Vari} \mathbb{R C}$. Renal response to atrial natriuretic factor in conscious dogs with caval constriction. Am I Physiol 248: R495-R500 (1985)

Fried TA, McCoy RN, Osgood RW and Stein JH (1986) Effect of atriopeptin II in determinants of glomerular filtration rate in the in vitro perfused dog glomerulus. Am J Physiol 251: F1119F1122

Fuijo N, Ohashi M, Nawata H, Kato K, Ibayashi $H$, Kangawa K and Matsuo H. Alpha-human atrial natriuretic polypeptide reduces the plasma arginine vasopressin concentration in human subjects. Clin Endocrinol 25: 181-187 (1986)

Fujii $\mathrm{K}$, Ishimatsu $\mathrm{T}$, Kuriyama $\mathrm{H}_{*}$ Mechainsm of vasodilation induced by alpha-human atrial natriuretic polypeptide in rabbit and guinea-pig renal arteries. J Physiol 377: 315-332 (1986)

Fujioka S Tamaki T, Fukui K, Okahara T and Abe Y. Effects of synthetic human atrial natriuretic polypeptide on regional blood flow in rats. EurJ Pharmacol 109: $301-304$ (1985)

Fujita T, Ito $Y$, Noda $H_{\text {., }}$, Sato $Y$, Ando $K$, Kangawa $K$ and Matsuo $H$. Vasodilator actions of $\alpha-$ human atrial natriuretic peptide and high $\mathrm{Ca}^{2+}$ effects in normal man. J Clin Invest 80: 832$840(1987)$

G

Garcia R, Cantin M, Thibault G, Ong $H$ and Genest J. Relationship of specific granules to the natriuretic and diuretic activity of rat atria. Experientia 38: 1071-1073 (1982)

Garcia $\mathbb{R}_{\text {, Thibault }} \mathrm{G}$ and Genest $J$. Effect of partially purified atrial natriuretic factor (ANF) on rat and rabbit vascular smooth muscle. Clin Invest Med 6 (suppl): 56A (1983)

Garcia $R$, Thibault $G$, Cantin $M$ and Genest J. Effect of purified atrial matriuretic factor on rat and rabbit vascular strips and vascular beds. Am J Physiol 247: R34-R39 (1984)

Garcia $R$, Thibault $G$, Seidah NG, Lazure $C$, Cantin $M$, Genest I and Cretien $M$. Structure activity relationships of atriall natriuretic factor (ANF). II. Effect of chain length modifications on vascular activity. Biochem Biophys Res Commun 126: 178-184 (1985a)

Garcia $R$, Gutkowska J, Genest $J$, Cantin $M$ and Thibault G. Reduction of blood pressure and increased diuresis and natriuresis during chronic infusion of atrial natriuretic factor (ANF Arg 101-Tyr 126) in conscious one-kidney, one-clip hypertensive rats. Proc Soc Exp Biol Med 179: $539-545$ (1985b)

Garcia R, Thibault $\mathrm{G}$, Gutkowska J, Horky $\mathrm{K}$, Hamet P, Cantin $\mathrm{M}$ and Genest J. Chronic infusion of low doses of atrial natriuretic factor (ANF Arg 101-Tyr 126) reduces blood pressure in conscious SHR without apparent changes in sodium excretion. Proc Soc Exp Biol Med 179: 396-401 (1985c)

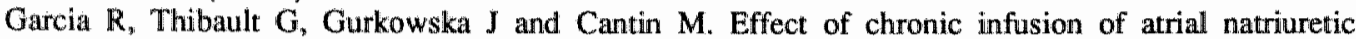
factor on plasma and urinary aldosterone, plasma renin activity blood pressure and sodium 
excretion in 2-K, $\mathbb{1}-\mathrm{C}$ hypertensive rats. Clin Exp Hypertension A8: $127-1147$ (1986)

Garcia R, Cantin M, Gutkowska $J$ and Thibault G. Atrial natriuretic factor during development and reversal of one-kidney, one-clip hypertension. Hypertension 9: 144-149 (1987a)

Garcia R, Gutkowska J, Cantin M and Thibault G. Renin dependency of the effect of chronically administered atrial natriuretic factor in two kidney, one clip rats. Hypertension 9: 88-95 (1987b)

Garcia $R$, Thibault $G$ and Cantin M. Correlation between cardiac hypertrophy and plasma levels of atrial natriuretic factor in non-spontaneous models of hypertension in the rat. Biochem Biophys Res Commun 145: $532-541$ (1987c)

Gardner DG, Hane S, Trachewsky D, Schenk D and Baxter JD. Atrial natriuretic peptide mRNA is regulated by glucocorticoids in vivo. Biochem Biophys Res Commun 139: 1047-1054 (1986a)

Gardner DG, Deschepper CF, Ganong WF, Hane S, Fiddes J. Extra-atrial expression of the gene for atrial natriuretic factor. Proc Natl Acad Sci USA 83: 6697-6701 (1986b)

Gardner DG, Vlasuk GP, Baxter JD, Fiddes IC and Lewicki JA. Identification of atrial natriuretic factor gene transcript in the central nervous system of the rat. Proc Natl Acad Sci USA 84: 2175-2179 (1987a)

Gardner DG, Deschepper CF and Baxter JD. The gene for the atrial natriuretic factor is expressed in the aortic arch. Hypertension 9: 103-106 (1987b)

Gellai M, Allen DE and Beeuwkes III R. Contrasting views on the action of atrial peptides: lessons from studies of conscious animals. Fed Proc 45: 2387-2391 (1986)

Genest J, Larochelle $P$, Cusson JR, Gutkowska $J$ and Cantin $M$. The atrial natriuretic factor in hypertension. Hypertension 11 (suppl I): I-3-I-7 (1988)

Genest $\mathbf{J}$ and Cantin $\mathrm{M}$. The atrial natriuretic factor: Its physiology and biochemistry. Rev Physiol Biochem Pharmacol 110: 2-145 (1988)

Gerzer R, Weil J, Strom T and Müller T. Mechanisms of action of atrial natriuretic factor: Clinical consequences. Klin Wochenschr 64 (suppl VI): 21-26 (1986)

Gnädinger MP, Weidmann $P$, Rascher W, Lang RE, Hellmüller $B$ and Uehlinger DE. Plasma arginine-vasopressin levels during infusion of synthetic atrial natriuretic peptide on different sodium intakes in man. J Hypert 4: 623-629 (1986)

Goetz KL, Wang BC, Geer PG, Sunder WD and Needleman P. Effects of atriopeptin infusion versus effects of left atrial stretch in awake dogs. Am J Physiol 250: R221-R226 (1986)

Goetz KL. Physiology and pathophysiology of atrial peptides. Am J Physiol 254: E1-E15 (1988)

Goetz KL. Evidence that atriopeptin is not a physiological regulator of sodium excretion. Hypertension 15: 9-19 (1990)

Goodfriend TL, Elliot ME and Atlas AS. Actions of synthetic atrial natriuretic factor on bovine adrenal glomerulosa. Life Sci 35: 1675-1682 (1984)

Grammer RT, Fuikemi H, Inagami T and Hisono KS. Rat atrial natriuretic factor. Purification and vasorelaxant activity. Biochem Biophys Res Commun 116: 696-703 (1983)

Granger JP, Opgenorth TJ, Salazar J, Romero JC and Burnett JC. Long-term hypotensive and renal effects of atrial natriuretic peptide. Hypertension 8 (suppl 2):112-116 (1986)

Greenwald, J.A., M. Sakata, M.L. Michener, S.D. Sides and P. Needleman. Is atriopeptin a physiological or pathophysiological substance? J Clin Invest 81: 1036-1041 (1988).

Gutkowska J, Thibault G, Milne RW, Januszewicz P, Schiller PW, Cantin M and Genest J. Radio immuno assay of atrial natriuretic factor (ANF) in rat atria. Proc Soc Exp Biol Med 176: $105-108(1984 a)$

Gutkowska $J$, Horky $K_{*}$, Thibault $G$, Januszewicz $P$, Cantin $M$ and Genest J. Atrial natriuretic factor 
is a circulating hormone. Biochem Biophys Res Commun 125: $315-323$ (1984b)

Gutkowska J, Racz $K$, Garcia $\mathbb{R}$, Thibault $G$, Kuchel $O$, Genest $J$ and Cantin $M$. The morphine effect on plasma ANF. Eur J Pharmacol 131: 91-94 (1986a)

Gutkowska J, Thibault G, Mine RW, Januszewicz P, Schiller PW, Cantin M and Genest J. Effect of dietary sodium on plasma concentration of immuno reactive atrial natriuretic factor in normal humans. Clin Invest Med 9: 222-224 (1986b)

Gutkowska $J$, Horky K, Lachance $C_{4}$ Racz $K$, Gardia $R$, Thibault $G$, Kuchel $O$, Genest $J$ and Cantin M. Atrial natriuretic factor in spontaneously hypertensive rats. Hypertension 8 (suppl 1): $1-137-1-140(1986 \mathrm{c})$

Guyton AC. Textbook of medical physiology. 7th ed. W. B. Saunders Company, London, ISBNO$7216-1260-1(1986)$

\section{HI}

Haass $M$, Zamir $N$ and Zukowska-Grojec Z. Plasma levels of atriall natriuretic peptides in conscious adult spontaneously hypertensive rats. Clin Exp Hypertens A8: 277-287 (1986)

Hackenthal E, Lang RE and Buhrle CP. Atrial natriuretic factor stimulates renin release from the isolated rat kidney. J Hypertension 3 (suppl 3): S323-S325 (1985)

Hamet $P$, Tremblay $J$, Thibault $G$, Garcia $R$, Cantin $M$ and Genest J. Effects of atrial natriuretic factor on metabolism of cGMP. Endocrinology 112: 289 (1983)

Hamet $P$, Tremblay $J$, Pang SC, Garcia $\mathbb{R}$, Thibault $G$, Gutkowska $J$, Cantin $M$ and Genest J. Effect of native and synthetic atrial natriuretic factor on cyclic GMP. Biochem Biophys Res Commun 123: $515-527(1984)$

Hamet P, Tremblay J, Pang SC, Skuherska R, Schiffrin EL, Garcia R, Cantin M, Genest J, Palmour R, Ervin FR, Martin S and Goldwater R. Cyclic GMP as mediator and biological marker of atrial natriuretic factor. J Hypertension 4 (suppl 2): S49-S56 (1986)

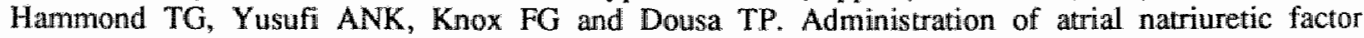
inhibits sodium-coupled transport in proximal tubules. J Clin Invest 75: 1983-1989 (1985)

Hansell $P$ and Ulfendahl HR. Atriopeptins and renal corical and papilliary blood flow. Acta Physiol Scand 127: 349-357 (1986)

Harris PJ, Thomas D and Morgan TO. Atrial natriuretic peptide inhibits angiotensin stimulated proximal tubullar sodium and water" reabsorption. Nature 326: 697-698 (1987)

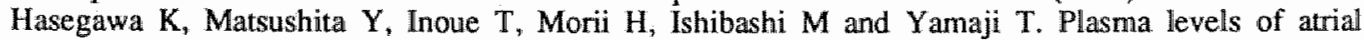
natriuretic peptide in patients with chronic renal failure. J Clin Endocrinol Metab 63: 819. 822. (1986)

Haskins JT, Zingaro FJ and Lappe RW. Rat atriopeptin III alters hypothalamic neuronal activity. Neurosci Lett 67: $279-284$ (1986)

Haywood JR, Schaffer RA, Fastenow C, Fink GD and Brody MJ. Regional blood flow measurement with pulsed Doppler flow meter in conscious rats. Am J Physiol 241: H273-H278 (1981)

Hedner T, Hedner J, Towle AC, Hartfold $\mathrm{M}$, Ljungman $\mathrm{S}$, Wikstrand $\mathrm{J}$ and Berglund $\mathrm{G}$. Plasma atrial natriuretic peptide (ANP) in patients with mild to moderate hypertension. $J$ Cardiovasc Pharmacol 8: 1299 (1986)

Hedner $\mathrm{I}^{4}$, Hartford $\mathrm{M}$, Caidahl $\mathrm{K}$, Hedner $\mathrm{J}$, Towle AC, Ljungman $\mathrm{S}$, Wikstrand $\mathbf{J}$ and Berglund G. Atrial natriuretic peptide (ANP) in relation to blood pressure: A study in middle-aged men with normal and elevated blood pressure. I Intem Med 225: 229-235 (1989)

Henry JP, Gauer GO and Reewes JL. Evidence of the atrial location of receptors influencing urine 
flow. Circ Res 4: 85-90 (1956)

Hintze TH, Currie $\mathrm{MG}$ and Needleman $\mathrm{P}$. Atriopeptins: renal-specific vasodilators in conscious dogs. Am J Plyysiol 248: H587-H591 (1985)

Hintze TH. Significance of atrial natriuretic factor in the conscious dog. Hypertension 12. 143151 (1988)

Hirata $Y$, Takata $S$, Tomita $M$ and Takaichi S. Binding, intemalization and degradation of atrial natriuretic peptide in cultured vascular smooth muscle cells of rat. Biochem Biophys Res Commun 132: $976-984$ (1985)

Hirose S, Akiyama F, Shinjo M, Ohno $H$ and Murakami $K$. Solubilization and molecular weight estimation of atrial natriuretic factor receptor from bovine adrenal cortex. Biochem Biophys Res Commun 130: 574-579 (1985)

Hirsch AT, Creager MA and Dzau VJ. Relation of atrial natriuretic factor to wasoconstrictor hormones and regional blood flow in congestive heart failure. Am J Cardiol 63: 211-216 (1989)

Hirth C, Stasch J-P, John A, Kazda S, Morich F, Neuser D and Wohlfeil S. The renal response to acute hypervolemia is caused by atrial natriuretic peptides. J Cardiovasc Pharmacol 8: 268 . 275 (1986)

Hiruma $\mathrm{M}$, Ikemoto $\mathrm{F}$ and Yamamoto $\mathrm{K}$. Rat atrial natriuretic factor stimulates renin release from renal cortical slices. Eur J Pharmacol 125: 151-153 (1986)

Hiwatari M, Satoh $K$, Angus JA, Johnston CI. No effect of atrial natriuretic factor on cardiac rate, force and transmitter release. Clin Exp Pharmacol Physiol 13: 163-168 (1986)

Hofbauer KG, Criscione L, Somenburg C, Muir A and Mah SC. Acute and chronic haemodynamic and natriuretic effects of atriopeptin II in conscious rats. J Hypert 4 (sappl 2): S41S47 (1986)

Hollister AS, Tanaka I, Imada T, Onrot J, Biaggioni I, Robertson D and Inagami T. Sodium loading and posture modulate human atrial natriuretic factor plasma levels. Hypertension 8:(suppl II): II-106-II-111 (1986)

Holmer SR, Riegger AJG, Notheis WF, Kromer EP and Kochsiek K. Hemodynamic changes and renal plasma flow in early heart failure: implications for renin, aldosterone, norepinephrine, atrial natriuretic peptide and prostacyclin. Basic Res Cardiol 82: 101-108 (1987)

Holtz J, Stewart DJ, Elsner D and Bassenge E. In vivo peptide-renodilation: Minimal potency relative to nitroglycerin in dogs. Life Sci $39: 2177-2184$ (1986)

Holtz $\mathrm{J}$, Sommer $\mathrm{O}$, Bassenge $\mathrm{E}$. Inhibition of sympathoadrenal activity by natriuretic factor. Hypertension 9: 350-354 (1987)

Horkey K, Gutkowska J, Garcia R, Thibault G, Genest J and Cantin M. Effect of different anesthetics on immunoreactive atrial natriuretic factor concentrations in rat plasma. Biochem Biophys Res Commun 129: 651-657 (1985)

Huang CL, Lewicki I, Johnson LK and Cogan MG. Renal mechanism of action of rat atrial natriuretic factor. J Clin Invest 75: 769-773 (1985)

Huang $\mathrm{CL}$ and Cogan MG. Atrial natriuretic factor inhibits maximal tubuloglomerular feedback response. Am J Physiol 252: F825-F828 (1987)

Huxley VH, Tucker VL, Verburg KM and Freeman RH. Increased capillary hydraullic conductivity induced by atrial natriuretic peptide. Circ Res 60: 304-307 (1.987)

I

limura $\mathrm{O}$, Shimamoto $\mathrm{K}$, Ando $T$, Ura $N$, Ishida $H$, Nakagawa $M$, Yokoyama $T$, Fukuyama $S$, 
Yamaguchi $Y$ and Yamaji I. Plasma levels of human atrial natriuretic peptide in patients with hypertensive diseases. Can J Physiol Pharmacol 65: 1701-1705 (1987)

litake $K$, share $\mathrm{L}$, Crofton $\mathrm{JT}$, Brooks DP, Ouchi $\mathrm{Y}$ and Blaine EH. Central atrial natriuretic factor reduces wasopressin secretion in the rat. Endocrinology 119: 438-440 (1986)

Intaglietta $M$ and Tompkins WR. Microvascular measurements by video image shearing and: splitting. Microvasc Res 5: 309312 (1973)

Ishi $M$, Suginoto $T$, Matsuoka $H$, Ishimitsu $T$, Atarashi $K$, Hirata $Y$, Sugimoto $T$, Kangawa $K$ and Matsuo H. Blood pressure, renal and endocrine responses to $\alpha$-human atrial natriuretic polypeptide in healthy volunteers. Jpn Heart J 27: 777.789 (1986)

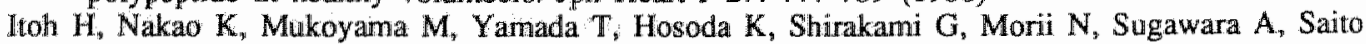
$Y$, Shiono $Y$, Arai $H$, Yoshida I and Imura $H$. Chronic blockade of endogenous atrial natriuretic polypeptide (ANP) by monoclonal antibody against ANP accelerates the development of hypertension in spontaneously hypertensive and deoxycorticosterone acetate-salt-hypertensive rats. J Clin Invest 84: 145 -154 (1989)

II

Jamieson $\mathrm{JD}$ and Palade GE Specific granules in atrial muscle cells. J Cell Biol 23: 151-172 (1964)

Janssen WMT, De Jong PE, Van der Hem GK and De Zeeuw D. Effect of human atrial natriuretic peptide on blood pressure after sodium depletion in essential hypertension. $\mathrm{Br} \mathrm{Med} \mathrm{J} \mathrm{293:}$ $351-353(1986)$

Janssen WMT, de Zeeuw, D, van der Hem GK and de Jong PE. Antihypertensive effect of a 5day infusion of atrial natriuretic factor in humans. Hypertension 13: 640-646 (1989)

Januszewicz $\mathrm{P}$, Larose $\mathrm{P}$, Ong $\mathrm{H}$, Gutkowska $\mathrm{J}$, Genest $\mathrm{J}$ and Cantin M. Effect of atrial natriuretic factor on plasma vasopressin in conscious rats. Peptides 7: 989.993 (1986)

Johannessen AC, Schütten HJ, Torp-Pedersen C, Warberg J and Bie P. Effects of synthetic human atrial natriuretic peptide (hANP) in conscious dogs. Acta Physiol Scand 127: 449-454 (1986)

Johnston CI, Amolda LF, Tsunoda K, Phillips PA and Hodsman GP. Responses of vasoactive hormones in congestive cardiac failure. Can J Physiol Pharmacol 65: 1706-1711, 1987.

Jïppner $H$, Brabant $G$, Kupteina $U$, Kirschner $M$, Klein $H$ and Hesch RD. Direct radioimmunoassy for human atrial natriuretic peptide (hANP) and its clinical evaluation. Biochem Biophys Res Commun 139: 1215-1223 (1986)

K

Kangawa $\mathbb{K}$ and Matsuo $H$. Purification and complete amino acid sequence of $\alpha$-human atrial natriuretic polypeptide ( $\alpha$-hANP). Biochem Biophys Res Commun 118: 131-139 (1984a)

Kangawa $K$, Tawaragi $Y$, Oikawa $S$, Miniano A, Sakuragawa $Y$, Nakazato $H$, Fukuda A, Minamino $\mathrm{N}$ and Matsuo $\mathrm{H}$. Identification of rat gamma atrial natriuretic polypeptide and characterization of the CDNA encoding its precursor. Nature 312:152-155 (1984b)

Katsube $N$, Schwartz D and Needleman P. Release of atriopeptin in the rat by vasoconstrictors or water immersion correlates with changes in right atrial pressure. Bioch Biophys Res Commun 133: $937-944$ (1985)

Kawata $M$, Nakao $K$, Morii $\mathbb{N}_{\text {, Kiso }} \mathrm{Y}$, Yamashita $H$, Imura $H$ and Sano $Y$. Atrial natriuretic polypeptide: Topographical distribution in the rat brain by radioimmunoassy and inmunohistochemistry. Neuroscience 16: $521-546$ (1985)

Kisch B. Studies in comparative electron microscopy of the heart II. Guinea pig and rat. Exp Med 
Surg 13: 404-428 (1955)

Knort M, Locher R, Stimpel M, Neyses $L$ and Vetter W. Cyclic GMP and cytosolic free calcium in the interaction between atrial natriuretic pollypeptide and angiotensin II in smooth muscle. In: Natriuretic Hormones in Hypertension, Satellite Symposium, 11 th Scientific Meeting of the Intemational Society of Hypertension, Heidelberg; abstract. (1986)

Kobrin I, Kardon MB, Trippodo NC, Pegram BL and Frohlich ED. Renal reponse to acute volume overload in conscious rats with atrial appendectomy. J Hypert 3: 145-148 (1985)

Koepke JP, Tyler LD, Trapani AJ, Bovy PR, Spear KL, Olins GM and Blaine EH. Interaction on non-guanylate cyclase linked atriopeptin receptor ligand and endopeptidase inhibitor in conscious rats. J Pharmacol Exp Ther 249: 172-176 (1989)

Kohzuki M, Hodsman GP and Jonhston CI. Attenuated response to atrial natriuretic peptide in ratts with myocardial infarction. An J Physiol 256: H533-H538 (1989)

Koike H, Sada T, Miyamoto $M$, Oizumi $K$, Sugiyama $M$ and Inagami T. Atrial natriutetic factor selectively increases renal blood flow in conscious spontaneously hypertensive rats. Eur II Pharmacol 104: 391-392 (1984)

Kondo K, Kida O, Sasalki A, Kato J and Tanaka $K$. Natriuretic effect of chronically administered $\alpha$-human atrial natriuretic polypeptide in sodium depleted or repleted conscious spontaneously hypertensive rats. Clin Exp Pharmacol Physiol 13: 417-424 (1986)

Kuchel O, Racz. K, Debinski W, Gutkowska J, Buu NT, Cantin M and Genst J. Catecholamines and atrial natriuretic factor in Dahl and spontaneously hypertensive rats. Can J Physiol Pharmacol 65: $1690-1696(1987 \mathrm{a})$

Kuchel O, Debinski W, Racz K, Buu NT, Garcia R, Cusson JR, Larochell P, Cantin M and Genest J. An emerging relationship between peripheral sympathetic nervous activity and atrial natriuretic factor. Life Sci 40: 1545-1551 (1987b)

Kurtz A, Bruna RD, Pfeilschifter $J$, Taugener $R$ and Bauer $C$. Atrial natriuretic peptide inhibits renin release from juxtaglomerular cells by a cGMP mediated process. Proc Natl Acad Sci USA 83: 4769-4773 (1986)

Kyncl J, Bush EN and Buckner SA. Atriopeptin III (ANF) interaction with alpha receptor subtypes and their pre- vs post-synaptic functions. J Cardiovase Pharmacol 8: 1312 (1986)

L.

Lachance D, Garcia R, Gutkowska J, Cantin M,and Thibault G. Mechanisms of release of atrial natriuretic factor: $\mathbb{I}$. Effect of several agonists and steroids on its release by atrial minces. Biochem Biophys Res Commun 135: $1090-1098$ (1986)

Lachance $D$ and Garcia $R$. Atrial natriuretic factor release by angiotensin $I I$ in the conscious rat. Hypert 11: $502-508$ (1988)

Lang RE, Tholken H, Ganten D, Luft FC, Ruskoaho H and Unger TH. Atrial natriuretic factor - a circulating hormone stimulated by volume loading. Nature 314: 264-266 (1985)

Lang RE, Dietz R, Merkel $A_{\text {, Unger }} T$, Ruskoaho $H$ and Ganten $D$. Plasma atrial natriuretic peptide values in cardiac diseases. J Hypert 4 (suppl 2): S119-S123 (1986)

Lang RE, Unger $T$ and Ganten D. Atrial natriuretic peptide: A new factor in blood pressiure control. J Hypert 5: 255-271 (1987)

Langer SZ and Hicks PE (1984) Alpha-adrenoceptor subtypes in blood vessels: physiology and pharmacology. J Cardiovasc Pharmacol 6: \$547-\$558

Lappe RW. Todt JA and Wendt RL. Mechanisms of action of vasoconstrictor responses to atriopeptin II in conscious SHR. Am J Physiol 249: R781 (1985a) 
Lappe RW, Smits JF, Todt JA, Debets JJ and Wendt RL. Failure of atriopeptin II to cause arterial wastodilation in the conscious rat. Circ Res 56: 606-612 (1985b)

Lappe RW, Todt JA and Wendt RL. Hemodynamic effects of infusion versus bolus administration af atrial natruretic factor. Hypertension $8: 866-873$ (1986)

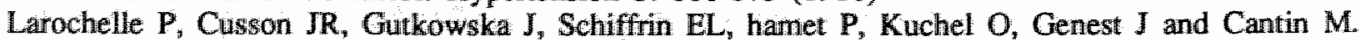
Plasma atrial natriuretic factor concentrations in essentiall and renovascular hypertenison. $\mathrm{Br}$ Med J 294: 1249-1252 (1987a)

Larochelle $\mathrm{P}$, Cusson JR, Hamet $\mathrm{P}$, Du Souich P, Gutkowska J, Schiffrin EL, Genest $J$ and Cantin M. Pharmacodynamic effects of bolus administration of atrial natriuretic factor in hormal volunteers. In: Brenner BM, Laragh JH (eds). Biologically active peptides. American Society of Hypertension Symposium Series, Raven Press, New York, NY, USA, vol 1, pp 451-454 (1987b)

Lattion AL, Michel JB, Arnauld E, Corrol P and Soubrier F. Myocardial recruitment during ANP mRNA increase in response to volume overload in the rat. Am J Physiol 251: H890-H896 (1986)

Leckie B. How the heart rules the kidneys. Nature 326: 644-645 (1987)

Ledsome JR, Wilson $N$, Courneya $C A$ and Rankin AJ. Release of atrial peptide by atrial distension. Can J Physiol Pharmacol 63: 739-742 (1985)

Ledsome JR, Wilson N, Rankin AJ and Courneya CA. Time course of release of atrial natriuretic peptide in the anesthetized dog. Can J Physiol Pharmacol 64: 1017-1022 (1986)

Leitman DC, Andresen JW, Kuno T, Kamisaki Y, Chang JK and Murad F. Identification of multiple binding sites for atrial natriuretic factor by affinity cross-linking in cultured endothelial cells. J Biol Chem 261: 11650-11655 (1986)

Le Noble JLML. Microcirculation in the spontaneously hypertensive rat. Thesis, University of Limburg, the Netherlands (1987)

Le Noble JLML, Smith TL, Hutchins PM and Struyker Boudier HAJ. Microvascullar alterations in adult conscious spontaneously hypertensive rats. Hypert 15: (in press) (1990)

Liu F-Y and Cogan MG. Atrial natriuretic factor does not inhibit basal or angiotensin II stimulated proximal transport. Am J Physiol 255: F434-F437 (1988)

Luft FC, Lang RE, Aronoff GR, Ruskoaho H, Toth M, Ganten D, Sterzel RB and Unger T. Atriopeptin III kinetics and pharmacodynamics in nomal and anephric rats. J Pharmacol Exp Ther 236: $416-418$ (1986)

Lynch DR, Braas KM and Snyder SH. Atrial natriuretic factor receptors in rat kidney, adrenal gland and brain: autoradiographic localization and fluid balance dependent changes. Proc Natl Acad Sci USA 83: 3357-3361 (1986)

$\mathbf{M}$

Maack T, Marion DN, Camargo MJ, Kleinert HD, Laragh JH, Vaughan ED and Atlas SA. Ëffects of auriculin (atrial natriuretic factor) on blood pressure, renal function and the renin-aldosterone system in dogs. Am J Med 77: 1060-1075 (1984)

Maki M, Takanayagi R, Misono KS, Pandey KN, Tibbetts C and Inagami T. Structure of rat atrial natriuretic factor precursor deduced from cDNA sequence. Nature 309: 722-724 (1984)

Manning PT, Schwartz D, Katsube NC, Homberg SW and Needleman P. Vasopressing-stimulated release of atriopeptin: endocrine antagonists in fluid homeostasis. Science 229; 395-397 (1985)

Marie JP, Guillemot $H$ and Hatt PY. Le degré de granulation des cardiocytes auriculaires. Etude 
planimétrique au cours de différents aports d'eau et de soduin chez le rat. Pathol Biol (Paris) 24: $549-554$ (1976)

Marin-Grez M, Fleming JT and Steinhausen M. Atrial Natriuretic peptide causes preglonnerular vasodilatation and post-glomerular vasoconstriction in rat kidney. Nature 324: 473-476 (1986)

Marsh EA, Seymour AA, Haley AB, Whinnery MA, Napier MA, Nutt RF and Blaine EH. Renal and blood pressure responses to synthetic atrial natriuretic factor in spontaneously hypertensvie rats. Hypert 7: 386-391 (1985)

Matsuo $\mathrm{H}$ and Nakazato $\mathrm{H}$. Molecular biology of atrial natriuretic peptide. Endocrinol Metab Clin North Am 16: 43-61 (1987)

Matsuoka $\mathrm{H}$, Ishii M, Sugimoto T, Hirata $\mathrm{Y}$, Sugimoto T, Kangawa $\mathrm{K}$ and Matsuo H. Inhibition of aldosterone production by alpha-human atrial natriuretic polypeptide is associated with an increase in cGMP production. Biochem Biophys Res Commun 127: 1052-1056 (1985)

Meloche S, Ong $\mathrm{H}$, Cantin $\mathrm{M}$, De Léan A. Affinity cross-linking of atrial natriuretic factor to its receptor in bovine adrenal zona glomerulosa. J Biol Chem 261 1525-1528 (1986)

Michener ML, Gierse JK, Seetharam R, Fok KF, Olins PO et al. Proteolytic processing of atriopeptin prohormone. Mol Pharmacol 30: 552-557 (1986)

Molina CR, Fowler MB, McCrory S, Peterson C, Myers BD, Schroeder IS and Murad F. Hemodynamic, renal and endocrine effects of atrial natriuretic peptide infusion in severe heart failure. J Am Coll Cardiol 12: 175-186 (1988)

Morii N, Nakao K, Sugawara A, Sakamoto M, Suda M, Shimokura M, Kiso Y, Kihara M, Yamori $\mathrm{Y}$ and Imura H. Occurence of atrial natriuretic polypeptide in brain. Biochem Biophys Res Commun 127: 413-419 (1985)

Morii N, Nakao K, Sugawara A, Sakamoto M, Yamori Y and Imura H. Decreased content in left atrium and increased plasma concentration of atrial natriuretic polypeptide in spontaneously hypertensive rats (SHR) and SHR stroke-prone. Biochem Biophys Res Commun 135: 74-81 (1986)

Mulvany MJ, Aalkjar C, Juul BM Nyborg NCB and Andresen J. Synthetic atrial natriuretic factor is a specific dilator of noradrenaline and serotonin activated renal resistance. $\mathrm{J}$ Hypert 3(suppl 3): S-307-S309 (1985)

Murphy KMM, McLaughlin LL, Michener ML and Needleman P. Autoradiographic localization of atriopeptin III receptors in rat kidney. Eur J Pharmacol 111: 291-292 (1985)

Murthy KK, Thibault G, Schiffrin EL, Garcia R, Chartier L, Gutkowska J, Genest J and Cantin M. Disappearance of atrial natriuretic factor from circulation in the rat. Peptides 7: 241-246 (1986)

$\mathbf{N}$

Nakayama $K$, Ohkubo $H$, Hiroso $T$, Inayama $S$ and Nakanishi $S$. mRNA sequence for human cardiodilatin-atrial natriuretic factor precursor and regulation of precursor mRNA in rat atria. Nature 309: 699-701 (1984)

Nakamura $\mathrm{M}$ and Inagami $\mathrm{T}$. Atrial natriuretic factor inhibits norepinephrine release evoked by sympathetic nerve stimulation in isolated perfused rat mesenteric arteries. Eur $\mathbf{J}$ Pharmacol 123: $459-461$ (1986)

Nakao K, Sugawara A, Morii N, Sakamoto M, Yarmada T, Itoh H, Shiono S, Saito Y, Nishimura $K$, Ban $T$, Kangawa $K$, Matsuo $H$ and Imura $H$. The pharmacokinetics of $\alpha$-human atrial natriuretic polypeptide in healthy subjects. Eur J Clin Pharmacol 31: 101-103 (1986)

Nakoako $\mathrm{H}$, Imataka $\mathrm{K}$, Amano $\mathrm{M}$, Fuji J, Ishibashi $\mathrm{M}$ and Yamaji $T$. Plasma levels of atrial 
natriuretic factor in patients with congestive heart failure. N Eng J Med 313: 892-893 (1985) Napier MA, Dewey RS, Albers-Schonberg G, Bennet GD, Rodkey JA, Marsh EA, Whinnerey M, Seymour AA and Blaine EH. Isolation and sequence determination of peptide components of atrial natriuretic factor. Biochem Biophys Res Commun 120: $981-988$ (1984)

Nanise $M$, Obana $K$, Naruse $K$, Sugino $N$, Demura $H$. Shizume $K$ and Inagami $T$. Antisera to atrial natriuretic factor reduces urinary sodium excretion and increases plasma renin activity in rats. Biochem Biophys Res Commun 132: 954-960 (1985)

Naruse $N$, Naruse $K$, Obana $K$, Kurimoto $F$, Sakurai $H$, Honda $T$, Higashida $T$, Demura $H$, Inagami $T$ and Shizume $K$. Immunoreactive alpha-human atrial natriuretic polypeptide in human plasma. Peptides $7: 141-145$ (1986)

Natsume T, Kardon MB, Trippodo NC, Januszewicz A, Pegran BI and Frohlich ED. Atriopeptin III does not alter cardiac peformance in rats. J Hypert 4: 477-480 (1986)

Needleman P, Admas SP, Cole BR, Currie MG, Geller DM, Michener ML, Saper CB, Schwartz D and Standaert DG. Atriopeptins as cardiac hormones. Hypertension 7: 469-482 (1985)

Needleman P and Greenwald JE. Atriopeptin: a cardiac hormone intimately involved in fluid, electrolyte and blood pressure homeostasis. $N$ Engl J Med 314: 828-834 (1986)

Needleman, P., E.H. Blaine, J.E. Greenwald, M.L. Michener, C.B. Saper, P.T. Stockmann and H.E. Tolunay. The biochemical pharmacology of atrial peptides. Annu Rev Pham Tox 29: 23-54 (1989)

Nemer M, Chamberland $M$, Srois D, Argentin S, Drouin J, Dixon RAF, Zivin RA and Condra JH. Gene structure of the human cardiac hormone precursor, pronatriodilatin. Nature 312: 654$656(1984)$

Nemer M, Argentin S, Lavigne JP, Chamberland $\mathrm{M}$ and Drouin J. Glucocorticoid regulation of pronatriodilatin gene expression. J. Cell Biochem 11A: 121 (1987)

Nonoguchi $\mathrm{H}$, Knepper MA and Manganiello VC. Effects of atrial natriuretic factor on cyclic guanosine monophosphate and cyclic adenosine monophosphate accumulation in microdissected nephron segments from rats. J Clin Invest 79: 500-507 (1987)

0

Obana K, Naruse M, Naruse K, Sakurai A, Demura H, Inagami $T$ and Shizume K. Synthetic rat atrial natriuretic factor inhibits in vitro and in vivo renin secretion in rats. Endocrinology 117: $1282-1284(1985)$

Ogihara T, Shima J, Hara $H_{n}$ Kumahara $Y$, Kangawa $K$ and Matsuo $H$. Changes in human plasma atrial natriuretic polypeptide concentration in normal subjects during passive leg raising and whole-body uilting. Clin Sci Lond 71: 147-150 (1986a)

Ogihara T, Shima J, Hara $H_{*}$ Tabuchi $Y$, Hashizime $K$, Nagano M, Katahira K, Kangawa K, Matsuo $H$ and Kumahara $Y$. Significant increase in plasma immunoreactive atrial natriuretic polypeptide concentration during head out water inmersion. Life Sci 38: 2413-2418 (1986b)

Ohishi K, Hishida A and Honda N. Direct vasodilatory action of atrial natriuretic factor on canine glomerular afferent arterioles. Am J Physiol 255: F415 F420 (1988)

Olins GM, Palton DR, Tjoeng FS and Blehm DJ. Specific receptors for atriopeptin III in rabbit lung. Biochem Biophys Res Commun 140: 302-307 (1986)

Opgenorth TJ, Burnett JC, Granger JP and Scriven TA. Effects of atrial natriuretic peptide on renin secretion in nonfiltering kidney. Am J Physiol 250: F798-F801 (1986)

Oshima T, Currie MG, Geller DM and Needleman P. An atrial peptide is a potent renal vasodilator substance. Circ Res 54: 612-616 (1984) 
Osol G, Hapern W, Tesfamariam B, Nakayama $K$ and Weinberg $D$ Synthetic atrial natriuretic factor does not dilate resistance-sized arteries. Hypertension 8. 606-610 (1986)

P

Pandey KN, Inagami $T$ and Misono KS. Three distinct forms of atrial natriuretic factor receptors: Kidney tubular epithelium cells and vascular smooth muscle cells contain different types of receptors. Biochem Biophys Res Commun 147: 1146-1152 (1987)

Papka RE, Traurig, $H H$ and Wekstein M. Localization of peptides in nerve terminals in the paracervical ganglion of the rat by light and electron microscopic immunhistochemistry: Enkephalin and atrial natriuretic factor. Neurosci lett 16: 285-290 (1985)

Parkes DG, Coghlan JP, McDougall JG and Scoggins BA. Long-term hemodynamic actions of atrial natriuretic factor (99-126) in conscious sheep. Am J Physiol 254: H811-H815 (1988)

Pettersson A, Ricksten SE, Towle AC, Hedner J and Hedner T. Plasma atrial natriureic peptide and haemodynamics in conscious normotensive and spontaneously hypertensive rats after acute blood volume expansion. I Hypert 3 (suppl 3): \$311-\$313 (1985)

Pichet $\mathbb{R}$, Cantin $M$, thibault $G$ and Lavallee $M$. Hemodynamic and renal responses to physiological levels of atrial natriuretic factor in conscious dogs. Hypert 14: 104-110 (1989)

Pollock DM and Banks RO. Effect of atrial extract on renal function in the rat. Clin Sci 65 : 47-55 (1983)

Pollock DM and Arendshorst WJ. Effect of atrial natriuretic factor on renal hemodynamics in the rat. Am J Physiol 251: F794-F801 (1986)

Q

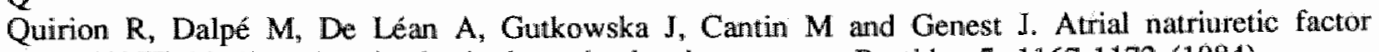
(ANF) binding sites in the brain and related structures. Peptides 5: 1167-1172 (1984)

Quirion $R$, Dalpe $M$ and Dam TV. Characterization and distribution of receptors for the atrial natriuretic peptide in mammalian brain. Proc Natl Acad Sci USA 83: 174-178 (1986)

$\mathbf{R}$

Raine AE, Eme P, Bürgisser E, Müller FB, Bolli $P$, Burkart $F$ and Bühler FR. Atrial natriuretic peptide and atriall pressure in patients with congestive heart failure. $N$ Enl $J$ Med 315: 533 537 (1986)

Rankin A, Rodi CP and Wiegand RC. Treatment of adult rats with either dexamethasone of dAVP results in a marked increase in steady state atriopeptigen mRNA levels. Fed Proc 45: Abstract $4398(1986)$

Remm, J. Congestive heart failure: Pathophysiology and medical treatment. I. Cardiovasc. Pharmacol. 8 (stuppl I): S-36-S52 (1986)

Richards AM, Nicholls MG, Expiner EA, Ikram H, Ynadle TG, Joyce SL and Cullens MM. Effects of allpha-human atrial natriuretic peptide in essential hypertension. Hypertension $7: 812-817$ (1985)

Richards AM, Ikram H, Yandle TG, Nicholls MG, Webster MWI and Espiner EA, Renal, hemodynamic and hormonal effects of human alpha-atrial natriuretic peptide in healthy wolunteers. The Lancet i: $545-549$ (1985)

Richards AM, Tonolo G and Davidson G. Plasma atrial natriuretic peptide in essential hyper* tension. Proceedings, Council for high blood pressure research, American Heart Association. Abstract no 46 (1986a) 
Richards AM, Tonolo G, Tillman D, Conell JM, Hepburn D and Robertson JIS. Plasma atrial natiuretic peptide in stable and accelerated essential hypertension. J Hypert 4" 790-791 $(1986 \mathrm{~b})$

Richards $\mathrm{AM}$, Espiner EA, Ikram $\mathrm{H}$ and Yandle $\mathrm{TG}$. Atrial natriuretic factor in hypentension: Bioactivity at normal plasma levels. Hypertension 14: 261-268 (1989)

Riegger GAJ, Kromer EP and Kochsiek $\mathrm{K}$. Human atrial natriuretic peptide: Plasma levels, hemodynamic, hormonal and renal effects in patients with severe congestive heart failure. J Cardiovasc Phamacol 8: 1107-1112 1986)

Riegger GAJ, Elsner D, Kromer EP, Daffner C, Forssmann WG, Muders F, Pascher EW and Kochsielk K. Atrial natriuretic peptide in congestive heart failure in the dog: plasma levels, cyclic guanosine monophosphate, ultrastructure of atrial myoendocrine cells and hemodynamic, hormonal and renal effects. Circulation 77: 398-406 (1988)

Rosmalen FMA, Tan ATICL, Tan HS and Benraad TJ. A sensitive radioimmunoassay of atrial natriuretic peptide in human plasma, using a tracer with an immobilized glycouril agents. Clin Chim Acta 165: 331-340, (1987)

Rudd, MA, Plavin S, Hirsch AT, Ingerfinger JR and Dzau VJ. Atrial natriuretic factor-specific antibody as a tool for physiological studies. Evidence for role of atrial natriuretic factor in aldosterone and renal electrolyte regulation. Circ. Res. 65: 1324 1329 (1989)

Ruskoaho $H$, Toth $M$ and Lang $R E$. Atrial natriuretic peptide secretion: synergistic effect of phorbol ester and A23187. Biochem Biophys Res Commun 133: 581-588 (1985)

Ruskoaho $H$, Toth $M$, Ganten D, Unger Th and Lang RE. The phorbol ester induced atrial natriuretic peptide secretion is stimulated by forskolin and bay K38644 and inhibited by 8bromocyclic GMP.. Biochem Biophys Res Commun 139: 266-274 (1986)

Ruskoaho HJ, and Leppaluot J. Adrenergic effect on the atrial natriuretic peptide secretion and vasoconstriction induced in the perfused rat heart by phorbol ester. Eur J Pharmacol 148: $317-325(1988)$

$\mathbf{S}$

Sagnella GA, Markandu ND, Shorf AC, MacGregor GA. Effects of changes in dietary sodium intake and saline infusion on immunoreactive atrial natriuretic peptide in human plasma. Lancet ii: $1208-1211$ (1985)

Sagnella GA, Markandu ND, Shore AC and MacGregor GA. Raised circulating levels of atrial natriuretic peptides in essential hypertension. Lancet $i$ : 179-180 (1986)

Sagnella GA, Markandu ND, Shore AC and MacGregor GA. Plasma immunoreactive atrial natriuretic peptide and changes in dietary sodium intake in man. Life Sci 40: 139-143 (1987)

Salaziar FJ. Fiksen-Olsen MJ, Opgenorth TJ, Granger JP, Bumett JC and Romero JC. Renal effects of ANP without changes in glomenular filtration rate and blood pressure. Am J Physiol 251: F532-F536 (1986)

Samson WK. Atrial natriuretic factor inhibits dehydration and hemorrhage induced vasopressin release. Neuroendocrinology 40: $277-279(1985)$

Saper CB, Standaert DG, Currie M,Schwartz D, Geller DM and Needleman P. Atriopeptin-immunoreactive neurons in the brain: Presence in cardiowascular regulatory areas. Science 227:1047-1049 (1985)

Sasaki A, Kida O, Kangawa K, Matsuo H and Tanaka K. Cardiosuppresive effects of alpha-human atrial natrituretic polypeptide $(\alpha-h$ ANP) in spontaneously hypertensive rats. Eur $J$ Pharmacol 115: $321-324(1985)$ 
Sasaki A, Osamu K, Kato J, Nakamura S, Kodama K, Miyata A, Kangawa K, Matsuo $H$ and Tanaka $K$. Effects of antiserum against $\alpha$-rat atrial natriuretic peptide in anesthetized rats. Hypert 10: 308-312 (1987)

Scarborough RM, Schenk DB, McEnroe GM, Arfsten A, Kang LL. Tnuncated atrial natriuretic peptide analogs: Comparison between receptor binding and stimulation of cyclic GMP accumulation in cultured vascular smooth muscle cells. J Biol Chem 261: 12960-12964 (1986)

Schenk DB, Phelps MN, Porter JG, Scarborough RM, McEnroe GA and Lewicki JA. Identification of the receptor for atrial natriuretic factor on cultured vascular cells. J Biol Chem 260: $14887-14890(1985)$

Schiebinger RJ, Baker MZ and Linden $\mathrm{JL}$. Effct of adrenergic and muscarinic cholinergic agonists on atrial natriuretic peptide secretion by isolated rat atria. J Clin Invest 80: 1687-1691 (1987)

Schiffrin EL, Gutkowska J, Kuchel O, Cantin M and Genest J. Plasma concentration of atrial natriuretic factor in a patient with paroxysmal atrial tachycardia. N Engl J Med 312: 11961197 (1985)

Schiffrin EL and St-Louis J. Vascular and adrenal binding sites for atrial natriuretic factor in rats: effects of sodium, mineralocorticoids and hypertension. Clin Invest Med 8: A-127 (1985)

Schiffrin EL, Down regulation of binding sites for atrial natriuretic in platelets of patients with congestive heart failure. Circ 74 (Suppl II): II-463 (1986)

Schiffrin EL, St-Louis J, Garcia $R_{*}$ "Thibault $G$, Cantin $M$ and Genest J. Vascular and adrenal binding sites for atrial natriuretic factor. Effects of sodium and Hypertension. Hypertension 8 (suppl I): I-141-I145 (1986a)

Schiffrin EL, Tremblay J, Hamet $P$ and St-Louis J. Vascular binding sites for atrial natriuretic peptide in rats: Down-regulation in volume expanded states is mediated by ANP. Clin Res 32: $486 \mathrm{~A}$ (1986b)

Schiffrin EL. Down regulation of binding sites for atrial natriuretic peptide in platelets of patients with congestive heart failure. Circulation 74 (suppl II):II-463 (1986)

Schoemaker RGS. Experimental heart failure in rats. Hemodynamic studies on pathophysiology and therapy. Thesis, University of Limburg, the Netherlands (1990)

Schwab TR, Edwards BS, Heublein DM and Burnett JC. Role of atrial natriuretic peptide in volume expansion natriuresis. Am J Physiol 251:R310-R313 (1986)

Schwantz D, Geller DM, Manning PT, Siegel NR, Fok KF, Smith CF and Needleman P. Ser-LeuArg-Arg-atriopeptin III: the major circulating form of atrial peptide. Science 229: 397-400 (1985)

Scriven TA, BA and Bumett JC. Effects of synthetic atrial natriuretic peptide on renal function and renin release in acute experimental heart failure. Circulation 72:892-897 (1985)

Seidah NG, Lazure C, Chrétien M, Thibault G, Garcia R, Cantin M, Genest J, Nutt RF, Brady SF, Lyle TA, Palevada WJ, Colton CD, Ciccarone TM and Veber DF. Amino acid sequence of homologous rat atrial peptides: natriuretic activity of native and synthetic forms. Proc Natl Acad Sci 81: 2640-2644 (1984)

Seidman CE, Duby AD, Choi E, Graham RM, Haber E, Homcy C, Smith JA and Seidman JG. The structure of rat preproatrial natriuretic factor as defined by a complementary DNA clone. Science 225: 324-326 (1984)

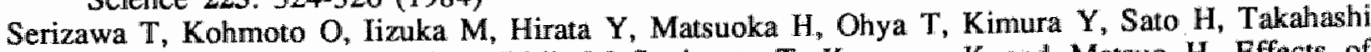
T, Masuo $M$, Mochizuki T, Ishii, $M$ Sugimoto T, Kangawa $K$ and Matsuo $H$. Effects of alpha human atrial natriuretic polypeptide on the systemic hemodynamics and coronary circulation in patients with ischemic hear disease. Jap Cric J 52: 1107-1113 (1988a) 
Serizawa $T$, Yasunobo $Y$, Kohmoto $O$, lizuka M, Matsuoka H, Sato H, Takahshi $T$, Machizuki $T$,

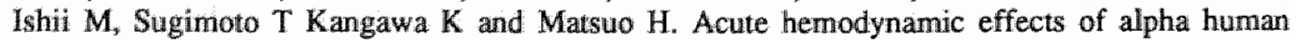
atrial natriuretic polypeptide in patients with congestive heart failure. Jpn Heart J 29: 143$150(1988 \mathrm{~b})$

Seymour AA, Blaine EH, Mazack EK, Smith SG, Stabilito II, Haley AB, Napier MA, Whinnery MA and Nutt RF. Renal and systemic effects of synthetic atrial natriuretic factor. Life Sci 36: 33-36 (1985a)

Seymour AA, Marsh EA, Mazack EK, Stabilito II and Blaine EH. Synthetic atrial natriuretic factor in conscious normotensive and hypertensiwe rats. Hypertension 7 (suppl I): I-35-I-42 (1985b)

Seymour AA, Sweet CS, Stabilito II and Emmert SE. Cardiac and hemodynamic responses to synthetic atrial natriuretic factor in rats. life Sci 401: $511-519$ (1987)

Share $\mathrm{L}$, litake $K$, Crofton JT, Brooks DP, Ouchi $Y$ and Blaine E. Central atrial natriuretic factor induces vasopressin release in conscious rats. Fed Proc 45: 166 (1986)

Smith TL, Osborne SW and Hutchins PH. Long-term micro- and macrocirculatory measurements in conscious rats. Microwasc Res 29: 360-370 (1985)

Smits JFM, Coleman TG, Smith TL, Kasbergen CM, van Essen $H$ and Struyker-Boudier HAJ. Anthihypertensive effect of propranolol in conscious spontaneously hypertensive rats: Central bemodynamics, plasma volume and renal function during B-blockade with propranolol. J Cardiovasc Pharmacol 4: 903-914 (1982)

Simits JFM, van Essen H, Struyker Boudier HAJ and Lappe RW. Lack of renal vasodilation during intrarenal infusion of synthetic atriopeptin II in conscious intact SHR. Life Sci 38: 81-87 (1986)

Smits JFM, le Noble JLM, van Essen H and Slaaf DW. Syntheric atrial natriuretic peptide does not increase protein extrawasation in rat mesentery. J Hypert 5 (suppll 5): S45-S47 (1987)

Snajdar RM and Rap JP. Atrial natriuretic factor in Dahl tats atrial content and renal and aortic responses. Hypertension 7: 775-782 (1985)

Sonnenberg H, Cupples WA, DeBold AJ and Veress AT. Intrarenal localization of the natriuretic effect of cardiac atrial extract. Can J Physiol Pharmacol 60: 1149-1152 (1982)

Sonnenberg $\mathrm{H}$ and Veress AT. Cellular mechanism of release of atrial natriuretic factor. Biochem Biophys Res Commun 124: 443-449 (1984)

Sonnenberg $\mathrm{H}$, Honrath $\mathrm{U}$, Chong $\mathrm{CK}$ and Wilson DR. Atrial natriuretic factor inhibits sodium transport in medullary collecting duct. Am I Physiol. 250: F963-F966 (1986a)

Sonnemberg $\mathrm{H}$, Muir $\mathrm{A}$, Kraetz $\mathrm{J}$ and Hofbauer $\mathrm{KG}$. Is the natriuretic effect of atrial natriuretic factor in conscious rats mediated by renal vasodilatation? J Hypert (1986b)

Sonnenberg H. Mechanisms of release and renal tubular action of atrial natriuretic factor. Fed Proc 45: $2106-2110$ (1986)

Sosa RE, Volpe M, Marion DN, Atlas SA, Laragh JH, Vaughan ED and Maack T. Relationship between renal hemodynamic and natriuretic effects of atrial natriuretic factor. Am J Physiol 250: F520-F524 (1986)

Springall DR, Bhatnagar M, Wharton J, Hamid Q, Gulbenkian $S$ et al. Expression of the atrial natriuretic peptide gene in the cardiac muscle of rat extrapulmonary and intrapulmonary veins. Thorax 43: 44-52 (1988)

Standaert DG, Needleman $P$ and Saper CB. Organization of Atriopeptin-like immunoreactive neurons in the central newous system of the rat. J Comp Neurol 253: 315-341 (1986)

Stasch J-P, Hirth C, Kazdla S and Neuser D. The reduction of renin and aldosterone as a response to acute hypervolemia is blocked by a monoclonal antibody directed against atrial natriuretic 
peptides. Life Sci 42: 511-516 (1988)

Sugawara A, Nekar K, Sakamoto M, Morii N, Yamada T, Itoh H, Shiono S and Imura H. Plasma concentrations of atrial natriuretic polypeptide in essential hypertension. Lancet ii: 1426 (1985)

Sugawara A,Nakao K, Morii N, Sakamoto M, Horii K, Shimokura M, Kiso Y, Nishimura K, Ban T, Kihara M, Yamori Y, Kangawa K, Matsuo H and Imura H. Significance of alpha-human atrial natriuretic polypeptide as a hormone in humans. Hypert 8 (suppl I):I-151-I155 (1986)

Sugimoto T, Ishii M, Hirata $Y$, Matsuoka $H$, Sugimoto $T$, Miyata A, Toshimori T, Masuda $H$, Kangawa $\mathrm{K}$ and Matsuo $\mathrm{H}$. Increased release of atrial natriuretic polypeptides in rats with DOCA-salt hypertension. Life Sci 38: 1351-1358 (1986)

T

Takayanagi $R$, Tanaka I, Maki $M$ and Inagami T. Effects of changes in water-sodium balance on levels of atrial natriuretic factor messenger RNA and peptide in rats. Life Sci 36: 1843-1848 (1985)

Takayanagi $R$, Inagami T, Snajdar RM, Tamura $M$ and Misono KS. Two distinct forms of receptors for atrial natriuretic factor in bovine adrenocortical cells. J Biol Chem 261: $12104-$ $12113(1987)$

Tanaka I, Misono KS and Inagami T. Atrial natriuretic factor in rat hypothalamus, atria and plasma: determination by specific radio immunoassy. Biochem Biophys Res Commun 124: 663-668 (1984)

Taylor $\mathrm{CJ}$ and Meisheri $\mathrm{KD}$. Inhibitory effects of a synthetic atrial peptide on contractions and ${ }^{45} \mathrm{Ca}$ fluxes in vascular smooth muscle. J Pharmacol Exp Ther 237: 803-808 (1986)

Taylor MA, Ragsdale NV, Ayers CR and Gear ARL. Atrial natriuretic factor in essential hypertension. Life Sci 44: 603-610 (1989)

Thibault G, Lazure C, Schiffrin El, Gutkowska J, Chartier L, Garcia R, Seidah NG, Chrétien M, Genest $J$ and Cantin $M$. Identification of a biologically active circulating form of rat atrial natriuretic factor. Biochem Biophys Res Commun 130:981-986 (1985)

Thibault G, Garcia R, Cantin M and Genest J. Atrial natriuretic factor. Characterization and partial purification. Hypertension 5 (suppl I): 175-180 (1983)

Thibauit G, Garcia R, Canier $F$, Seidah NG, Lazure C, Chretien M, Cantin $M$ and Genest J. Structure activity relationshipo of atrial natriuretic factor (ANF). I. Natriuretic activity and relaxation in intestinal smooth muscle. Biochem Biophys Res Commun 125: 938-946 (1984)

Thibault G, Garcia R, Gutkowska J, Lazure C, and Seidah NG. Identification of the released form of atrial natriuretic factor by the perfused rat heart. Proc Soc Exp Biol Med 182: 137-141 (1986)

Thibault G, Garcia R, Gutkowska J, Bilodeau J, Lazure C, Seidah NG, Chrétien M Genest J and Cantin $M$. The propeptide Asn $n^{1}-T_{y}^{126}$ is the storage form of rat atrial natriuretic factor. Biochem J 241: 265-272 (1987)

Thibault G. In vivo elimination of ANF. In: The atrial natriuretic factor: Its physiology and biochemistry. Rev Physiol Biochem Pharmacol 110: 14-1.5 (1988)

Thibault G, Nemer $M$, Drouin J. Lavigne JP, Ding J, Charbonneau C, Garcia R, Genest J, Jasmin $G$, Sole $M$ and Cantin $M$. Ventricles as a major site of atrial natriuretic factor synthesis and release in cardiomypathic hamsters with heart failure. Circ Res 65: 71-82 (1989)

Thomsen JK, Storm TL, Thamsborg G, de Nully M, Bodker B and Skouby S. Atrial natriuretic peptide concentrations in pre-eclampsia. Brit Med J 294: 1508-1510 (1987) 
Tikkanen I, Fyhrquist $F$, Metsärinne $K$ and Leidenius $R$. Plasma atrial natriuretic peptide in cardiac disease and during infusion in healthy subjects. Lancer ii: 66-69 (1985)

Tikkanen T, Svartström-Fraser M, Tikkanen I, Sariola H and Fyhrquist F. Haemodynamic effects of atriall natriuretic peptide in rats with heart failure. Eur J Pharmacol 140: 187-193 (1987)

Tikkanen T, Tikkanen I, Sariola H, Svartstrom-Fraser $M$ and Fyhrquist $F_{\text {. }}$ Attenuated diuretic and natriuretic effects of atrial matriuretic peptide in rats with heart failure. Horm Metabol Res 21: $185-188(1989)$

Tremblay $J$, Gerzer $R$, Vinay $P$, Pang SC, Beliveau $R$ and Hamet $P$. The increase of cGMP by atrial natriuretic factor correlates with the distribution of particulate guanylate cyclase. FEBS Lett 181: $17-22(1985)$

Trippodo NC, Walsh GM, Ferrone RA and Dugan R. Fluid partition and cardiac output in volume depleted goldblatt hypertensive rats. Am J Physiol 237: H18 H24 (1979)

Trippodo $\mathrm{NC}$, Cole FE, Frohlich ED and MacPhee. Atrial natriuretic peptide decreases circulatory capacitance in areflexic rats. Circ Res 59: 291-296 (1986)

Trippodo NC. An update on the physiology of atrial natriuretic factor. Hypertension 10 (suppl 1): I$122-I \times 127$ (1987)

Tsuda K, Shima H, Nishio I and Masuyama Y. Inhibitory action on alpha-human atrial polypeptide on vascular adrenergic neurotransmission is attenuated in spontaneously hypertensive rats. Jap Circ J 51: $589-593$ (1987)

Tsunoda K, Mendelsohn FAO, Sexton PM, Chai SY, Hodsman GP and Johnston CI Decreased atrial natriuretic peptide binding in renal medulla in rats with chronic heart failure. Circ Res 62: $155-161(1988)$

Tunny $\mathrm{TJ}$, Higgins $\mathrm{BA}$ and Gordon RD. Plasma levels of atrial natriuretic peptide in man in primary aldosteronism, in Gordon's Syndrome and in Bartter's Syndrome. Clin Exp Pharmacol Physiol 13: 341-345 (1986)

$\mathrm{V}$

Vandlen $\mathrm{RL}_{0}$ Arcuri $\mathrm{KE}$ and Napier MA. Identification of a receptor for atrial natriuretic factor in rabbit aorta membranes by affinity cross-linking. J Biol Chem 260: 10889-10892 (1985)

Vari RC, Freeman RH, Davis JO, Villareal D and Verbrug KM. Effect of synthetic atrial natriuretic factor on aldosterone secretion in the rat. Am J Physiol 251: R48-52 (1986)

Verburg KM, Freeman RH, Davis JO, Villarreal D and Vari RC. Control of atrial natriuretic factor release in conscious dogs. Am J Physiol 251: R947-R956 (1986)

Veress $_{*}$ AT and Sonnenberg $\mathrm{H}$. Right atrial appendectomy reduces the renal response to acute hypervolemia in the rat. Am J Physiol 247: R610-R613 (1984)

Villarreal, C, Freeman RH, Davis JO, Verburg KM and Vari RC. Effects of atrial appendectomy on circulating atrial natriuretic factor during volume expansion in the rat. Proc Soc Exp Biol Med 183: $54-58$ (1986a)

Villarreal D, Freeman $\mathrm{RH}_{n}$ Davis JO, Verbrug $\mathrm{KM}$ and Vari RC. Renal mechanisms for suppression of renin secretion by atrial natriuretic factor. Hypert 8: 1128-1133 (1986b)

Volpe M, Odell G, Kleinert HD, Muller F, Camargo MJ, Laragh JH, Maack T, Vaughan ED and Atlas SA. Effect of atrial natriuretic factor on blood pressure, renin and aldosterone in Goldblatt hypertension. Hypertension 7 (suppl I): I-43-I-48 (1985)

Volpe M. Sosa RE, Müller FB, Camargo MJF, Glorioso N, Laragh JH, Maack T and Atlas SA. Differing hemodynamic responses to atrial natriuretic factor in two modells of hypertension. Am J Physiol 250: H871-H878 (1986) 
Vries, PJF de, Tyssen CM, Smits JFM and Struyker Boudier HAJ. Atrial natriuretic peptide (ANP) increases albumin extravasation in conscious rats. Eur I Physiol 1990

W

Waeber B, Matsueda GR, Aubert J, Nussberger J and Brunner HR. The hemodynamic response of conscious normotensive rats to atriopeptin III: lack of a role of the parasympathetic nervous system. Eur J Pharnacol 125: 177-184 (1986)

Wakitani K, Cole BR, Geller DM, Currie MG, Adams SP, Fok KF and Needleman P. Atriopeptins: correlation between renal vasodilation and natriuresis. Am J Physiol 249: F49-F53 (1985)

Wallenstein, S., C.L. Zucker and J.L. Fleis. Some statistical methods useful in circulation research. Circ. Res. 47: 1-9, 1980.

Weidman $P$, Hellmueleler $B$, Uchlinger DE, Lang RE, Gradinger MP, Hasler L, Shaw $S$, and Bachman C. Plasma levels and cardiovascular, endocrine and excretory effects of atrial natriuretic peptide during different sodium intakes in man. J Clin Endocrinol Metab 62: 10271036 (1986)

Weselcouch EO, Humphrey WR and Aiken JW. Effect of pulmonary and renal circulations on activity of atrial natriuretic factor. Am J Physiol 249: R595-R602 (1985)

Williamson JR, Holmberg SW, Chang K, Marvel J, Sutera SP and Needleman P. Mechanisms underlying atriopeptin induced increases in hematocrit and vascular permeation in rats. Circ Res 64: 890-899 (1989)

Winquist RJ, Faison EP and Nutt RF. Vasodilator profile of synthetic atrial natriuretic factor. Eur J Pharmacol 102: 169-173 (1984a)

Winquist RJ, Faison EP, Waldman SA, Schwartz K, Murad F and Rappoport RM. Atrial natriuretic factor elicits an endothelium-independent relaxation and activates particulate guanylate cyclase in vascular smooth muscle. Proc Nat Acad Sci USA 81: $7661-7664$ (1984b)

$\mathbf{Y}$

Yamamoto K, Kosaki G, Suzuki K, Tanoue K and Yamzaki H. Cleavage site of calcium-dependent protease in human platelet membrane glycoprotein Ib. Thromb Res 43: 41-55 (1986)

Yandie TG, Espiner EA, Nicholls MG and Duff $H$. Radio immuno assay and characterization of atrial natriuretic peptide in human plasma. J Clin Endocrin Metab 63: 72 (1986a)

Yandle TG, Richards AM, Nicholls MG, Cuneo R, Espiner EA and Livisey JH. Metabolic clearance rat and plasma half-life of alpha-human atrial natriuretic peptide in man. Life Sci 38: $1827-1833(1986 b)$

Yamaji T, Ishibashi M Nakaoka $\mathbf{H}$ Imatak $\mathrm{K}$, Amano $\mathrm{M}$ and Fuji J. Possible role for atrial natriuretic peptide in polyuria associated with paroxysmal atrial arthytmias. Lancet ii: 93 (1985)

Yamaji $T$, Ishibashi $M$, Yamada A, Takaku F, Itabashi $A$, Katayama $S$, Ishii J, Takami $M$ and Fukushima T. Plasma levels of atrial natriuretic hormone in Cushing's Syndrome. J Clin Endocrinol Metab 67: 348-352 (1988)

Yamanaka M, Greenberg B, Johnson L, Seilhamer J, Brewer M, Friedemann T, Miller J, Atlas S, Laragh J, Lewicki $J$ and Fiddes J. Cloning and sequence analysis of cDNA for the rat atrial natriuretic factor precursor. Nature 309: 719-722 (1984)

Yukimura $T$, Ito K, Takenaga T, Yamarnoto K, Kangawa K and Matsuo H. Possible tubular site of action in anesthetized dogs of a synthetic $\alpha$-Human atrial natriuretic polypeptide. J Pharmacol Exp Ther 238: 707-712 (1986) 
ANP in cardiovascular homeostasis

$\mathbf{Z}$

Zacharialh PK, Bumett JC, Ritter $\mathrm{S}$ and Strong $\mathrm{CG}_{\text {. }}$. Atrial natriuretic peptide in human essential hypertension. Mayo Clin Proc 62: 782-786 (1987)

Zeidel ML, Seifter JL, Lear S, Brenner BM and Silva P. Atrial peptides inhibit oxygen consumption in kidney medullary collecting duct cells. Am J Physiol 251: F370-F383 (1986)

Zeidell ML. Silva P, Brenner BM and Seifter JL. CGMP mediates effects of atrial peptides on medullary collecting duct cells. Am J Physiol 252: 551-559 (1987a)

Zeidel ML and Brenner MB. Actions of atrial natriuretic peptides on the kidney. Semin Nephrol 7: 91-97 (1987b)

Zimmerman RS, Schirger JA, Edwards BS, Schwab TR, Heublein DM an Burnett JC. Cardiorenal-endocrine dynamics during stepwise infusion of physiological and pharmacological concentrations of atrial natriuretic factor in the dog. Circ Res 61: 63-69 (1987) 


\section{SUMMARY}

Introduction During the past few years an enormous scientific effort has been made to gain insight in the characteristics of atrial natriuretic peptides (ANP). In the introduction (chapter 1) an overview is given of the recent literature about ANP.

Glomerular and tubular effects are involvied in renal excretion due to ANP

ANP-analogues affeet central and regional hemodynamics
After introducing the experimental approach and methods in chapter 2, chapter 3 describes the effects of ANP on renal function. The role of ANP in renal function has been investigated extensively as described in section 1.6.2. However, an actual role of ANP in the control of renal function is still debated because of contrasting results and a lack of studies in intact and conscious animals.

Therefore the dose-effect relationship of ANP on renal function was studied in conscious spontaneously hypertensive rats. The increased diuresis and natriuresis were parallelled by an increase in filtration fraction and fractional water excretion. Glomerular filtration rate and effective renal plasma flow did not change. This suggests that a primary tubular mechanism, together with an increased $\mathrm{FF}$, are involved in the renal excretory effects of pharmacological doses of ANP.

Many investigations have been performed to elucidate the structureactivity relationship of ANP with respect to its hemodynamic effects. In conscious animals, no systematic research has been done with ANP analogues differing at the amino terminal part of the chain, despite a 2 to 10 fold difference in vasorelaxant properties in studies on isolated arteries. In the fourth chapter the effects of acute administration of $\operatorname{ANP}(1-28)$ and $\operatorname{ANP}(5-28)$ on regional hemodynamics in normotensive (WKY) and spontaneously hypertensive rats (SHR) and central hemodynamics in normotensive and spontaneously hypertensive rats and rats with experimental heart failure (IWKY) are discussed in view of 1) the effect of the amino terminal residues and 2) differing responses due to pathology. No differences in hemodynamic responses to ANP(1-28) and ANP(5-28) occurred in the animal models used. Structural variation in the $N$ terminal part of ANP does not seem to influence its hemodynamic properties in conscious rats. Also no difference in response due to pathological conditions could be observed.

In chapter four, the central hemodynamic response of long term low dose infusions to ANP(5-28) in SHR were also studied. Long term low dose infusions induced a fall in cardiac output which equalled 
ANP decreastes blood volume by increstsing plasma extrat vasatllon

Extravasation occurs through venular constriction by ANP

ANP does not play a role In basal renal fumction the fall to the highest acute dose. This indicates that ANP may play a role in hemodynamic regulation within several hours.

Infusion of ANP results in a decrease in blood volume in normal and nephrectomized rats [Flückiger et al 1986]. The latter indicates that renal effects are not responsible for the reduction in blood volume. This means that fluid has to leave the circulation at an other site. Microvascular extravasation is the logical alternative. Clearance of albumin can be used to study extravasation of plasma protein. In chapter 5 , the results of the regional clearance of labeled albumin, due to increased circulating ANP, are discussed. A reduction of plasma volume of $10 \%$ was parallelled by an increased extravasation of labeled albumin in skeletal muscle and ileum. This indicates that ANP is involved in circulatory homeostasis through the control of intra- and extravascular fluid volumes.

An increase in endothelial permeability and an increase in resistance to venous return may both account for the extravasation, described in chapter 5. Therefore the effects of ANP on the microcirculation were studied in skin chambers containing subcutaneous striated muscle. In chapter 6, these experiments are discussed. Arterioles do not respond to infusion of ANP(1-28), whereas venules, especially the $V_{1}$ and $V_{2}$ vessels, constrict. Such a mechanism may contribute to the reduction in blood volume. Furthermore, an increased resistance to venous return will result in a fall in cardiac output in conscious rats.

Effects resulting from pharmacological doses of exogenous ANP can only suggest, but not prove the physiological role of ANP in hemodynamic regulation. Antagonism of ANP might give a view on its physiological role. However, antagonists against ANP are not yet available. In chapter 7 , bilateral atrial appendectomy was performed to reduce circulating ANP. Levels of ANP were reduced in resting conditions and in response to stimulation with acute volume loading. Under basal conditions renal sodium and water excretion were not affected despite a $40 \%$ reduction of circulating ANP. During volume expansion, natriuresis and diuresis were significantly reduced. Furthermore, in the sham operated animals the renal response was of late onset. This study indicates that ANP does not contribute to renal function under basal conditions and is not directly responsible for the natriuretic and diuretic response to acute volume loading. 
Depriving animals In the second approach to reduce circulating ANP, monoclonal of circulating ANP antibodies raised against ANP (5-27) were injected into WKY, SHR and WKY with heart failure from myocardial infarction (chapter 8).

output This resulted in an instant, lasting increase in cardiac output and stroke volume in WKY. In SHR and IWKY only a transient increase in cardiac output, around 10 minutes after injection, was observed. Blood pressure did not change to monoclonal antibody injections in either animal model. These results suggest a physiological role for ANP in the regulation of central hemodynamics.

Conclusion The results from the renal studies, described in this thesis, do not suggest a direct role for ANP in renal function. The hemodynamic studies give evidence for a physiological role of ANP in the regulation of cardiac output. Regulation of venous resistance and circulating blood volume appear to be the primary mechanisms, whereby ANP regulates cardiac output. 



\section{SAMENVATTING}

Introduktie De laatste jaren is een grote wetenschappelijke unspanning verricht om meer inzichten te krijgen in de karakteristieken van de atriele natriuretische peptiden (ANP). In de introduktie (hoofdstuk 1) is een overzicht gegeven van de recente literatuur over $\mathrm{ANP}$.

Glomerulaire en tubulaire efrekten zijn betrokken bij de renale uitscheiding tengevolge van ANP

Na de beschrijving van de materialen en methoden, die zijn gebruikt voor de experimenten, in dit proefschrift, worden in hoofdstuk 3 de effekten beschreven van ANP op de nier funktie. De rol van ANP in de nier funktie is uitgebreid onderzocht, zoals beschreven in paragraaf 1.6.2. De tegengestelde resultaten en het tekort aan studies in wakkere dieren waren redenen om de effekten van ANP in wakkere spontaan hypertensieve ratten te bestuderen. De verhoogde natriurese en diurese gingen gepaard met een toeneming in de filtratie fraktie en fraktionele wateruitscheiding. De glomerulaire filtratie snelheid en de effektieve plasma flow veranderden niet. Deze studie suggereert dat renale effekten van farmakologische doses van ANP primair worden veroorzazkt door een tubulaire werking, maar ook door een verhoging van de filtratie fraktie.

ANP analoga beînvloeden de centrale en regionale hemodynamika
Veel onderzoeken zijn uitgevoerd om de relatie tussen de struktuur van ANP en de hemodynamische effekten te beschrijven. In wakkere dieren is echter geen systematisch onderzoek vericht met ANP-analoga die verschillen in het $\mathrm{N}$-terminale deel van de aminozuur keten, terwijl deze analoga een 2 tot 10 voudig verschil in vasorelaxerende aktiviteit hebben in geïsoleerde arteriën. In hoofdstuk 4 worden de effekten van akute infusies van ANP(1-28) en ANP(5-28) op de regionale hemodynamika in normotensieve ratten (WKY) en spontaan hypertensieve ratten (SHR) en de effekten van akute infusies van ANP(1-28) en ANP(5-28) op de centrale hemodynamika in WKY, SHR en WKY met hartfalen tengevolge van een myokardinfarkt (IWKY) beschreven. De verschillen in hemodynamische effekten tengevolge van 1) de strukturele variatie in het amino-terminale deel van het eiwit en 2) de pathologische konditie van de dieren zijn hierin bestudeerd. Strukturele variatie in het amino-terminale deel van het eiwit lijkt de hemodynamische eigenschappen van ANP in wakkere dieren niet te beïnvloeden. Ook is er geen verschil in hemodynamische respons gekonstateerd in de verschillende pathologische kondities. 
ANP vermindert het bloedvolume door wen trencming van plasma extravasatie

Extravasatie wordt veroorzakakt door venulaire konstriktie

ANP speelt geen rol in de basalle nier funktle
Lange termijn infusie van een lage dosis ANP(5-28) in SHR induceerde een daling van het hartminuutvolume die gelijk was aan de daling van het hartminuutvolume gedurende de hoogste doses van de akute infusies. ANP lijkt daarom een rol te spelen in de hemodynamische regulatie binnen enkele uren.

Infusie van ANP veroorzaakt een daling van het bloedvolume in normale, maar ook in genefrektomiseerde ratten. De renale effekten zijn niet verantwoordelijk voor de afneming van het bloedvolume. Elders in de cirkulatie moet dus wloeistof uittreden. Een logisch alternatief is mikrovaskulaire extravasatie. Klaring van albumine kan worden gebruikt om de uittreding van plasma eiwitten te bestuderen. In hoofdstuk 5 wordt de regionale klaring wan albumine, tengevolge van ANP infusie, bediskusiëerd. Een afneming van het plasma volume van $10 \%$ ging gepaard met een toeneming van de albumineklaring in skelet spieren en de dunne darm. ANP lijkt betrokken te zijn in de cirkulatoire homeostase door de kontrole van intra- en extravaskulaire volumina.

Mogelijke verklaringen voor de toeneming in extravasatie zijn 1) een verhoogde endotheliale doorlaatbaarheid en 2) een toeneming van de veneuze weerstand. In hoofdstuk 6 worden de effekten beschreven wan ANP-infusies op de mikrocirkulatie van de huidspier in wakkere ratten. ANP-infusie heeft geen effekt op de arteriolen, maar de venulen, met name de $\mathrm{V}_{1}$ en $\mathrm{V}_{2}$ vaten, kontraheren. Een dergelijk mechanisme kan bijdragen aan de reduktie van het bloedvolume. Verder kan een verhoogde veneuze weerstand het hartminuutvolume doen dalen in wakkere ratten.

De effekten van farmakologische doses van exogeen ANP zijn slechts aanwijzingen voor de fysiologische rol van ANP in de hemodynamische regulatie. Antagonering van ANP kan deze aanwijzingen verder onderbouwen. Antagonisten tegen ANP zijn echter nog niet beschikbaar. In hoofdstuk 7 is, door middel wan billaterale atriële appendektomie, het cirkulerende ANP onder basale en onder gestimuleerde omstandigheden verminderd. Ondanks een vermindering van plasma ANP met $40 \%$, waren de renale zout en water uitscheiding niet veranderd. Tijdens een volume belasting waren natriurese en diurese signifikant verminderd. In de schijn geopereerde ratten was de renale respons verlaat ten opzichte van de stijging in plasma ANP. Deze studie geeft aan dat 


\begin{abstract}
ANP geen rol speelt in de basale regulatie van de nier funktie en dat ANP niet direkt verantwoordelijk is voor de natriuretische en diuretische respons op een akute volume belasting.
\end{abstract}

Reduktie van cirku- In de tweede benadering om cirkulerend ANP te verminderen, zijn lerend ANP verhougd het hartminuutvolume monoklonale antilichamen, opgewekt tegen ANP(5-27), geïnjekteerd in WKY, SHR en WKY met hartfalen (IWKY) (hoofdstuk 8). Injektie van antilichamen resulteerde in een toeneming van het hartminuutvolume en het slagvolume in WKY. In SHR en IWKY werd een tijdelijke toeneming in hartminuutvolume waargenomen, ongeveer 10 minuten na injektie. De bloeddruk veranderde in geen van de drie diermodellen na toediening van monoklonale antilichamen. Deze resultaten suggereren dat ANP een fysiologische funktie heeft in de regulatie van de centrale hemodynamika.

Konklusie Het proefschrift samenvattend, blijkt dat ANP geen direkte rol speelt in de zout en waterhuishouding door de nieren. Daarentegen speelt ANP wel een belangrijke fysiologische rol in de regulatie van het hartminuutvolume. Dit gebeurt door de regulatie van de veneuze weerstand en het bloedvolume. 


\section{CURRICULUM VITAE}

$29-5-1959$

Juni 1977

Juni 1980

Juni 1983

April 1986

Juni 1986

Maart 1.986

Augustus 1990 geboren te Nijmegen

Afsluitend examen VWO-B, Canisius College te Nijmegen

Afsluitend examen kandidaats Biologie aan KU-Nijmegen, Faculteit der Wiskunde en Natuurwetenschappen

Afsluitend examen Doctoraal Biologie aan KU-Nijmegen, Faculteit der Wiskunde en Natuurwetenschappen

Afsluitend examen kandidaats Humane Voeding aan LHWageningen

Afsluitend examen Ingenieurs Humane Voeding aan LHWageningen

Doctoraal onderzoeken verricht tijdens beide opleidingen:

- Serum ureum in vrijwilligers van 30-65 jaar, uitgevoerd aan de vakgroep Humane Voeding, LH-Wageningen, onder begeleiding van dr. ir. J.A.M. van Raaij.

- Gebilsgezondheid van 11 en 12 jarige kinderen, uitgevoerd aan Preventiewe en Sociale Tandheelkunde, Fac. der Geneeskunde en Tandheelkunde, KU-Nijmegen, onder begeleiding van dr. ir. A.B. Cramwinckel.

- Onderzoek naar Melkzuur decontaminatic, decontaminatie met gammastraling en decontaminatie met melkzuur én gammastraling, uitgevoerd aan de vakgroep Voedingsmiddelen van Dierlijke Oorsprong, afdeling Levensmiddelenmicrobiologie, Fac. der Diergeneeskunde, RU-Utrecht, onder begeleiding van dr. D.A.A. Mossel.

- Lipolytische activiteit van vetweefsel onder verschillende omstandigheden, vitgevoerd aan de capaciteitsgroep Humane Biologie, onder begeleiding: Prof. dr. ir. W.H.M. Saris, Algemene Faculteit, RUL, Maastricht.

- Boomontwikkeling en interacties tussen een geluidsveld en een model vegetatie, uitgevoerd aan de sectie Botanie, Fac. der Wiskunde en Natuurwetenschappen, KU-Nijmegen. Begeleiding: dr. MJ.M. Martens.

Aanstelling als wetenschappelijk assistent aan de capaciteitsgroep Farmacologie, Medische Faculteit, RUL, Maastricht, in het kader van het onderzoek: De rol van atriopeptines in de kardiovaskulaire homeostase tijdens normotensie en spontane hypertensie in de rat. Begeleiding: $\mathrm{dr}$. J.F.M. Smits, Prof. dr. H.A.J. Struiker Boudier.

Aanstelling als post-doc aan de vakgroep Farmacologie, Medische Faculteit, RUL, Maastricht 
Lijst van publikaties:

- A.B. Cramwinckel, W.G.M. Boeijen, M.A. van "t Hof, P.J.F. de Vries and F.M.M. van Waesberghe. Onderzoek naar factoren die van inwloed zijn op het cariésvrij zijn van 11- tot 12-jarige kinderen. Ned Tijdschr Tandheelk 93: 190-193 (1986)

- P.J.F. de Vries and C.M. Tyssen. The acute effect of calcium entry blockers on plasma irANP in conscious SHR. Naunyn-Schmiedeberg's Archives of Pharmacology, 337(supplement): r51 Abstract (1988)

- P.J.F. de Vries, C.M. Tyssen and J.F.M. Smits. The effect of different ANP analogues on the regional hemodynamics in conscious WKY and SHR. Pharm. Wkbl. Sci Ed 10, 227 Abstract (1988)

- P.J.F. de Vries, C.M. Tyssen, H.A.J. Struyker Boudier and J.F.M. Smits. Effects of deprivation from atrial natriuretic factor on central hemodynamic regulation in WKY, WKY with 5 weeks old myocardial infarction (IWKY) and spontaneously hypertensive rats (SHR). Pharmaceutisch Weekblad 11: J4 Abstract (1989)

- P.J.F. de Vries, M.J.A.P. Daemen, H.A.J. Struyker Boudier and J.F.M. Smits. Atrial natriuretic factor and cardiovascular homeostasis. Hypertension, brain catecholamines and peptides. Editors Nijkamp \& De Wied, Elseviers Science Publishers BV pg 51-57 (1989)

- P.J.F. de Vries, C.M. Tyssen and J.F.M. Smits. Effects of atrial natriuretic factor (ANF) on regional albumin clearance. Pflügers Archiv, Dutch Physiological Society, Young Physiologists Meeting, S199 Abstract (1990)

- P.J.F. de Vries, C.M. Tyssen, H.A.J. Struyker Boudier and J.F.M. Smits. Atrial natriuretic factor increases albumin extravasation in conscious rats. Pflügers Archiv 415: 507-509 (1990).

- P.J.F. de Vries, C.M. Tyssen, H.A.J. Struyker-Boudier and J.F.M. Smits. Homeostatic function of ANP in rat models for hypertension and heart failure. (submitted to Am J Physiol)

- P.J.F. de Vries, C.M. Tyssen, H.A.J. Struyker Boudier and J.F.M Smits. Physiological role of ANP under resting and volume expanded conditions in normotensive rats. (submitted)

- P.J.F. de Vries, C.M. Tyssen, H. van Essen, H.A.J. Struyker Boudler and J.F.M. Smits. Hemodynamic effects of ANP(1-28) and ANP(5-28) in conscious normotensive, spontaneously hypertensive rats and in experimental heart failure. (submitted)

- P.J.F. de Vries, M. Messing, H. van Essen, J.F.M. Smits and H.A.J. Struyker Boudier. Atrial Natriuretic Peptide increases venous resistance in the cutaneous skeletal muscle of conscious spontaneously hypertensive rats. (submitted) 